\author{
Universidade de São Paulo \\ Instituto de Física de São Carlos \\ Departamento de Física e Ciência dos Materiais
}

\title{
Produção de Moléculas Frias Heteronucleares no Estado Fundamental
}

\section{Marília Wellichan Mancini}

Tese apresentada ao Instituto de Física de São Carlos, da Universidade de São Paulo, para a obtenção do título de Doutor em Ciências: Física básica.

Orientador: Prof. Dr. Luis Gustavo Marcassa

São Carlos

USPIIFSCISBI

2003



IFSC-USP SERVICODE BIBLIOTECA
INFORMACÁO 


\begin{tabular}{|l|}
\hline Mancini, Marilia Wellichan \\
"Produção de Moléculas Frias Heteronucleares no Estado Fundamental." \\
Marilia Wellichan Mancini - São Carlos, 2003 \\
Tese (Doutorado) - Área de Física Básica do Instituto de Física de São Carlos \\
da Universidade de São Paulo \\
2003 - Páginas: 158 \\
Orientador: Prof. Dr. Luis Gustavo Marcassa \\
Física Atômica, Átomos e Moleéculas Frias, Estado Fundamental. \\
I. Título
\end{tabular}

$$
\begin{gathered}
\text { MSC-USP SLIVUCODE BIBLIOTECA } \\
\text { INFORMACÁO }
\end{gathered}
$$


MEMBROS DA COMISSÃO JULGADORA DA TESE DE DOUTORADO DE MARÍLIA WELLICHAN MANCINI APRESENTADA AO INSTITUTO DE FÍSICA DE SÃO CARLOS, UNIVERSIDADE DE SÃO PAULO, EM 21-11-2003.

COMISSÃO JULGADORA:

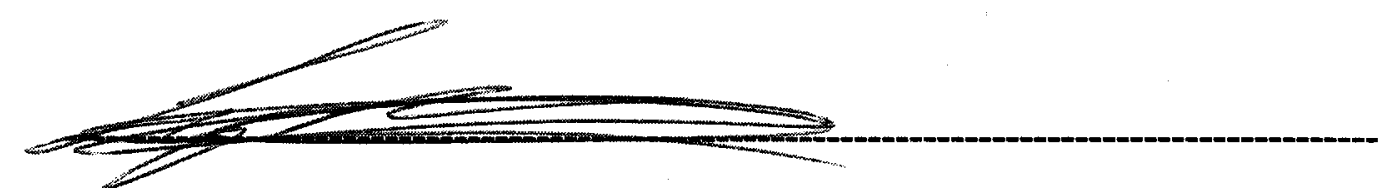

Prof. Dr. Luis Gustavo Marcassa (Orientador e Presidente) - IFSC/USP

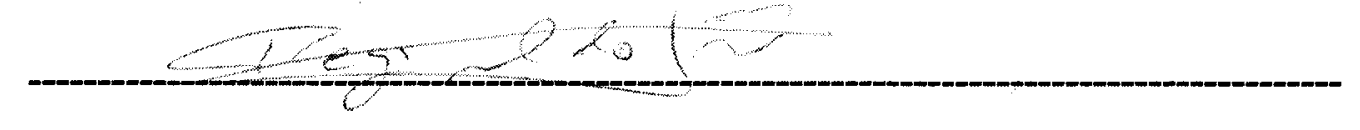

Prof. Dr. Reginaldo de Jesus Napolitano - IFSC / USP


Prof. Dr. Cláudio Lenz César - UFRJ

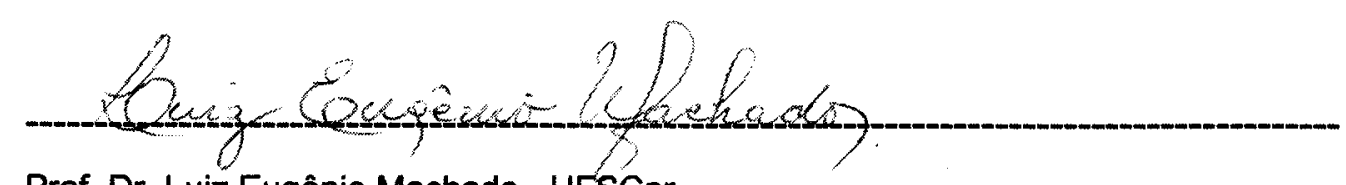

Prof. Dr. Luiz Eugênio Machado - UFSCar 
Aos meus pais, Eddie e Daisy IFSC-USP SERVICOO DE BIBLIOTEC.
INFOAHACAO 


\section{Agradecimentos}

Ao Prof. Dr. Luis G. Marcassa, pela orientação. Agradeço pela oportunidade de trabalhar com diferentes tópicos, desde átomos de Rydberg até a produção de moléculas frias, durante o período concernente ao meu trabalho de doutorado. Isto certamente me fez aprender muitas coisas, e tenho a certeza de que tudo o que aprendi durante estes quatro anos será de extrema valia durante toda a minha vida profissional.

Aos colegas do laboratório de colisões mistas ultrafrias: Anderson Caires, Gustavo Telles e Valter Nascimento. Agradeço o apoio na montagem e realização dos experimentos e o coleguismo em todos os momentos. Meus sinceros agradecimentos.

Ao Lino Misoguti, pela ajuda no alinhamento (primoroso!) do laser de corante comercial. Uma das primeiras pessoas com quem tive o enorme prazer de trabalhar, competentíssimo e sempre pronto a ajudar.

Aos docentes com quem tive aula durante a pós graduação, em especial aos professores Lidério Ioriatti, com quem tive o prazer de cursar Mecânica Quântica durante o mestrado, Prof. Zílio, pelo curso de Eletrônica Quântica, e ao Prof. Vanderlei Bagnato, pelo curso de Física Atômica.

Ao professor Vanderlei Bagnato agradeço também pelas discussões acerca dos resultados e pelo suporte técnico, sempre nos dando suporte com relação aos equipamentos que necessitávamos e que foram imprescindíveis à realização dos experimentos deste trabalho.

Ao Prof. Reginaldo Napolitano, pelas discussões acerca dos aspectos teóricos de 
colisões frias.

Ao Prof. Olivier Dulieu, da Universidade Paris Sud, pelo esclarecimento de minhas dúvidas teóricas, desde o tempo do mestrado.

Aos pesquisadores Andrea Fioretti e Marcel Mudrich, pelas respostas tempestivas à minhas questões.

Aos meus pais, à quem dedico este trabalho, pelo carinho, pelo encaminhamento que me deram na vida, pela educação que me proporcionaram. Não poderiam ter feito melhor. Agradeço-os por tudo o que sempre fizeram por mim.

A minha mãe, Daisy: pelo ombro amigo nos momentos mais difíceis e pelas aulas de Yoga na parte final deste trabalho. Se não fossem as suas aulas - os ásanas, pranayamas, relaxamentos, e as nossas conversas, eu não teria conseguido terminar meu trabalho e dar aula na UFScar simultaneamente, e teria abandonado algo que hoje gosto muito de fazer: ensinar. Obrigada por ter-me praticamente obrigado a comparecer no dia do concurso! Você e meu pai esteveram me ensinando sobre yamas e nyamas esse tempo todo... Espero estar aprendendo a por em prática. Obrigada por tudo.

Ao meu pai, o Prof. Eddie Mancini: agradeço além dos ensinamentos como pai, ter me transmitido o gosto pela carreira científica, a seriedade e a honestidade. Espero que um dia possa sentir por mim, o orgulho que tenho pelo senhor.

À minha avó, Helena Chacon Mancini, pelo amor, carinho, pela ajuda sempre, seja ela financeira ou todas as outras que me prestou desde que nasci até hoje. A 
senhora é a pessoa que mais admiro, por tudo o que é, tudo o que conquistou por sua conta própria e com sua enorme força de vontade, por sua bondade e generosidade para com qualquer pessoa, por sua carreira e cuidado da família, realizados brilhante e simultaneamente. Exemplo de que podemos fazer sim, e muito bem, mais do que uma coisa ao mesmo tempo.

Ao meu avó Orpheu, em memória, com muita saudade. Por ter me ensinado a gostar de brincar com chaves de fenda e outras ferramentas, a escrever meu nome quando eu ainda não era alfabetizada, e por ensinar aos netos a como ser sério sem deixar de ser criança.

À Solange Mancini, minha querida tia. Se eu conseguir ser uma exímia professora como você foi, eu já terei feito algo importante em minha vida.

Ao meu filho, Igor. Ser sua mãe é, para mim, um enorme orgulho. Tenho certeza que aprendi até mais coisas com você do que as eu lhe ensino!

Ao meu irmão, Daniel, e à minha cunhada Carolina, pelo carinho e amizade. Ao meu irmão por corrigir os meus erros de português em minha monografia de qualificação! A presença de vocês, mesmo à distância, sempre foi muito importante para mim.

A Nivalda, pelo apoio em casa; afinal sou dona de casa e mãe do Igor! Por sua ajuda, tão prestativa e carinhosa, durante todos esses anos.

As bibliotecárias do IFSC, em especial à Sibely, Mara e Neusa, pela atenção, prestatividade e rapidez sempre!

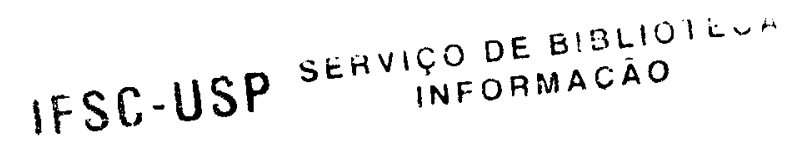


À secretárias do Grupo de Óptica: Isabel e Gláucia, e também à Maria Benedita. Aos funcionários da Oficina Mecânica do IFSC, pelos serviços prestados.

Aos funcionários da Oficina de Óptica, em especial ao Marcos pelos serviços.

Aos funcionários da Oficina de Eletrônica, em especial ao Daniel Magalhães.

Ao André Luiz de Oliveira, com quem trabalhei com átomos frios de Rydberg, na fase inicial de meu doutoramento. Pela amizade por todos esses anos, desde o tempo do mestrado. Pelo modo não tão austero com que você me ensinou a enxergar as coisas da vida.

Aos demais colegas do Laboratório de Física Atômica e Molecular, pelo convívio e coleguismo.

Aos colegas dos demais Laboratórios do Grupo de Óptica, pelo convívio.

A todos aqueles que contribuíram, de forma direta, ou até mesmo indiretamente, ao êxito deste trabalho.

À Deus, nosso pai e criador. Que nos guie sempre em Sua imensa luz.

A CAPES pelo apoio financeiro. 


\section{Sumário}

Lista de Figuras $\quad$ iii

1 Introdução

2 Moléculas diatômicas alcalinas frias no estado fundamental: Aspectos Gerais

2.1 Colisões Frias em Armadilhas Atômicas . . . . . . . . . . . . 15

2.1.1 Processos colisionais em Armadilhas Atômicas . . . . . . . . 17

2.2 Estados Moleculares e Potenciais de Interação . . . . . . . . . . . 24

2.3 Fatores de Franck-Condon para Fotoassociação Heteronuclear . . . . 34

2.4 Moléculas Frias em Sistemas Homonucleares: Breve Histórico . . . . . 45

2.5 Esquema Geral de Formação Molecular em Sistemas Homonucleares . 47

2.6 Esquemas de Formação Molecular para o Sistema Heteronuclear KRb 54

2.7 Detecção de Moléculas no Estado Fundamental através das Bandas Difusas . . . . . . . . . . . . . . . . . . 59

2.8 Mecanismos de Formação de Moléculas Estáveis . . . . . . . . . 65

3 Montagem e Procedimento Experimental para Produção e Deteç̧ão de KRb Frias

3.1 Aprisionamento de ${ }^{39} \mathrm{~K} \mathrm{e}^{85} \mathrm{Rb} \quad 69$

3.2 Sistemas de Deteç̧ão e Aquisição de Dados . . . . . . . . . . . 84

3.3 Detecção . . . . . . . . . . . . . . . . . . . . . . . . . 84

3.4 Aquisição de dados . . . . . . . . . . . . . . . . . . . . . . . 88

3.5 Esquema Temporal . . . . . . . . . . . . . . 89

4 Resultados Experimentais $\quad 92$

4.1 Detecção de Moléculas KRb Frias . . . . . . . . . . . . . . . . . . 92

4.2 Espectroscopia Molecular na Região da Banda Difusa do Rb $\mathrm{R}_{2}$. . . . 99

4.3 Medida da Temperatura Translacional Molecular . . . . . . . . . . . 104 
4.4 Mecanismo de Formação Molecular Homonuclear . . . . . . . . . . 114

4.5 Taxas de Formação Homonucleares . . . . . . . . . . . . . . . 117

4.6 Mecanismos de Formação Molecular Heteronuclear . . . . . . . . . . . 119

4.7 Taxa de Formação Heteronuclear . . . . . . . . . . . . . 126

5 Espectroscopia Fotoassociativa de Moléculas Heteronucleares 130

5.1 Determinação dos estados ligados de longo alcance . . . . . . . . . . 133

5.2 Procedimento de LeRoy e Bernstein para determinação do Coeficiente $C_{6} \ldots \ldots \ldots \ldots \ldots \ldots \ldots \ldots \ldots$

6 Conclusões 146

$\begin{array}{ll}\text { Referências Bibliográficas } & 150\end{array}$ 


\section{Lista de Figuras}

2.1 Curvas de potencial não-relativísticas dos estados eletrônicos de curto alcance da molécula KRb (Hund's case (a)) correlacionados aos estados atômicos assintóticos fundamental $\mathrm{K}(4 \mathrm{~S})+\mathrm{Rb}(5 \mathrm{~S})$ e os primeiros excitados $\mathrm{K}(4 \mathrm{~S})+\mathrm{Rb}(5 \mathrm{P})$ e $\mathrm{K}(4 \mathrm{P})+\mathrm{Rb}(5 \mathrm{~S})$ obtidos a partir de cálculos químico-quânticos por Rousseau et al. As curvas são conectadas a longo alcance com cálculos assintóticos de Marinescu-Sadeghpour. $\left(1 a_{0}=0,529177 \times 10^{-10} \mathrm{~m}\right) \ldots \ldots \ldots \ldots \ldots \ldots$

2.2 Estados fundamentais do $\mathrm{KRb}$ em detalhe: potenciais dos estados moleculares eletrônicos singleto e tripleto, calculados por Rousseau et

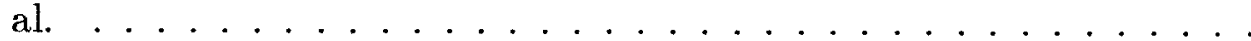

2.3 Curvas de potencial relativísticas, incluindo a interação spin-órbita (Hund's case (c)) do KRb associadas aos estados $\mathrm{K}(4 \mathrm{~S})+\mathrm{Rb}(5 \mathrm{P})$ e $\mathrm{K}(4 \mathrm{P})+\mathrm{Rb}(5 \mathrm{~S})$. Observe que conectados à assíntota $\mathrm{K}^{*}-\mathrm{Rb}$, à longo alcance os estados apresentam carácter repulsivo. . . . . . . . . . .

2.4 Fatores de Franck-Condon relativos representando as probabilidades de fotoassociação para diferentes moléculas heteronucleares considerandose estados de simetria ${ }^{1,3} \Lambda^{+}=0$, com potenciais atrativos . . . . . .

2.5 Fatores de Franck-Condon relativos para estados de simetria ${ }^{1,3} \Lambda=1$

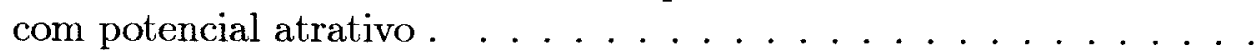


2.6 Esquema geral de formação de moléculas no estado fundamental através da fotoassociação de dois átomos nos estados atômicos fundamentais, em um estado excitado com duplo mínimo. A absorção de um fóton do laser de aprisionamento (a longo alcance, indicada pela transição eq.2.28) fotoassocia os átomos em estados ligados do poço externo. Uma transição feita por um fóton de um laser de prova bem mais dessintonizado pode fotoassociar o par a mais curto alcance (transição 2), contudo, o número de pares para menores separações internucleares é bem menor do que os acessados a longo alcance. Emissão espontânea para o estado fundamental pode popular os estados ligados mais excitados (transição 3) e mais profundos (transição 4) do estado molecular fundamental, dependendo da região onde ocorre o decaimento. . . .

2.7 Curvas de potencial relativísticas (incluindo a interação spin-órbita) dos estados de simetria $0_{g}^{+}$do KRb. Uma das curvas $(5) 0_{g}^{+}$dissocia a longo-alcance em $4^{2} \mathrm{P}_{3 / 2}$ e a outra, $(4) 0_{g}^{+}$em $4^{2} \mathrm{P}_{1 / 2} \ldots \ldots \ldots$. . . .

2.8 Representação esquemática dos potenciais envolvidos na produção de

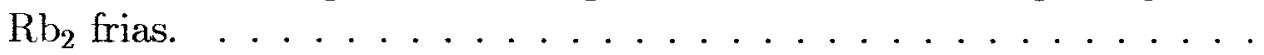

2.9 Energias dos fótons das bandas difusas (quadrados) comparadas com a metade da energia de ionização (círculos) para todos os alcalinos.

3.1 Distribuições espaciais das amostras atômicas de rubídio $\left({ }^{85} \mathrm{Rb}\right)$ e potássio $\left({ }^{39} \mathrm{~K}\right)$, mostrando a sobreposição entre elas. . . . . . . . . . . . .

3.2 Representação dos feixes de aprisionamento de $\mathrm{K}$ e $\mathrm{Rb}$ e das bobinas responsáveis pelo campo magnético dos MO'Ts na armadilha mista. $\mathrm{Na}$ direção z ambos os feixes, do K e do Rb são combinados. Nas demais direções, o acesso ao centro da armadilha é feito por acessos ópticos distintos, como mostra a figura. Também pode ser observado o feixe do laser de detecção (corante pulsado) que é incidido sobre a região de sobreposição entre as amostras frias. O detector de íons (CEM) quando no interior da câmara de aprisionamento, fica posicionado a uma distância de aproximadamente $10 \mathrm{~cm}$ do centro da armadilha, e portanto das amostras. . . . . . . . . . . . . . . . .

3.3 Representação esquemática dos niveis atômicos hiperfinos dos estados fundamentais $\mathrm{Rb}\left(5^{2} \mathrm{~S}_{1 / 2}\right)$ e $\mathrm{K}\left(4^{2} \mathrm{~S}_{1 / 2}\right)$ e dos primeiros estados excitados $\mathrm{Rb}\left(5^{2} \mathrm{P}_{3 / 2}\right)$ e $\mathrm{K}\left(4^{2} \mathrm{P}_{3 / 2}\right)$ envolvidos no aprisionamento de ${ }^{85} \mathrm{Rb}$ e ${ }^{39} \mathrm{~K}$ (correspondentemente às linhas D2), onde podemos observar as transições de aprisionamento e de rebombeio. O detuning do laser de aprisionamento do $\mathrm{Rb}$ é $\Delta_{\mathrm{Rb}}=-10 \mathrm{MHz}$ e ambas as frequências (aprisionamento e rebombeio) do $\mathrm{K}$ são dessintonizadas por $\Delta_{\mathrm{K}}=-36$ $\mathrm{MHz} \ldots \ldots \ldots \ldots \ldots \ldots \ldots$ 
3.4 Representação esquemática da montagem experimental empregada na produção de moléculas KRb frias. Podem ser observados os lasers de Ti:Safira usados para aprisionamento de ${ }^{85} \mathrm{Rb}$ e ${ }^{39} \mathrm{~K}$, e o laser de detecção (laser de corante pulsado), que é bombeado por um laser Nd:YAG. Moduladores eletro-ópticos (EOM), acoplados a chaves de $\mathrm{RF}$, são utilizados para desligar/ligar a frequência de rebombeio para ambas as espécies atômicas. . . . . . . . . . . . . .

3.5 Visão parcial da montagem experimental: detalhe mostrando a câmara de aprisionamento, as bobinas responsáveis pelo campo magnético quadrupolar, a janela de acesso óptico para observação da fluorescência (tubo fotomultiplicador) e para o sistema de imagem das armadilhas (câmara CCD). São mostrados também os reservatórios de $\mathrm{K}$ e Rb acoplados à câmara principal. . . . . . . . . . . . . . .

3.6 Visão parcial da montagem experimental mostrando o bombeamento do laser Ti:Safira (aprisionamento $\mathrm{Rb}$ ) pelo laser de estado sólido Verdi. 80

3.7 Detalhe mostrando o sistema de translado do detector de ions. Quando fora da câmara de aprisionamento, o CEM fica separado da mesma, e uma válvula mantém o detector livre de vapores alcalinos presentes na câmara. . . . . . . . . . . . . . . . . .

3.8 Detalhe do sistema experimental: sistema de absorção saturada do $\mathrm{Rb}$. É mostrado o laser de aprisionamento de $\mathrm{Rb}$, a célula de referência deste alcalino, o modulador acusto-óptico (AOM), e o VCO (que sintoniza a rádio-frequência injetada no $\mathrm{AOM}$ ). A chave de rádiofreqüencia (RF) acoplada junto ao AOM é usada para desligar/ligar a armadilha, comandada pelo gerador de função/delay. Também aparece nesta figura o fotodetector que comandas a aquisição do sinal de íons pela captação da luz do laser de corante. O modulador eletro-óptico (EOM) não aparece nesta foto. . . . . . . . . . . . . . .

3.9 Visão geral do sistema experimental: ao fundo o laser de corante pulsado, bombeado pelo laser pulsado de nanosegundos Nd:YAG. Sobre a mesa elevada, a óptica de aprisionamento de $\mathrm{K}$ e de $\mathrm{Rb}$. A frente, o laser de aprisionamento de Rb e o sistema de espectroscopia de saturação. A direita, a câmara de aprisionamento e o sistema óptico de detecção de imagem e fluorescência (situados do lado oposto da parede vertical . . . . . . . . . . . . . . . . . . .

3.10 Transição de deteç̧ão realizada pelo laser de corante pulsado, a partir do estado fundamental. Os dois fótons levam à excitação dos estados $8 \mathrm{D}_{3 / 2,5 / 2}$ do $\mathrm{Rb}$ e $16 \mathrm{D}_{3 / 2,5 / 2}$ do $\mathrm{K}$. O limite de ionização do $\mathrm{Rb}$ é $33691,02 \mathrm{~cm}^{-1}$ e o do $\mathrm{K}$ é $34991,2 \mathrm{~cm}^{-1}$. A energia do estado $\mathrm{Rb}(16 \mathrm{D})$ é $33180,03 \mathrm{~cm}^{-1}$, e $\mathrm{K}(8 \mathrm{D})$ é $33178,36 \mathrm{~cm}^{-1}$. . . . . . . . . . .

3.11 Esquema dos sistemas de detecção e aquisição de dados. . . . . . . . 89 
3.12 Esquema temporal dos experimentos envolvendo produção de moléculas frias no estado fundamental. A ionização e a detecção do sinal iônico ocorrem em fases de desligamento das duas armadilhas. . . . .

4.1 Espectro de tempo-de-vôo onde são observados picos de formação de moléculas homonucleares frias conjuntamente à formação de KRb térmicas. . . . . . . . . . . . . . . . . .

4.2 Evidência da formação de $\mathrm{KRb}^{+}$frias. Resultados preliminares onde ainda não havia sido comprovada a natureza dos átomos (frios ou térmicos) a partir dos quais se originou neste caso a formação molecular heteronuclear. . . . . . . . . . . . . . .

4.3 Espectro de tempo-de-vôo apresentando os picos iônicos homonucleares $\mathrm{K}_{2}^{+}$e $\mathrm{Rb}_{2}^{+}$e o pico heteronuclear $\mathrm{KRb}^{+}$, que só é observado na presença de ambas as armadilhas, evidenciando o fato de que o sinal é proveniente dos átomos frios de $\mathrm{K} \mathrm{e} \mathrm{Rb.} \mathrm{.} \mathrm{.} \mathrm{.} \mathrm{.} \mathrm{.} \mathrm{.} \mathrm{.} \mathrm{.} \mathrm{.} \mathrm{.} \mathrm{.}$

4.4 Espectro de tempo-de-vôo onde podemos observar claramente o pico iônico heteronuclear $\mathrm{KRb}^{+}$com relação aos homonucleares $\mathrm{K}_{2}^{+}$e $\mathrm{Rb}_{2}^{+}$.

4.5 Espectro dos estados excitados na banda difusa do $\mathrm{Rb}_{2}$ das moléculas frias $\mathrm{KRb}$ e $\mathrm{K}_{2}$. A energia do estado $\mathrm{K}(8 \mathrm{D})$ é $33178,36 \mathrm{~cm}^{-1}$ e a do estado $\mathrm{Rb}(16 \mathrm{D})$ é $33180,03 \mathrm{~cm}^{-1}$. . . . . . . . . . . . .

4.6 Espectro na região da banda difusa do $\mathrm{Rb}_{2}$, para o isótopo ${ }^{85} \mathrm{Rb}$. $\mathrm{Na}$ parte superior do gráfico observamos as ressonâncias do sinal iônico, $\mathrm{e}$ abaixo, o sinal de fluorescência. . . . . . . . . . . . . . . . . . 101

4.7 Fspectro na região da banda difusa do $\mathrm{Rb}_{2}$, para o isótopo ${ }^{87} \mathrm{Rb}$. . . . 102

4.8 Esquema de aprisionamento de ${ }^{85} \mathrm{Rb}$ e ${ }^{87} \mathrm{Rb}$ e de detecção de $R b_{2}$ a



4.9 Gráfico mostrando a comparação entre os espectros moleculares contendo as ressonâncias relativas aos estados excitados da banda difusa

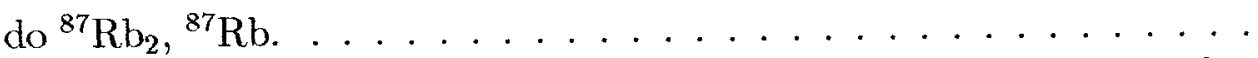

4.10 Íons moleculares $\mathrm{K}_{2}^{+}$como função do tempo de atraso entre o pulso de detecção e o desligamento da armadilha. As linhas contínuas são

resultados de uma simulação numérica. . . . . . . . . . . . . . . . . . .
4.11 Íns moleculares $\mathrm{Rb}_{2}^{+}$como funça do tempo de atraso entre o pulso de detecção e o desligamento da armadilha. As linhas contínuas são resultados de uma simulação numérica para várias temperaturas. . . .

4.12 Íons moleculares $\mathrm{KRb}^{+}$como função do tempo de atraso entre o pulso de ionização e o desligamento das armadilhas de $\mathrm{K}$ e $\mathrm{Rb}$. As linhas contínuas são resultados de uma simulação numérica. . . . . . . . . 
4.13 Íons moleculares $\mathrm{KRb}^{+}$como função do tempo de atraso entre o pulso de ionização e o desligamento das armadilhas de $\mathrm{K}$ e Rb para outra medida, em uma diferente condição de overlap. Podemos observar que distintas condições de alinhamento produzem diferentes resultados para a medida da temperatura molecular. . . . . . . . . . . .

4.14 f́ons moleculares homonucleares $\mathrm{K}_{2}^{+}$e $\mathrm{Rb}_{2}^{+}$e hetronucleares $\mathrm{KRb}^{+}$ como função do tempo de desligamento das armadilhas. As linhas contínuas correspondem ao ajuste pela expressão analítica de Lambrecht et al. . . . . . . . . . . . . . . . .

4.15 Íons moleculares $\mathrm{K}_{2}^{+}$como função da intensidade do laser de corante pulsado. Acima da potência média de $18 \mathrm{~mW} / \mathrm{cm}^{2}$ podemos notar que ocorre saturação. . . . . . . . . . . . . . . . .

4.16 fons moleculares $\mathrm{Rb}_{2}^{+}$como função da intensidade do laser de corante pulsado. Podemos observar a dependência quadrática, a qual indica a ionização como sendo um processo de dois fótons a partir do estado fundamental.Acima da potência média de $18 \mathrm{~mW} / \mathrm{cm}^{2}$ podemos notar que ocorre saturação. . . . . . . . . . . . . . . . . .

4.17 Íons moleculares $\mathrm{K}_{2}^{+}$como função da densidade atômica de pico da armadilha de K. . . . . . . . . . . . . . .

4.18 Íons moleculares $\mathrm{Rb}_{2}^{+}$como função da densidade atômica da armadilha de Rb. . . . . . . . . . . . . . . . . . .

4.19 Íons moleculares $\mathrm{KRb}^{+}$como função da intensidade do laser de corante pulsado (laser de deteç̧ão). Podemos observar a dependência quadrática, a qual indica a ionização como sendo um processo de dois fótons a partir do estado fundamental ${ }^{1,3} \Sigma^{+}$. Acima da potência média de $25 \mathrm{~mW} / \mathrm{cm}^{2}$ podemos notar que ocorre saturação. . . . . . . . . . . . . .

4.20 Esquema proposto para a formação das moléculas KRb no estado fundamental. No gráfico encontra-se representado apenas o estado singleto, porém o estado tripleto é também populado pelo decaimento espontâneo. A transição de dois fótons de $16.59530 \mathrm{~cm}^{-1}$ popula o estado fundamental da molécula ionizada $\mathrm{KRb}^{+} . \ldots . . . . .$.

4.21 f́ons moleculares $\mathrm{KRb}^{+}$como função da densidade atômica de pico da armadilha de Rb. As linhas sólidas correspondem a ajustes teóricos lineares, mostrando que as moléculas são formadas em processos de dois corpos. O erro na determinação da densidade é aproximadamente $30 \%$. . . . . . . . . . . . . . . .

4.22 Distribuições espaciais gaussianas representando o perfil de densidade das amostras de $\mathrm{Rb}$ e $\mathrm{K}$ para um corte transversal em uma das direções das armadilhas. Pode-se observar que a amostra de Rb esteve durante todo o experimento compreendida pelo MOT de $\mathrm{K}$, menos denso (maior volume). Neste gráfico, $n_{K}=1,2 \times 10^{9} \mathrm{~cm}^{-3}$. . . . . . . . 
5.1 Ajuste das curvas de potencial calculadas por Rousseau et al., pela função potencial de Morse para os estados moleculares correlacionados à assíntota $\mathrm{K}\left(4^{2} \mathrm{~S}\right)+\mathrm{Rb}\left(5^{2} \mathrm{P}\right)$.

5.2 Ajuste das curvas de potencial pelas funções potencial de Morse e Hulburt-Hirschfelder. Note que o ajuste teórico utilizando a segunda função é notavelmente melhor, principalmente com relação à curvatura dos potenciais. . . . . . . . . . . . . . . . . 138

5.3 Energia dos estados vibracionais como função do número vibracional v. 140

5.4 Energias dos níveis vibracionais próximos ao limite de dissociação $\mathrm{K}(4 \mathrm{~S})+\mathrm{Rb}(5 \mathrm{P})$ para os estados eletrônicos $\Sigma$ e $\Pi$. . . . . . . . . . 145 


\section{Resumo}

Neste trabalho apresentamos a produção de moléculas frias heteronucleares em uma armadilha magneto-óptica mista de ${ }^{39} \mathrm{~K} \mathrm{e}^{85} \mathrm{Rb}$ e detectadas no estado fundamental. A técnica de deteç̧ão consiste na fotoionização pulsada das moléculas que, após terem sido fotoassociadas, decaem através de emissão espontânea para estados ligados do potencial do estado molecular fundamental. A partir dos resultados da produção de moléculas frias KRb, estudamos-as com relação ao tipo de colisões que as originam, e à temperatura associada ao seu movimento translacional. Experimentos foram também realizados para comprovar que as moléculas detectadas são provenientes do estado fundamental. Finalmente, também estudamos neste trabalho, a taxa segundo a qual são formadas. Concomitantemente à produção de $\mathrm{KRb}$, moléculas frias homonucleares ${ }^{39} \mathrm{~K}_{2}$ e ${ }^{85} \mathrm{Rb}_{2}$ são também formadas, detectadas e caracterizadas. São apresentados também, os primeiros passos dados em direção à realização de espectroscopia fotoassociativa dos estados ligados das moléculas heteronucleares obtidas. 


\begin{abstract}
In this work, cold ground-state KRb molecules were produced by photoassociation in a two species magneto-optical trap (MOT) containing ${ }^{39} K$ and ${ }^{85} R b$. The KRb molecules are produced through photoassociation and detected in the ground state by multiphoton pulsed ionization. We have characterized their translational temperature and measured their formation rate constant. Homonuclear cold molecules ${ }^{39} K_{2}$ and ${ }^{85} \mathrm{R} b_{2}$ detected in their ground state were also formed in our trap and characterized as well. It is also reported our first efforts towards the realization of photoassociation spectroscopy of the heteronuclear molecules produced in our trap.
\end{abstract}




\section{Capítulo 1}

\section{Introdução}

A física atômica e molecular, em especial a dos gases atômicos ultrafrios, é uma área que tem sofrido rápidos e consideráveis avanços, especialmente ao longo das duas últimas décadas, graças ao advento da evolução das técnicas de aprisionamento e resfriamento de amostras gasosas no regime de temperaturas frias e ultrafrias, mostrando resultados espetaculares, sobretudo ao longo dos 10 últimos anos.

As temperaturas no regime de microkelvin alcançadas em gases resfriados por laser cooling correspondem a energias térmicas por partícula de apenas poucos nano elétron-volts, e as forças proporcionadas por campos elétricos ou magnéticos atuando sobre tais sistemas atômicos são utilizadas para aprisionar conservativamente átomos durante vários segundos, comprimindo-os à densidades de até $10^{15}$ átomos $/ \mathrm{cm}^{3}$.

Para temperaturas típicas abaixo de milikelvin, que são conseguidas em armadilhas magneto-ópticas (MOT) [1], o comprimento de onda de de Broglie dos pa- 
cotes de onda atômicos adquirem valores macroscópicos, na escala de microns, de tal forma que a natureza quântica das partículas começa a se revelar. Para o regime de sub-microkelvin, alcançado por resfriamento evaporativo, degenerescência quântica é alcançada nestes sistemas atômicos.

Apenas para ressaltar a importância deste recente e relevante campo da física atômica, o trabalho pioneiro de S. Chu, C. Cohen-Tannoudji e W.D. Phillips em laser cooling and trapping de átomos alcalinos neutros rendeu-lhes há cinco anos o Prêmio Nobel de Física de 1997, pela implementação da técnica de resfriamento de átomos no final da década de $80[2,3,4]$.

Após apenas três anos em seguida, o grupo de pesquisadores E. Cornell, W. Ketterle, e C. Wieman, foi agraciado com esta mesma honra, pela obtenção da Condensação de Bose-Einstein $[5,6]$. Após o trabalho destes autores em uma amostra de átomos de rubídio ultrafrios aprisonados, a condensação foi obtida para todos os átomos alcalinos aprisionáveis, aqui listados não em ordem cronológica, mas em ordem crescente da coluna 1A da tabela periódica: desde o hidrogênio em 1998 [7], em lítio [8] em 1997, o condensado de sódio em 1998 [9], o trabalho pioneiro, em rubídio [10] em 1995, o condensado de potássio em 2002 [11], até o césio em 2003. Este último, em um trabalho recentemente publicado, para o qual degenerescência foi obtida por meios exclusivamente ópticos [12] em 2003, como no trabalho de obtenção de BEC em rubídio em 2002 [13] em uma armadilha óptica, em vez do tradicionalmente utilizado aprisionamento magnético.

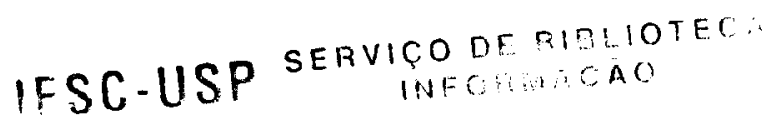


A abordagem inicial de resfriamento de átomos neutros, baseada no espalhamento ressonante de fótons que constitui o cerne da técnica de aprisionamento atômico nas armadilhas magneto-ópticas (MOTs), acompanhada pela técnica de resfriamento evaporativo (evaporative cooling), consistindo na remoção das partículas mais energéticas aprisionadas e na subsequente termalização dos átomos remanescentes através de espalhamento elástico, e também pela recentemente aplicada técnica no regime ultrafrio denominada de resfriamento "solidário" (sympathetic cooling), cuja idéia é extremamente simples e baseada na termalização entre duas amostras gasosas quando uma delas, geralmente difícil de ser resfriada por técnicas tradicionais (em geral por resfriamento evaporativo), é colocada em contato térmico com outra amostra mais fria. A termalização também se baseia nas colisões elásticas ocorrendo entre os átomos de ambas as amostras como no caso de resfriamento evaporativo.

Recentemente trabalhos interessantíssimos em misturas de átomos ultrafrios vem sendo realizados. Graças a sympathetic cooling, degenerescência quântica têm sido obtida simultaneamente tanto em amostras mistas bosônicas mistas quanto em misturas de Fermi-Bose. Em 2002 foi reportado o primeiro trabalho onde um mar de Fermi de ${ }^{6} \mathrm{Li}$ foi obtido na presença de um condensado de Bose- Einstein de ${ }^{23} \mathrm{Na}$ [14]. A partir de então, através da utilização da mesma técnica empregada neste trabalho pioneiro, a obtenção simultânea de degeneresência em sistemas binários têm sido demonstrada em outros sistemas de Fermi-Bose [15, 16, 17] e Bose-Bose [11].

Esta técnica de resfriamento vem sendo utilizada com grande sucesso na obtenção 
de degenescência quântica de espécies fermiônicas (que apresentam baixíssimas taxas de colisões elásticas necessárias para a realização de resfriamento evaporativo, técnica de resfriamento tradicional para obtenção de degenescência quântica em bósons) e mesmo para espécies bosônicas apresentando baixas taxas de espalhamento elástico (caso do potássio) e portanto difíceis ou impossíveis de serem resfriadas evaporativamente. Desta maneira a condensação de Bose-Einstein foi simultaneamente atingida em uma mistura $\mathrm{K}-\mathrm{Rb}$ de espécies bosônicas ${ }^{41} \mathrm{~K}-{ }^{87} \mathrm{Rb}$ [11], bem como degenerescência na mistura de gases de Fermi-Bose ${ }^{40} \mathrm{~K}-{ }^{87} \mathrm{Rb}[17]$.

Em adição à estes trabalhos mencionados existe uma grande diversificação referentemente à pesquisa utilizando amostras atômicas aprisionadas. Átomos frios e ultrafrios são empregados desde em estudos de interações colisionais e de espectroscopia fotoassociativa, até em metrologia, redes ópticas, etc.

A evolução em laser cooling propiciou concomitantemente um considerável avanço no estudo das interações atômicas nos regimes frio e ultrafrio, que apresentam características extremamente peculiares, que fazem do estudo das colisões atômicas nestes regimes de temperatura um fascinante objeto de estudo, tanto experimental quanto teoricamente. Especialmente, o estudo de colisões atômicas e de estados moleculares formados durante o encontro colisional de átomos frios aprisionados teve seu início dos anos 90 (mais especificamente à partir de 1993) e extende-se até os presentes dias por também representar um tópico de grande interesse.

O estudo de processos colisionais entre átomos frios aprisionados iniciou-se logo

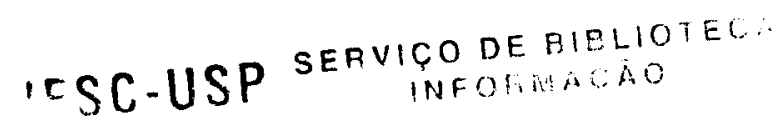


após a implementeação das primeiras armadilhas magneto-ópticas (MOTs) [18], e destinava-se a abordar colisões inélasticas, denominadas também de exoérgicas, que ocorrem na presença do campo de radiação do laser, e que são responsáveis em limitar números e densidades obteníveis nos MOTs. Passou-se estudar tais fenômenos uma vez que eram desejáveis amostras densas e com grande número de atomos aprisionados.

Este tipo de estudo estende-se até os dias atuais por revelar informações importantes sobre as interações atômicas de longo alcance e sobre os principais mecanismos de perdas em diferentes amostras alcalinas incluindo-se aqui também as amostras frias heteronucleares.

Logo após estes primeiros estudos de colisões de perdas, uma técnica de espectroscopia de altíssima resolução conhecida por espectroscopia fotoassociativa (PA), proposta por Thorsheim, Weiner e Julienne em 1987 [19], e foi realizada para a maioria dos alcalinos aprisionavéis passou a ser empregada, que pelo fato da vantagem de ser livre do efeito Doppler, pode fornecer com grande acurácia resultados relacionados aos potenciais de interação entre os átomos colidentes. Além disso, é um tipo de espectroscopia que permite que seja estudada a região de longo alcance dos potenciais de interação, incluindo-se os estados moleculares de puro longo-alcance propostos por Stwalley em 1978 [20].

Experimentos de colisões de perdas em misturas têm sido realizados nos últimos sete anos, quando foi demonstrado o aprisionamento pioneiro de duas espécies atômi- 
cas distintas em um MOT, Na e K [21]. Desde então, estudos colisionais de perdas em MOTs têm sido realizados em uma série de combinações de amostras frias simultaneamente aprisionadas $\mathrm{Na}-\mathrm{Rb}$ [22], $\mathrm{K}-\mathrm{Rb}$ [23], K-Cs [24], K-Cs [25], Li-Na [26]. Um estudo de ionização foto-associativa foi realizado em uma mistura $\mathrm{Na}-\mathrm{Cs}[27]$.

As colisões atômicas ocorrendo no regime de temperaturas abaixo de $1 \mathrm{mK}$ são marcadamente distintas de colisões térmicas. O fato de o encontro ocorrer entre átomos extremamente lentos faz com que existam consequências extremamente peculiares. O fato dos átomos serem muitíssimo lentos faz com que seja possível, por exemplo, observar-se a formação de um dímero à partir da interação de dois átomos inicialmente separados por grandes distâncias internucleares (da ordem de 1000 raios de Bohr, no caso de colisões envolvendo átomos idênticos) em uma armadilha atômica.

No contexto da obtenção de amostras quânticas degeneradas, o estudo de processos de espalhamento elástico e inelástico são cruciais do ponto de vista da produção de condensados e da caracterização destas amostras. Contudo hoje, através da utilização de campos externos pode-se sintonizar o sinal do comprimento de espalhamento de onda-s através de ressonâncias de Feshbach, levando-se assim a produção do condensado a partir de situações de instabilidade até a produção de condensados estáveis.

Em especial, a mistura $\mathrm{K}-\mathrm{Rb}$ que utilizamos neste trabalho, já vem sendo explorada em estudos colisionais de trap-loss [23] (espalhamento inelástico) e também em medidas da taxa de espalhamento elástico [28] entre as combinações isotópicas ${ }^{41} \mathrm{~K}-$ ${ }^{87} \mathrm{Rb}$ e ${ }^{40} \mathrm{~K}-{ }^{87} \mathrm{Rb}$. 
Do ponto de vista espectroscópico a molécula diatômica KRb é de particular interesse principalmente devido ao fato de apresentar coeficientes de dispersão dos potenciais de interação de longo alcance notavelmente grandes se comparados aos de outros dímeros alcalinos heteronucleares [29]. Além disso, em 1998 Wang e Stwalley sugeriram que esta molécula apresenta fatores de Franck-Condon bastante favoráveis para o processo de fotoassociação [30] em colisões frias, sendo portanto um excelente candidato para formação de moléculas heteronucleares e a espectroscopia de fotoassociação. Neste sentido, nosso trabalho corrobora estas especulações teóricas de uma maneira inequivoca, uma vez que as nossas moléculas foram as produzidas a uma taxa bastante razoavel. Várias tentativas foram realizadas por nosso grupo durante os dois últimos anos em outras misturas (K-Cs, $\mathrm{Na}-\mathrm{Cs}$ e $\mathrm{Na}-\mathrm{Rb}$ ) mas nenhum resultado favorável foi obtido.

Apesar da grande evolução nas técnicas de laser cooling, esta técnica aplica-se somente a átomos, e ainda, à especial classe dos átomos alcalinos, átomos hidrogenóides que apresentam esquemas de transições fechadas entre dois níveis com uma grande força de oscilador, o que favorece intensamente a implementação de resfriamento e aprisionamento destas espécies. Além destes, apenas os alcalinos terrosos e gases nobres também podem ser aprisionados por esta técnica.

A principal dificuldade de implementação desta técnica para os demais espécies da tabela periódica se deve à indisponibilidade de lasers com frequências necessárias, e ainda ao problema de decaimento espontâneo a partir do estado excitado envolvido 
na transição de cooling, que pode popular estados não aprisionáveis. No caso dos metais alcalinos, isto é corrigido apenas com a adição de uma frequência secundária, conhecida como frequência de rebombeio. Em outras espécies, existem canais de decaimento múltiplos para outros níveis, tornando a técnica inviável de ser implementada. No caso de moléculas este fato torna-se ainda mais drástico [31].

Atualmente, um grande esforço tem sido devotado à obtenção de moléculas frias, uma vez que este passo parece ser bastante natural na evolução das técnicas de aprisionamento e resfriamento atômicas e nos estudos de gases quânticos degenerados, por exemplo, além de estudos de interações inter-moleculares, espectroscopia, etc... Além disso a observação de BEC em um sistema molecular parece bastante atraente, bem como o laser de moléculas (em analogia ao laser de átomos [32]). Para tanto é necessário contar-se com uma fonte de moléculas frias no estado molecular eletrônico fundamental, e ainda: no estado vibracional fundamental. Esta tarefa contudo está ainda longe de ser realizada, mas certamente a sua realização consiste numa grande motivação em direção a isso.

O resfriamento de moléculas com esquemas similares aos utilizados para aprisionar e resfriar átomos em armadilhas do tipo MOT é totalmente impossível de ser implementado. Uma molécula, mesmo as mais simples como as diatômicas, apresenta estados de energia muito mais complexos do que os átomos, de modo que a necessidade da existência de uma transição fechada e com uma grande força de oscilador, como por exemplo as correspondentes à linha D2 dos átomos alcalinos, previne que 
este tipo de abordagem possa ser usado. As moléculas apresentam, além dos estados eletrônicos, estados vibracionais e rotacionais, de modo que existem múltiplos canais de decaimento espontâneo para níveis não ressonantes com a radiação de aprisionamento [31]. Por exemplo, usualmente um potencial molecular que descreve um estado molecular eletrônico pode apresentar algumas centenas de estados vibracionais.

Uma alternativa é a produção de moléculas frias estáveis em um MOT pelo processo de fotoassociação. Os dímeros frios estáveis produzidos a partir de átomos frios podem serem aprisionados em armadilhas conservativas, como as magnéticas ou em uma armadilha óptica de modo a produzir-se armadilhas moleculares.

A produção de moléculas frias estáveis por fotoassociação de átomos frios têm recebido especial atenção ao longo dos últimos quatro anos. Em 1998 foi demonstrado, pela primeira vez, a produção de moléculas com velocidades associadas ao seu movimento translacional tão baixas quanto as dos átomos aprisionados em um MOT, através de fotoassociação de átomos de Cs [33]. Este primeiro experimento inspirou a obtenção de moléculas diatômicas alcalinas frias no estado fundamental para os demais átomos alcalinos aprisionáveis $[34,35,36]$.

- A produção de moléculas frias em um MOT envolve além da fotoassociação de dois átomos frios colidentes em seus estados fundamentais atômicos, a necessidade de uma probabilidade favorável de decaimento espontâneo da molécula formada neste processo na região de curto alcance do potencial excitado, onde a sobreposição com a função de onda do estado fundamental molecular seja considerável. Para tanto, além 
disso, existe a necessidade de utilizar-se técnicas de detecção favoráveis dos dímeros formados por esta rota. A abordagem seguida nestes trabalhos será descrita com detalhe na seção a seguir, bem como as demais propostas de detecção propostas.

Um primeiro passo dado em direção a obtenção de uma fonte contínua de moléculas frias aprisionadas é representado pelo trabalho que demonstrou o aprisionamento simultâneo de átomos e moléculas em uma armadilha híbrida, magneto-óptica e magnética, onde as próprias bobinas responsáveis em gerar o campo quadrupolar do MOT é usado para aprisionar as moléculas de $\mathrm{Cs}_{2}$ [37]. Uma outra abordagem é o aprisionamento óptico em uma armadilha do tipo QUEST (quasi-eletrostatic trap) [38, 39] constituída pelo foco de um laser de $\mathrm{CO}_{2}$ com potência da ordem de $100 \mathrm{~W}$.

Outras abordagens complementares à abtenção e aprisionamento de moléculas frias (contudo em temperaturas da ordem de $100 \mathrm{mK}$, ao invés das temperaturas da ordem de $100 \mu \mathrm{K}$ das moléculas produzidas por fotoassociação) basearam-se no aprisionamento magnético de moléculas paramagnéticas (CaH, $10^{8}$ moléculas à $400 \mathrm{mK}$ ) resfriadas por sympathetic cooling com um gás buffer (He) resfriado criogênicamente [40], e na desaceleração e aprisionamento de moléculas polares $\left(\mathrm{ND}_{3}, 10^{6}\right.$ moléculas à $350 \mathrm{mK}$ ) por um campo elétrico inomogêneo [41].

Até o presente momento, entretanto, apenas sistemas homonucleares haviam sido utilizados com a finalidade de fotoassociação, levando à formação de moléculas frias estáveis. Um passo seguinte em complexidade e com vista em futuras aplicações, consiste na extensão aos sistemas heteronucleares. Portanto, um passo nesta direção 
consiste na obtenção de uma fonte contínua de moléculas heteronucleares, formadas em um MOT misto. A formação e deteç̧ão de dímeros alcalinos frios heteronucleares no estado fundamental têm sido objeto de pesquisa por vários grupos. Até o presente momento, apenas nosso grupo foi capaz de produzir tais moléculas, à partir da fotoassociação em uma armadilha mista.

Neste trabalho será descrito nosso esforço experimental para a obtenção de moléculas $\mathrm{KRb}$ frias no estado fundamental e a caracterização dos dímeros heteronucleares e homonucleares produzidos. As moléculas $\mathrm{KRb}$ frias pelo processo de fotoassociação de átomos de ${ }^{85} \mathrm{Rb}$ e ${ }^{39} \mathrm{~K}$ colidindo em uma armadilha-magneto óptica mista, em um dímero excitado. Uma fração das moléculas fotoexcitadas decai por emissão espontânea de radiação para o estado molecular fundamental, permanecendo translacionamente frias. O esquema de deteç̧ão das moléculas heteronucleares é realizado por fotoionização, de maneira bastante similar àquelas usadas nos experimentos de $\mathrm{Cs}_{2}$ [42], e principalmente de $\mathrm{Rb}_{2}[34]$.

Conforme poderá ser observado na seção destinada aos resultados experimentais, a dependência do sinal iônico $\mathrm{KRb}^{+}$com a intensidade do laser pulsado nos mostra que o processo de ionização procede via uma transição de dois fótons a partir do estado fundamental. Também é apresentado o espectro obtido na região do comprimento de onda de deteç̧ão da molécula mostra que o pico de formação ocorre na frequência ótima para a detecção.

A medida da temperatura translacional das moléculas $\mathrm{K}_{2}, \mathrm{Rb}_{2}$, e $\mathrm{KRb}$ comprovam 
o fato de que as moléculas detectadas foram formadas a partir dos átomos frios presentes nos MOTs e não dos átomos quentes presentes no vapor de fundo da câmara de aprisionamento. A comparação com os resultados de outros autores $[34,35]$ mostram que os valores por nós encontrados para a temperatura das moléculas homonucleares por nós produzidas mostram uma concordância bastante bastante razoável entre nossos resultados e os outros da literatura. A concordância entre as taxas de formação molecular também é satisfatória.

No próximo capítulo, abordaremos aspectos gerais concernentes às colisões ultrafrias ocorrendo em armadilhas magneto-ópticas (temperaturas típicas da ordem de $100 \mu \mathrm{K})$, e aos mecanismos de formação moleculares e também à fotoassociação heteronuclear.

No terceiro capítulo serão descritos a montagem e o procedimento experimentais. No capítulo 4 são apresentados os resultados experimentais referentes à produção, deteç̧ão e a caracterzização das moléculas frias heteronucleares e homonucleares. No capítulo 5 são discutidos os passos já dados em direção a realização de espectroscopia de fotoassociação heteronuclear. Finalmente, o capítulo 6 é destinado às conclusões acerca deste trabalho e à discussões de futuros experimentos que poderão ser realizados à partir da obtenção das moléculas heteronucleares frias produzidas neste trabalho. 


\section{Capítulo 2}

\section{Moléculas diatômicas alcalinas frias}

\section{no estado fundamental: Aspectos}

\section{Gerais}

O processo de fotoassociação conforme proposto na ref. [19], no qual dois átomos aprisionados colidindo, ambos em seus estados fundamentais, absorvem um fóton do campo de radiação do laser e o par atômico é promovido ao estado excitado, originando uma quasi-molécula, tornou-se a primeira rota para a produção de moléculas frias no estado excitado, as quais podem ser detectadas experimentalmente através de detecção de íons [43], ou através do espectro de trap-loss (fluorescência) [44].

Contudo, moléculas ultrafrias em estados eletrônicos fundamentais emergindo da assíntota fundamanetal $S_{1 / 2}+S_{1 / 2}$, são formadas e detectadas com a ocorrência de 
um evento adicional. O processo de fotoassociação é o primeiro passo no processo de formação, mas insuficiente para que moléculas estáveis sejam formadas. É necessário que uma transição, a partir do estado excitado, ocorra através da emissão espontânea ou estimulada de radiação em direção ao estado eletrônico molecular fundamental.

De modo a este processo ser favorecido, deve existir um ponto de retorno na região de longo-alcance [45], ou um chamado near lying perturbing molecular state [46], como no caso do $\mathrm{Cs}_{2}$. A fotoassociação de $\mathrm{Rb}$ em uma molécula de puro longo alcance tambśm foi utilizada para produzir-se dímeros de rubídio ultrafrios no estado fundamental tripleto [34]. Dímeros alcalinos homonucleares ultrafrios no estado molecular fundamental singleto $\mathrm{X}^{1} \Sigma_{g}^{+}$foram também observados para o K [35] e até mesmo os níveis vibracionais mais baixos deste estado foram populados [47].

É interessante notar-se que quase todos os desenvolvimentos neste sentido baseiamse em estudos experimentais e teóricos [48] de auto-alargamento em vapores alcalinos, que levaram à proposição da existência das moléculas de puro longo-alcance [20], e também nos estudos das chamadas bandas difusas dos dímeros alcalinos, que foram estudadas há duas décadas em experimentos de absorção e fluorescência em vapores alcalinos densos a altas temperaturas, e que são utilizados como estratégia de detecção das moléculas frias detectadas no estado eletrônico fundamental.

A seguir abordaremos aspectos importantes relacionados à formação de moléculas alcalinas ultrafrias via fotoassociação, como as colisões binárias ultrafrias, passando por um histórico sobre a observação de dímeros alcalinos homonucleares, e os princi- 
pais mecanismos utilizados para detecção de dímeros frios no estado fundamental.

\subsection{Colisões Frias em Armadilhas Atômicas}

Uma das grandes motivações ao desenvolvimento das armadilhas atômicas foram os novos processos colisionais que passaram a ser estudados a partir do início da década passada. A física de átomos colidindo em ultrabaixas temperaturas representa uma recente área onde novos e singulares fenômenos passariam a ser estudados. As baixíssimas energias envolvidas em uma colisão ultrafria permitem a observação de efeitos que são convencionalmente negligiveis ou até mesmo não observáveis em uma colisão ocorrendo entre átomos térmicos. Neste regime de temperaturas, abaixo de $1 \mathrm{mK}$, o comportamento do encontro atômico é predominantemente quântico, uma vez que o comprimento de onda térmico de de Broglie associado aos átomos participantes da colisão, $\lambda_{D}=h / \sqrt{2 \pi M k_{B} T}$, onde $\mathrm{M}$ é a massa do átomo e $k_{B}$ é a constante de Boltzmann, são comparáveis ao alcance do potencial de interação entre eles.

Uma das características ímpares das colisões ultrafrias são as escalas de tempo colisionais. Colisões convencionais (térmicas) duram poucas centenas de fentossegundos, enquanto no regime ultrafrio os átomos têm tempos típicos de dezenas de nanossegundos para completarem o encontro colisional. Estes longos tempos colisionais asseguram ao par atômico colidente tempo suficiente para que absorvam energia do campo de radiação e emitam por processos espontâneos ou estimulados. A frequência, intensidade e a polarização do campo óptico pode alterar efetivamente os 
potenciais de interação e controlar a probabilidade dos produtos através da manipulação dos inelásticos e elásticos envolvidos no processo de espalhamento. Neste regime, a distribuição de velocidades torna-se bastante estreita, da ordem da largura natural da transição de dipolo, permitindo-se assim a realização desta espectroscopia do tipo free-bound, de ultra-alta precisão [49].

Outra peculiaridade das colisões ocorrendo entre átomo frios aprisionados é a participação de apenas poucas ondas parciais. Devido à existência da barreira centrífuga do potencial de interação a curto alcance, apenas as ondas parciais mais baixas contribuem ao evento de espalhamento pelo fato da barreira evitar que ondas mais altas alcancem a região de curto-alcance. Para o caso de colisões ultrafrias temos apenas colisões de ondas s $(\ell=0)$ participando da colisão.

As (grandes) seções de choque totais de espalhamento em temperaturas ultrafrias são bem descritas pelo formalismo fornecido pela teoria quântica de espalhamento [50]:

$$
\sigma(E)=\frac{\pi}{k^{2}} \sum_{\ell=0}^{\infty}(2 \ell+1) \operatorname{sen}^{2} \eta_{\ell}
$$

onde somamos sobre todas as ondas parciais $\ell$ (a soma é truncada no valor máximo $\ell_{\text {máx }}$ permitido penetrar a barreira centrífuga), $k=\sqrt{2 \mu E / \hbar^{2}}$ e $\eta_{\ell}$ é o o deslocamento de fase.

$\mathrm{Na}$ análise quântica de espalhamento, o espalhamento de cada onda parcial $\ell$ é computado resolvendo-se a equação de Schrödinger para o seguinte Hamiltoniano: 


$$
H=-\frac{\hbar^{2}}{2 \mu R^{2}} \frac{d}{d R}\left(R^{2} \frac{d}{d R}\right)+\frac{\hbar^{2} \ell(\ell+1)}{2 \mu R^{2}}+V(R)
$$

onde $\mu$ é a massa reduzida do par atômico, $\mu=\mathrm{M}_{\mathrm{A}} \mathrm{M}_{\mathrm{B}} /\left(\mathrm{M}_{\mathrm{A}}+\mathrm{M}_{\mathrm{B}}\right)$, composto das partículas A e B, e o segundo termo corresponde à barreira centrífuga para uma dada onda parcial.

É comum, entretanto, atribuir-se ao invés da seção de choque, um coeficiente de taxa ao evento colisional, pois é esta a grandeza que é medida experimentalmente. Este, relaciona-se ao número de eventos colisionais por unidade de tempo e de volume, relacionando-se com a seção de choque da seguinte maneira:

$$
K=\langle\sigma v\rangle
$$

onde a integração através da distribuição de velocidades envolve todas as velocidades colisionais possíveis na armadilha. Em um MOT, a distribuição de velocidades é a distribuição de Maxwell Boltzmann, pois o regime de temperaturas obtido neste tipo de armadilha ainda é descrito pela estatística clássica.

\subsubsection{Processos colisionais em Armadilhas Atômicas}

As armadilhas magneto-ópticas continuam sendo as mais utilizadas para o estudo de tais tipos de processos, embora ultimamente estudos colisionais elásticos e inelásticos envolvendo átomos no estado fundamental venham sendo realizados também em armadilhas magnéticas $[51,52]$ e em armadilhas ópticas de dipolo [53]. 
Em um MOT, os átomos podem estar tanto no estado fundamental quanto no primeiro estado excitado. Isto cria várias possibilidades para os átomos inciarem um encontro colisional. Se ambos os átomos envolvidos em uma colisão binária estão inicialmente no estado fundamental e nele permanecem durante todo o processo colisional, a influência do processo de emissão espontânea obviamente não se faz presente, e o sistema não troca energia com o campo de radiação.

Existem dois tipos principais de colisões envolvendo dois átomos colidindo em seus estados S, do tipo ground-ground. Um deles é o espalhamento elástico, constituindo o tipo de colisões que são importantes do ponto de vista da obtenção da Condensação de Bose Einstein (BEC) e das propriedades de um gás de Bose (e também na obtenção de mares de Fermi). Uma alta taxa de eventos de espalhamento deste tipo é necessária para que o resfriamento evaporativo possa ser realizado de modo que a degenerescência quântica seja alcançada em um sistema diluído. Em geral, tais colisões são bastante sensíveis à aplicação de campos externos, e campos magnéticos podem alterar drasticamente a seção de choque de espalhamento elástico, produzindo as chamadas ressonâncias de Feshbach.

Por outro lado, os processos inelásticos em uma colisão podem em algumas circunstâncias resultar em perdas do par atômico da armadilha, limitando o número de átomos aprisionados em armadilhas. Os átomos alcalinos apresentam spin nuclear não nulo e portanto apresentam estrutura hiperfina no estado fundamental e também no estado excitado. Uma colisão inciando-se em um estado fundamental hiperfino 
pode terminar em um estado hiperfino de mais baixa energia e, se a diferença relativa entre os dois níveis for superior à profundidade da armadilha, os átomos serão perdidos da região de aprisionamento.

Colisões ocorrendo na presença de um campo de radiação do laser, onde o par pode absorver um fóton do laser de aprisionamento ou de um laser de prova, podem ser classificadas como colisões do tipo ground-excited. Devido às baixíssimas energias colisionais típicas deste regime, os átomos interagem através de potenciais de longo alcance começando a interagir mesmo a distâncias internucleares da ordem de $\bar{\lambda}$, isto é, da ordem do comprimento de onda reduzido da radiação de aprisionamento.

O comportamento predominante do potencial excitado no caso das colisões frias envolvendo o estado excitado, é de longo alcance, do tipo $\pm C_{3} / R^{3}$ para o caso de colisões homonucleares envolvendo átomos incialmente nos estados $n \mathrm{~S}+n \mathrm{P}, \mathrm{e} \pm C_{6} / R^{6}$ para colisões heteronucleares envolvendo um par de átomos distintos, $n \mathrm{~S}+n \mathrm{P}$, onde $R$ é a separação internuclear, e dependendo da dessintonia do laser (negativa ou positiva) estados atrativos ou repulsivos podem ser acessados.

Conforme já mencionado, devido aos longos tempos colisionais, o decaimento espontâneo pode alterar significativamente a dinâmica colisional através de uma mudança abrupta de estado molecular eletrônico, que ocorre conjuntamente à emissão de um fóton para o vermelho comparado ao absorvido do laser de aprisionamento. Neste caso, parte da energia interna do sistema atômico é transferida para a forma cinética. Se a velocidade ganha pelos átomos não for suficientemente alta, o meio viscoso do 
MOT é capaz de dissipar o aquecimento ocasionado; caso contrário, os átomos são ejetados da armadilha, em um processo que é referido como escape radiativo (RE).

Ainda para o caso dos alcalinos, existe um segundo mecanismo colisional importante de perdas. Devido à existência da estrutura fina do estado excitado, $P_{J}$ $(\mathrm{J}=1 / 2,3 / 2)$ com o momentum angular total sendo $\mathbf{J}=\mathbf{L}+\mathbf{S}$, onde $\mathrm{L}$ é o momentum angular orbital e S o momentum angular de spin eletrônico, o encontro iniciado na asssíntota $\mathrm{nS}_{1 / 2}+\mathrm{nP}_{3 / 2}$ pode resultar em uma colisão de mudança de estrutura fina (FSC). Este tipo de processo, ocorre via predissociação. A colisão então termina com os átomos no estado final $n \mathrm{~S}_{1 / 2}+n \mathrm{P}_{1 / 2}$ e pode, uma vez que tenha ocorrido, fornecer ao par atômico energia cinética correspondente à separação entre os níveis finos do estado excitado, a qual dividida entre os dois átomos e que é mais do que suficiente para que escapem da armadilha, a qual apresenta profundidades típicas da ordem de $1 \mathrm{~K}$.

No caso do $\mathrm{Rb}$, por exemplo, $\Delta \mathrm{E}=238 \mathrm{~cm}^{-1}$, ou $\Delta \mathrm{E} / k_{B}=342,24 \mathrm{~K}$ onde $k_{B}$ é a constante de Boltzmann, e para o $\mathrm{K}$, esta energia corresponde a $\Delta \mathrm{E}=58 \mathrm{~cm}^{-1}$ ou, $\Delta \mathrm{E} / k_{B}=83,4 \mathrm{~K}$. Este tipo de colisão foi estudada experimentalmente através de medidas diretas e taxas colisionais a elas relacionadas medidas para o ${ }^{85} \mathrm{Rb}[54,55,56]$ e para Cs [57]. No caso do potássio, FSC foi estudada através da obtenção do espectro de predissociação dos estados envolvidos na colisão [58].

As colisões de trap-loss descritas acima foram extensivamente estudadas durante a última década e meia, tanto para sistemas homonucleares [49] e para heteronucleares, 
e forneceram informações experimentais importantes relativas às interações atômicas. Com relação a estes tipos de processos colisionais inelásticos, as investigações são feitas em geral com relação à intensidade do laser de aprisionamento e com o detuning. Contudo, nos alcalinos, a região de pequenos detunings (longas separações internucleares e alta densidade de estados ro-vibracionais) a estrutura hiperfina leva a uma grande complicação nos potenciais interatômicos devido aos múltiplos canais colisionais representados pelas curvas de potencial hiperfinas desta região, fazendo com que a comparação de resultados experimentais com os modelos teóricos disponíveis, seja profundamente dificultada. Os modelos semiclássicos para trap-loss [59, 60], entretanto, apesar de simples, são capazes de incorporar todos os processos físicos importantes dos processos colisionais envolvidos apesar de não fornecerem uma concordância quantitativa. Mesmo os modelos totalmente quânticos são incapazes de lidar com a complexidade imposta pelos canais colisionais hiperfinos acessados nestes experimentos $[61,62]$. Assim, estas colisões para regime de pequenos detunings continuam não completamente entendidas e a área continua em aberto à espera de um maior esforço teórico neste sentido.

- Ainda, outros mecanismos colisionais em MOTs foram estudados no início dos anos 90, tais como a ionização fotoassociativa [63, 64], e blindagem de colisões (optical shielding) através da excitação de potenciais repulsivos [65, 66].

Outra motivação importante que levou a desenvolvimentos importantes na área de colisões frias foi a espectroscopia fotoassociativa de átomos frios, proposta por 
Thorsheim et al. no final da década de 80 [19]. Desde então, esta técnica de altíssima resolução por utilizar átomos frios e ser livre do efeito Doppler, vem sendo utilizada para determinar-se em medidas de alta-precisão, parâmetros atômico-moleculares associados aos potenciais interatômicos, principalmente relacionados à região de longo alcance que descrevem uma colisão atômica, como por exemplo, tempos de vida radiativos, os coeficientes do potencial de longo alcance, comprimentos de espalhamento, formas de linha, etc. Os espectros de fotoassociação de átomos colidindo em armadilhas do tipo MOT são obtidos a partir de duas principais técnicas: detecção de trap-loss e ionização de estados moleculares excitados por uma ou duas frequências [49]. Os espectros obtidos por estas duas técnicas em geral não revelam as mesmas características, sendo portanto complementares.

O estudo das colisões ultrafrias seguiu ainda mais adiante devido a mais uma questão bastante recente: a obtenção de degenerescência quântica em sistemas atômicos dilutos fracamente interagentes constituídos por átomos ultrafrios aprisionados. O estudo de colisões ocorrendo na ausência do campo de radiação de um laser quaseressonante, em armadilhas magnéticas ou puramente ópticas, tanto as inelásticas que são indesejáveis sob tal contexto, quanto as colisões elásticas, que são singularmente necessárias para que o regime de degenerescência seja atingido, passa a ser crucial. Atualmente, em adição à famosa condensação de Bose-Einstein, obtenção de gases quânticos degenerados fermiônicos também têm sido obtidos, através de técnicas baseadas na necessidade de altas taxas de colisões elásticas. Devemos ressaltar 
que os recentes experimentos envolvendo misturas onde degenerescência quântica foi atingida simultaneamente em sistemas de gases Fermi-Bose $[14,15,16]$ têm sido motivados com o intuito de observação da transição BCS em um sistema atômico diluto, ou seja, a obtenção de um condensado fermiônico.

Os termos "frio" e "ultrafrio" são comumente utilizados indistintamente, porém as colisões que ocorrem em cada um destes dois regimes apresentam características bastante distintas. De acordo com a classificação feita por Suominen [67], o regime das colisões frias é compreendido pelo regime de temperaturas características do resfriamento Doppler e optical molasses (entre $1 \mathrm{mK}$ e $1 \mu \mathrm{K}$ ). A maior parte dos processos colisionais neste regime ocorrem em presença dos campos de radiação usados para confinar os átomos e provar as suas interações. O regime das colisões ultrafrias é caracterizado por temperaturas compreendidas no intervalo $1 \mu K \rightarrow 0$, e ocorrem no escuro. Neste regime, o resfriamento evaporativo e a condensação de Bose-Einstein e mares de Fermi representam o foco principal de estudos neste intervalo de temperaturas. Neste regime, colisões entre os átomos em seus estados fundamentais ocorrem apenas através do movimento radial $(\ell=0)$, e são caracterizadas pela .grandeza denominada comprimento de espalhamento. Desse modo, denominaremos nossas moléculas frias por serem formadas a partir de colisões binárias entre átomos frios aprisionados em um MOT, que portanto se inserem na primeira classe, onde as temperaturas atômico-moleculares típicas são da ordem de $100 \mu \mathrm{K}$.

É evidente que a importância das colisões frias se faz particularmente notável no 
processo de formação de moléculas frias. Através da fotoassociação de dois átomos frios colidindo no estado fundamental, a quasi-molécula formada pela absorção de um fóton do laser de aprisionamento ou de prova, é excitada para um estado molecular correlacionado à assíntota $\mathrm{S}+\mathrm{P}$. É sob a ação deste potencial, que os átomos colidem até alcançarem a região de curtas separações internucleares, onde existe uma janela de Franck-Condon favorável para o decaimento espontâneo que irá popular o estado molecular fundamental, gerando moléculas frias estáveis.

\subsection{Estados Moleculares e Potenciais de Interação}

As curvas de potencial que descrevem os estados moleculares diatômicos assintoticamente correlacionados aos estados $n \mathrm{~S}+n \mathrm{P}_{\mathrm{J}}\left(\right.$ ou $n \mathrm{~S}+n \mathrm{P}_{\mathrm{J}}$ ) formados a partir de dois átomos separados por longas distâncias internucleares (da ordem de1000 $a_{0}$ para pares homonucleares e $100 a_{0}$ para heteronucleares), são descritas de acordo com o tipo de interação predominante entre os átomos que constituem a molécula durante o encontro colisional. O tempo de vida destes estados, formados pela interação dos átomos com o campo de radiação do laser, são da ordem de poucas dezenas de nanosegundos, e variam de acordo com a simetria molecular [60].

A classificação das curvas de potencial dos estados moleculares eletrônicos resultantes dos estados eletrônicos assintóticos $\mathrm{S}+\mathrm{P}_{\mathrm{J}}$ (atômicos) depende da magnitude da interação entre diferentes momenta angulares e com relação ao acoplamento deste com o eixo molecular, descritos por diferentes Hund's cases [68]. Abaixo, veremos 
uma breve introdução acerca dos potenciais de interação e os estados moleculares eletrônicos, envolvidos em colisões atômicas binárias.

Na região de longo alcance $(R \gtrsim 20 \AA)$ dos potenciais, a interação entre dois átomos alcalinos ocorre basicamente através da interação eletrostática coulombiana entre seus momentos de dipolo, e estes podem ser expressos pela seguinte expansão de potências inversas da separação internuclear entre os átomos:

$$
V(R)=-\sum_{n \geq m} \frac{C_{n}}{R^{n}}
$$

onde $m$ é o coeficiente que caracteriza a interação principal, que no caso das assíntotas fundamentais $\mathrm{S}+\mathrm{S}$ homo e heteronucleares correspondem à interação de Van der Walls $(\mathrm{n}=6)$ atrativa $-C_{6} / R^{6}$. Para a primeira assíntota excitada $\mathrm{S}+\mathrm{P}$, a interação predominante para o caso de dois átomos idênticos é a interação dipolo-dipolo ressonante, $\pm C_{3} / R^{3}$, e no caso hetero temos a interação de van der Walls $\pm C_{6} / R^{6}$ como predominante.

Os potenciais de interação de longo alcance de moléculas diatômicas, isto é, para a região de grande separação internuclear, podem ser inferidos através de abordagens aproximativas utilizando teoria de perturbação.

Quando os átomos encontram-se bastante separados uns dos outros e interagem através de seus dipolos elétricos, e as demais interações (interação de troca, spinórbita, hiperfina) apresentam nesta região menores intensidades comparadas à eletrostática, o potencial de interação é descrito por uma expansão multipolar elétrica

$$
\begin{aligned}
& \text { OSC-USP SERVICOODE BIBLIOTECA } \\
& \text { INFORMACAO }
\end{aligned}
$$


representada por potências inversas da separação internuclear dos átomos colidindo concernentemente as várias ordens perturbativas, como já dito acima. Neste caso, os átomos interagem através de seus dipolos elétricos e às várias ordens aproximativas são calculadas considerando-se as diferentes interações multipolares. Modelos simples considerando átomos de dois níveis, teoria de perturbação de segunda ordem fornece, corretamente a dependência da energia da interação com a separação internuclear, incluindo o sinal da interação, e cálculos perturbativos mais sofisticados fornecem os coeficientes para as diversas simetrias que descrevem os diferentes estados moleculares.

Um fato importante é concernente às diferenças entre as interações a longo alcance homonucleares e heteronucleares. Enquanto no caso homonuclear a interação predominante é a do tipo dipolo-dipolo ressonante, $\pm C_{3} / R^{3}$, dois átomos de espécies distintas interagem via força de Van der Walls. Neste segundo caso, a correção em primeira ordem à energia dos átomos separados, $E_{A}+E_{B}$, é nula, e o potencial é caracterizado pelo próximo termo, a correção de segunda ordem, que corresponde à interação de Van der Walls, $\pm C_{6} / R^{6}$. Esta característica tem efeitos importantes so.bre aspectos relacionados à fotoassociação de átomos frios a longo alcance. Se por um lado as interações homonucleares são mais intensas, variando com $R^{-3}$, produzindo uma aceleração mais efetiva dos átomos em direção um ao outro, a sobreposição entre as funções de onda dos estados fundamental e excitado na região dos poços contendo os estados ligados, parece ser maior no caso dos dímeros heteronucleares, apesar destes 
não apresentarem características desejáveis como estados de puro longo-alcance, etc.

Os estados moleculares de longo alcance são caracterizados pela notação ${ }^{2 S+1} \Lambda^{\sigma}$ referentes ao Hund's case (a). Para a região de longo alcance, $L$ é considerado como um bom número quântico. Neste caso de acoplamento entre momenta angulares, os estados moleculares são caracterizados pela projeção do momentum angular orbital $L$ ao longo do eixo molecular, $\Lambda$, e pela paridade com respeito à reflexão sobre o plano molecular contendo o eixo molecular, $\sigma= \pm[68]$. A multiplicidade de spin dos estados, $2 S+1$, pode ser 1 ou 3 . Em analogia à notação espectroscópica atômica, $\Lambda=0$ corresponde aos estados ${ }^{1,3} \Sigma^{ \pm}$, como os estados $\mathrm{S}$ correspondem a estados com momentum angu$\operatorname{lar} \ell=0$ (estados $\mathrm{S})$, e $\Lambda=1$ a estados ${ }^{1,3} \Pi$, em analogia aos estados atômicos $\mathrm{P}$, e assim por diante. Apenas os estados $\Sigma$ apresentam simetria de reflexão sobre o plano. No caso homonuclear as simetrias $g$ e $u$ (gerade e ungerade) descrevem a troca de orbitais.

O estado fundamental molecular apresenta dois subestados, o estado singleto $(2 S+$ $1=1$ ), correspondendo aos dois átomos com spins eletrônicos anti-paralelos, e o estado tripleto $(2 S+1=3)$ representando ambos os átomos apresentando spins paralelos. $\mathrm{O}$ estado singleto ${ }^{1} \Sigma^{+}$apresenta uma grande energia de ligação devido à intensa interação de troca para curtas distâncias interatômicas [68]. O estado tripleto, ${ }^{3} \Sigma^{+}$, por outro lado, suporta poucos estados ligados e apresenta uma interação de Van der Walls muito mais fraca [29].

Na Fig.2.1 abaixo, podemos observar as curvas de potencial para o KRb para 


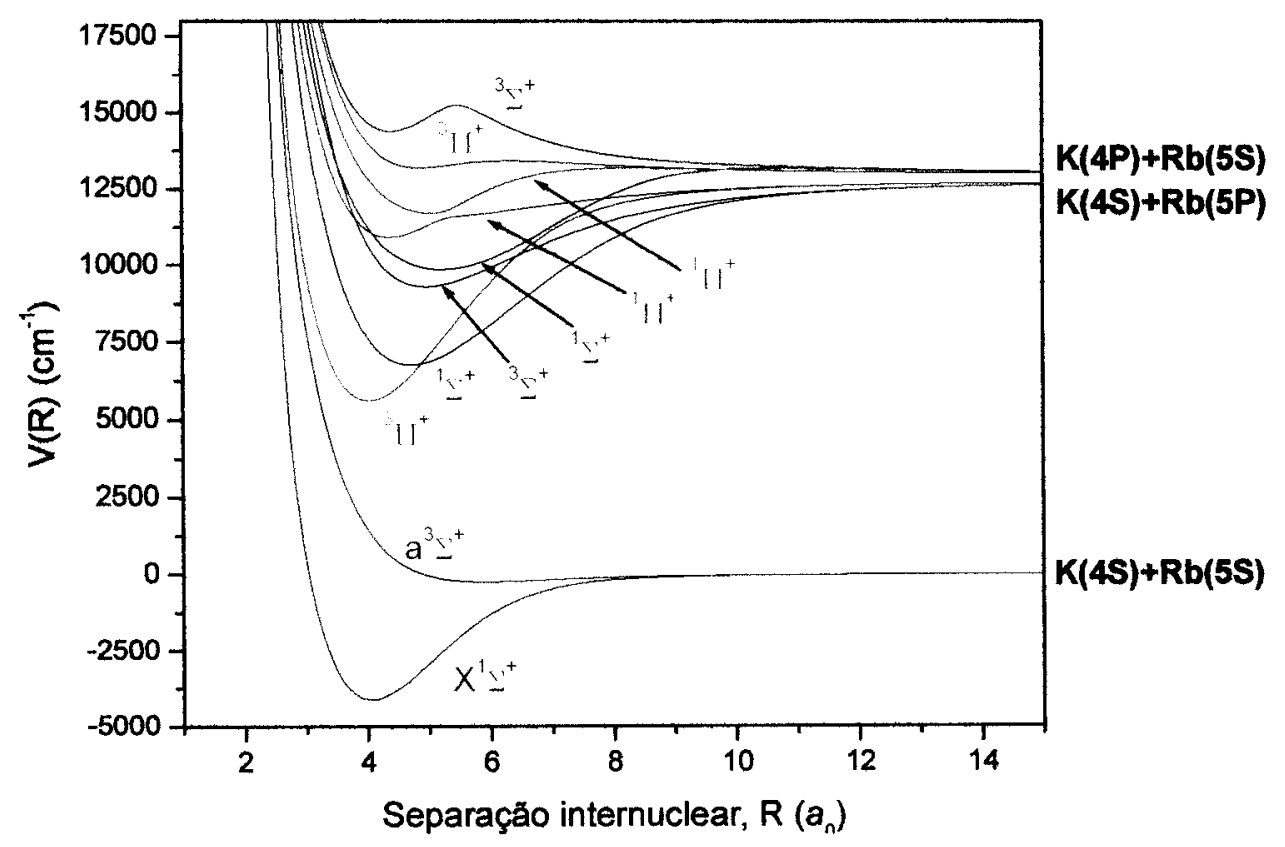

Figura 2.1: Curvas de potencial não-relativísticas dos estados eletrônicos de curto alcance da molécula KRb (Hund's case (a)) correlacionados aos estados atômicos assintóticos fundamental $\mathrm{K}(4 \mathrm{~S})+\mathrm{Rb}(5 \mathrm{~S})$ e os primeiros excitados $\mathrm{K}(4 \mathrm{~S})+\mathrm{Rb}(5 \mathrm{P})$ e $\mathrm{K}(4 \mathrm{P})+\mathrm{Rb}(5 \mathrm{~S})$ obtidos a partir de cálculos químico-quânticos por Rousseau et al. As curvas são conectadas a longo alcance com cálculos assintóticos de MarinescuSadeghpour. $\left(1 a_{0}=0,529177 \times 10^{-10} \mathrm{~m}\right)$.

o Hund's case (a), obtidas a partir de cálculos ab initio por Rousseau et al.[69] correlacionadas às duas assíntotas excitadas heteronucleares, $n \mathrm{~S}+n \mathrm{P}$ (sem estrutura fina), e à assíntota do estado fundamental, $n \mathrm{~S}+n \mathrm{~S}$.

- As curvas de longo alcance conectam-se aos estados assintóticos atômicos, e a curto alcance com as curvas ab initio [69], utilizando cálculos químico-quânticos (ou então empiricamente pelo procedimento RKR (Rydberg-Klein-Rees) [68] que utiliza dados experimentais obtidos por espectroscopia convencional utilizando átomos térmicos).

Na Fig.2.2 são mostradas as curvas do estado fundamental em detalhe. 


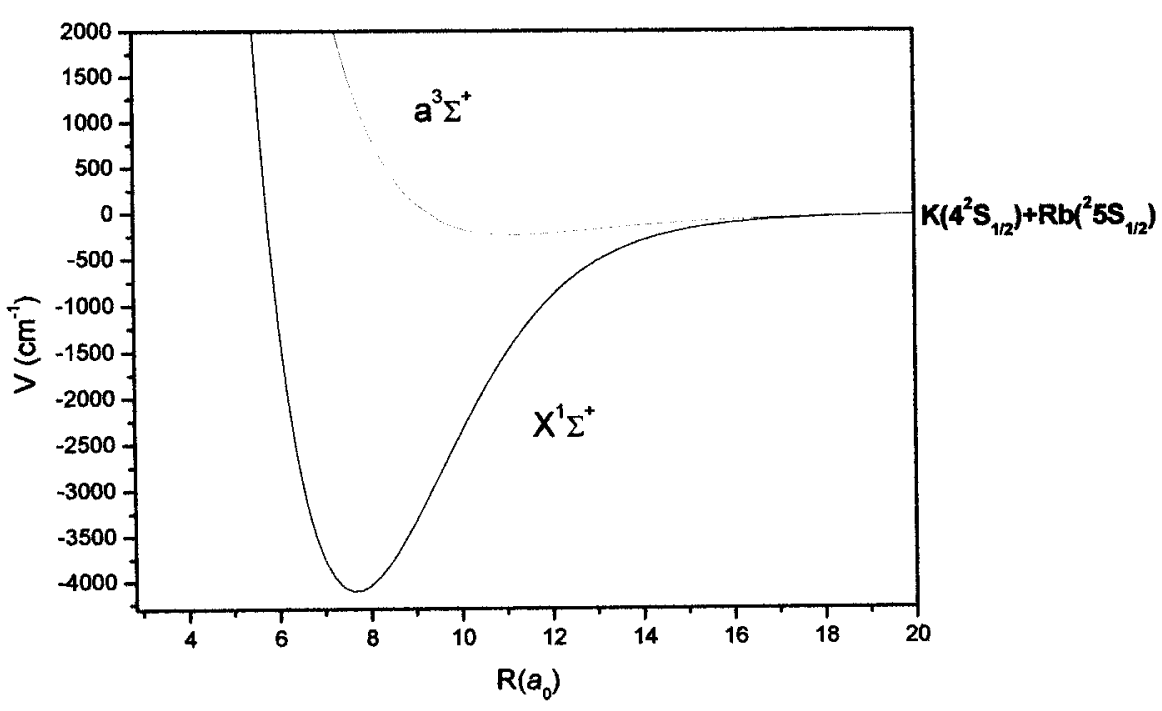

Figura 2.2: Estados fundamentais do KRb em detalhe: potenciais dos estados moleculares eletrônicos singleto e tripleto, calculados por Rousseau et al.

Podemos observar que as curvas de potencial de estados atrativos conectam-se à assíntota $\mathrm{K}(4 \mathrm{~S})+\mathrm{Rb}(5 \mathrm{P})$, enquanto que as curvas respresentando os estados correlacionados assintoticamente a $\mathrm{K}(4 \mathrm{P})+\mathrm{Rb}(5 \mathrm{~S})$ apresentam, quase todas, um caráter repulsivo.

No processo de fotoassociação, que constitui o primeiro passo na formação de moléculas frias no estado fundamental, apenas curvas atrativas efetivamente contribuem. Assim, podemos em princípio, excluir o canal onde temos um átomo de $\mathrm{K}$ excitado e um de $\mathrm{Rb}$ no estado fundamental como responsáveis pela formação de $\mathrm{KRb}$ no estado fundamental.

As regras de seleção para as transições entre os estados do Hund's case (a) permitem transições entre estados de mesma simetria com relação a reflexões no plano: 
$+\leftrightarrow+\mathrm{e}-\leftrightarrow-, \mathrm{e}$ com relação à troca entre orbitais atômicos: $g \leftrightarrow u$ e $g \leftrightarrow g$ para o caso de moléculas diatômicas homonucleares. Também temos: $\Delta \Lambda=0, \pm 1, \Delta S=0$, i.e., a multiplicidade de spin $2 \mathrm{~S}+1$ deve ser mantida em uma transição permitida por dipolo elétrico. Como no caso dos estados fundamentais, que não têm estrutura fina, estaremos tratando no caso das moléculas frias com transições entre os estados do Hund's case (a) uma vez que as transições via emissão espontânea ou estimulada para o estado fundamental acontecem na zona de pequenas separações internucleares $R$.

Quando os átomos estão colidindo em separações ainda maiores, onde a magnitude da interação relativística spin-órbita, caracterizada pela separação $\Delta E_{F S}$ entre os estados que compõe o dubleto da estrutura fina dos estados atômicos caracterizados por $\ell \geq 1$, passa a ser da ordem da interação eletrostática. Assim, na região onde $R>R_{F S}=\left(C_{6}^{e x c} / \Delta E_{F S}\right)^{1 / 6}$, os estados são caracterizados por uma outra notação espectroscópica, que diz respeito ao caso de acoplamento de momentum angular denominado Hund's case (c).

As intensidades relativas entre os diferentes momenta angulares entre si e com o - eixo molecular é que determinam qual é o Hund's case mais apropriado para descrever a molécula em um dado estado eletrônico. Em especial, a região onde os estados são populados em experimentos de fotoassociação, quando o laser não é fortemente dessintonizado para o vermelho da frequência de ressonância, corresponde às regiões onde as interações fina e hiperfina são comparáveis ou mais intensas do que a eletros- 
tática. Para este particular caso de interesse, o momentum angular L e sua projeção ao longo do eixo molecular, que caracterizam os estados de longo alcance, deixam de ser bons números quânticos. Neste caso, os momenta angulares orbital e de spin se acoplam através da interação spin-órbita, formando o momentum angular total $(J=L+S)$, cuja projeção ao longo do eixo internuclear $\Omega$ é o número quântico que designa os estados neste caso, $(\Omega=\Lambda+\Sigma)$ onde $\Lambda$ é a projeção do momentum angular orbital L ao longo do eixo molecular e $\Sigma$ é a projeção de S sobre o mesmo eixo.

No caso homonuclear valem as simetrias $g$ e $u$ (gerade e ungerade) e $\sigma= \pm$. Para moléculas diatômicas homonucleares, a designação de simetria correspondendo aos números quânticos g ou u corresponde aos estados ímpares ou pares com respeito à troca de orbitais atômicos. No caso hetero temos apenas a simetria com relação à reflexão num plano molecular \pm , pois obviamente não há simetria com relação à troca de orbitais uma vez que, neste caso, os átomos não são idênticos. Assim, os estados são caracterizados pela notação espectroscópica por $\Omega^{ \pm}$.

A conversão do caso (a) para o caso (c) é feita usando-se teoria de perturbação conxencional, e o problema consiste na diagonalização de matrizes onde os termos não diagonais contêm o operador que caracteriza a interação LS e os diagonais contém as interações eletrostáticas. Existem no total 16 estados de longo alcance (Hund's case (c)) correlatos à quatro assíntotas.

A diagonalização é realizada para todas as separaçôes internucleares $R$ considerando- 


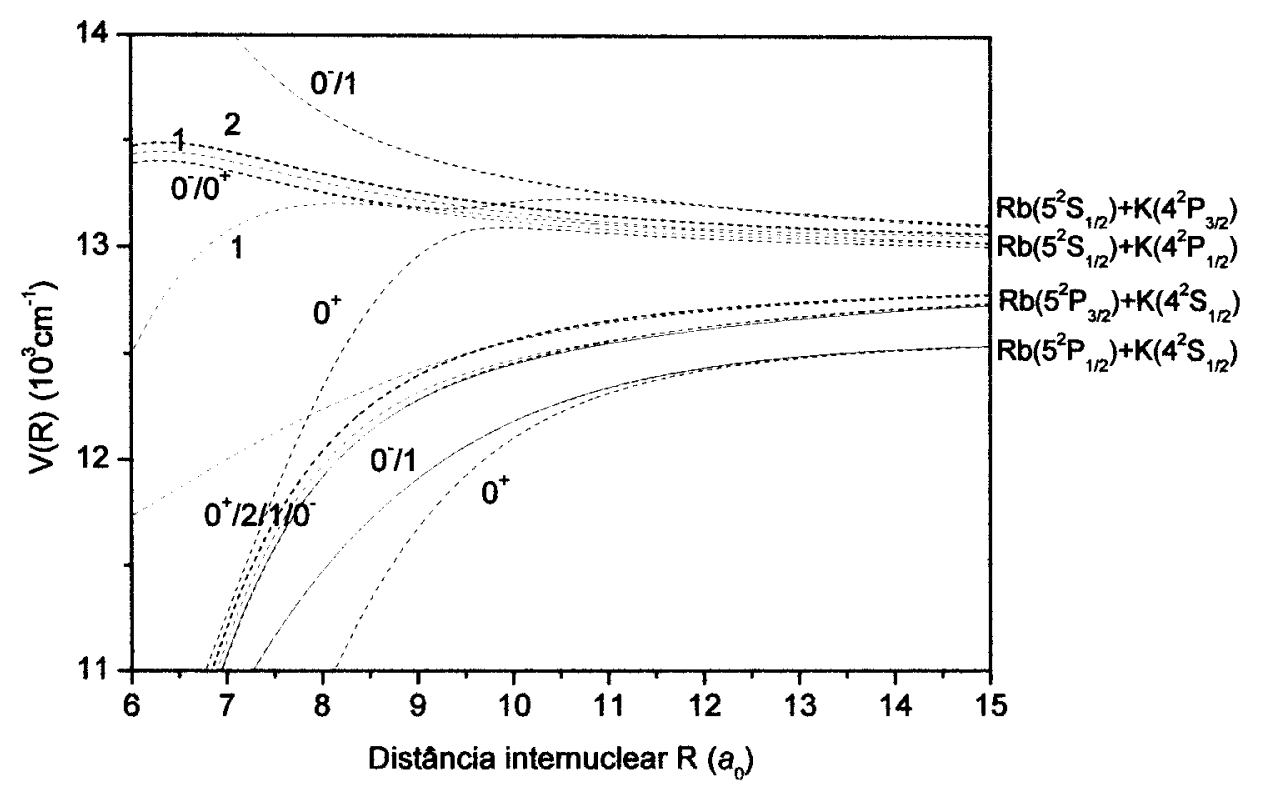

Figura 2.3: Curvas de potencial relativísticas, incluindo a interação spin-órbita (Hund's case (c)) do KRb associadas aos estados $K(4 \mathrm{~S})+\mathrm{Rb}(5 \mathrm{P})$ e $\mathrm{K}(4 \mathrm{P})+\mathrm{Rb}(5 \mathrm{~S})$. Observe que conectados à assíntota $K^{*}-R b$, à longo alcance os estados apresentam carácter repulsivo.

se, em adição ao potencial coulombiano, a interação spin-órbita AL·S, que é proporcional à separação $\Delta E$ entre os estados atômicos $\mathrm{P}_{3 / 2}$ e $\mathrm{P}_{1 / 2}$.

Os potenciais resultantes associados à assíntota $n \mathrm{~S}+n \mathrm{P}_{\mathrm{J}}$, onde $\mathrm{J}=1 / 2$ e $3 / 2$ são no caso heteronucleares seguintes: três estados, $0^{+}, 0^{-}$e 1 , correlacionados aos limites $A\left(S_{1 / 2}\right)+B\left(P_{1 / 2}\right)$ e $A\left(P_{1 / 2}\right)+B\left(S_{1 / 2}\right)$, cinco estados $\left(0^{+}, 0^{-}, 1,1\right.$, e 2) para cada limite: $\mathrm{A}\left(\mathrm{S}_{1 / 2}\right)+\mathrm{B}\left(\mathrm{P}_{3 / 2}\right)$ e $\mathrm{A}\left(\mathrm{P}_{3 / 2}\right)+\mathrm{B}\left(\mathrm{S}_{1 / 2}\right)$, onde $\mathrm{A}$ e $\mathrm{B}$ designam as espécies atômicas envolvidas. Os potenciais do Hund's case (c) para os primeiros estados excitados da molécula KRb podem ser vistos na Fig.2.3.

Ao estado fundamental três estados degenerados $0^{+}, 0^{-}$e 1 se conectam à assíntota $\mathrm{A}\left(\mathrm{S}_{1 / 2}\right)+\mathrm{B}\left(\mathrm{S}_{1 / 2}\right)$, similarmente ao caso homonuclear. As constantes dos potenciais 
de interação de longo alcance foram calculadas por Bussery et al. [70]. As regras de seleção para os estados do Hund's case (c) são as seguintes: $+\leftrightarrow+\mathrm{e}-\leftrightarrow-, g \leftrightarrow u$ e $g \leftrightarrow g$ para moléculas homo e $\Delta \Omega=0, \pm 1[68]$.

Um fato interessante de ser notado é que, das quatro assíntotas excitadas de sistemas alcalinos heteronucleares, as duas mais baixas (nas quais o átomo excitado apresenta a energia do estado excitado mais baixa) dos dez dímeros calculados, originam apenas estados atrativos, enquanto que as demais assíntotas (onde o átomo excitado tem energia mais alta) geram, quase que exclusivamente, apenas estados repulsivos. Exceções existem apenas para o sistema $\mathrm{NaK}$ (duas exceções), $\mathrm{NaRb}$ (uma) e $\mathrm{NaCs}$ (seis exceções) [69].

Ainda, devemos ressaltar que a molécula $\mathrm{KRb}$ apresenta os maiores coeficientes do potencial de interação de Van der Walls dentre todos os dez sistemas alcalinos heteronucleares abordados. Isto se deve ao fato de que os primeiros estados excitados destes dois átomos são quase degenerados. As separações entre as assíntotas atômicas apresentam as seguintes separações: $\Delta \mathrm{E}\left[\mathrm{K}\left(4 \mathrm{P}_{1 / 2}\right)-\mathrm{Rb}\left(5 \mathrm{P}_{1 / 2}\right)\right]=406,21 \mathrm{~cm}^{-1}$, e $\Delta \mathrm{E}\left[\left(\mathrm{K} 4 \mathrm{P}_{3 / 2}\right)-\mathrm{Rb}\left(5 \mathrm{P}_{3 / 2}\right)\right]=226,33 \mathrm{~cm}^{-1}$. As assíntotas $n \mathrm{~S}+n \mathrm{~S}$ (heteronuclear) ou $n \mathrm{~S}+n \mathrm{~S}$ (homonuclear) não apresentam interação spin-órbita, pois $\ell=0$.

A interação de longo alcance no caso deste dímero em especial tem um pseudocaráter $1 / R^{3}$ na região intermediária de longo alcance. Embora o estado fundamental também seja caracterizado por este mesmo tipo de interação, van der Walls, os coeficientes para o potencial de interação heteronuclear são mais fortes comparados aos 
do estado fundamental, conforme pode ser observado na Tabela 1.

Para separações internucleares ainda maiores, quando a separação atômica hiperfina $\Delta E_{H F S}$ torna-se comparável ao potencial coulombiando, onde $R>R_{H F S}=$ $\left(C_{6}^{g} / \Delta E_{H F S}\right)^{1 / 6}$, as curvas de potenciais hiperfinos tornam-se importantes.

\subsection{Fatores de Franck-Condon para Fotoassociação}

\section{Heteronuclear}

Uma vez que este trabalho envolve a formação de moléculas frias através da fotoassociação entre átomos frios aprisionados em MOTs na presença de um campo de radiação, é importante revisar-se alguns conceitos importantes para o entendimento de tal processo.

Os potenciais do estado excitado e do estado fundamental são acoplados pelo campo de radiação do laser com frequência $\omega$ dessintonizado por uma quantidade $\Delta=\omega_{L}-\omega_{0}$ com relação à frequência de ressonância atômica $\omega_{0}$ no ponto de Condon, $\mathrm{R}_{\mathrm{C}}$ :

$$
\hbar \Delta=-\frac{C^{n}}{R_{C}^{n}} \text { ou } R_{C}=\left(\frac{C_{n}}{\hbar|\Delta|}\right)^{1 / n}
$$

Assim, dois átomos colidindo em seus estados fundamentais atômicos $n \mathrm{~S}+n \mathrm{~S}$ são ditos como fotoassociados pela absorção do par atômico de um fóton do laser de aprisionamento ou de um laser de prova adicional.

O ponto de Condon para um laser dessintonizado apenas poucas larguras de linha 
para o vermelho da ressonância atômica é tipicamente da ordem de 1000-5000 $a_{0}$ para uma colisão homonuclear, enquanto que para um encontro heteronuclear, o ponto de excitação localiza-se tipicamente na região entre 100-500 $a_{0}$. Portanto, ocorre a separações internucleares bem menores do que no caso homonuclear.

Vejamos, a seguir, quais são os principais pontos abordados por Wang e Stwalley [30] em sua estimativa dos fatores de Franck-Condon [68] para fotoassociação heteronuclear e as bases para a consideração da molécula KRb, juntamente com os dímeros alcalinos mais pesados, RbCs e KCs, como uma das mais prováveis de serem fotoassociadas em experimentos de deteç̧ão de moléculas heteronucleares e principais candidatas para realização de espectroscopia fotoassociativa.

As expressões analíticas obtidas por estes autores, servem para estimar-se os fatores de Franck-Condon para transições a longo alcance tanto para dímeros homonucleares quanto para heteronucleares, o que é expresso pelo coeficiente do termo principal da expansão do potencial de interação em potências da separação internuclear, R e pelo expoente $(n=3$ ou $n=6)$ respectivamente para colisões homo e heteronucleares.

Um fato importante concernente à formação de moléculas frias é a probabilidade de fotoassociação do par atômico, colidindo no estado fundamental, em direção a um estado molecular excitado. Outro aspecto necessário é o carácter atrativo do potencial. Isto é essencial para que tenhamos uma probabilidade considerável de que o par seja acelerado sob a ação do potencial alcançando assim a região de curtas separações internucleares onde existe a janela de Franck-Condon favorável à emissão espontânea 
em direção aos poços dos potenciais $X^{1} \Sigma^{+}$e $a^{3} \Sigma^{+}$do estado molecular fundamental. Neste contexto, a molécula KRb no estado atrativo correlato à assíntota relacionada a um átomo de $\mathrm{K}$ no estado fundamental e um Rb no estado excitado, é especial por apresentar o maior coeficiente de dispersão $C_{6}$, quase uma ordem de magnitude maior do que o mesmo coeficiente para os demais dímeros alcalinos heteronucleares.

Os fatores de Franck-Condon representando as probabilidades de transição a partir do contínuo do estado fundamental para um estado ligado do potencial excitado ocorrendo na região de longo alcance, isto é, transições do tipo free-bound, acessadas por um laser sintonizado para o vermelho da ressonância $(\Delta<0)$ levando à fotoassociação de dois átomos colidindo no estado fundamental a um estado ligado do potencial do estado molecular excitado, podem ser escritos da seguinte forma, conhecida como reflexion approximation [71], proporcional ao módulo ao quadrado da função de onda do estado fundamental:

$$
\begin{aligned}
F_{e g}(E, v) & =\left|\left\langle\psi_{e}(R) \mid \psi_{g}^{\dagger}(E, R)\right\rangle\right|^{2}= \\
& =\frac{d E_{v}}{d v} \frac{1}{D_{C}}\left|\psi_{g}\left(E, R_{C}\right)\right|^{2}
\end{aligned}
$$

onde $\psi_{e}(R)$ e $\psi_{g}(E, R)$ são as funções de onda radiais bound e free, respectivamente, $E_{v}$ é a energia do estado vibracional excitado, $D c$ é a diferença entre as inclinações entre as curvas de potencial no ponto $R=R_{C}$, sendo $R_{C}$ o ponto de Condon, onde a energia do fóton corresponde exatamente à diferença de energia entre os potenciais excitado e fundamental, sendo o ponto onde a quasimolécula composta pelo par de 
átomos colidindo encontra-se em ressonância com o laser. Faremos a partir daqui $R_{C}=R_{v^{+}}^{n}$, que é o ponto de retorno clássico externo do potencial excitado, ponto onde a transição é mais provável de ocorrer pois é nos pontos de retorno externo e interno do potencial que os átomos passam a maior parte do tempo.

Para grandes separações internucleares, isto é, próximo ao limite de dissociação, podemos escrever o potencial de interação da seguinte maneira:

$$
V(R)=D-\sum_{n} \frac{C_{n}}{R^{n}}
$$

Considerando-se apenas o termo principal da expansão, temos:

$$
V(R)=D-\frac{C_{n}}{R^{n}}
$$

ou,

$$
E_{v}=D-\frac{C_{n}}{R_{v^{+}}^{n}}
$$

onde $D$ é a energia do limite de dissociação e $R_{v^{+}}$corresponde ao ponto de retorno externo do potencial excitado.

Se a Eq.2.6 for usada na aproximação WKB para os auto-valores de um potencial $\dot{V}(R)[72]:$

$$
v+\frac{1}{2}=\frac{(2 \mu)^{1 / 2}}{\pi \hbar} \int_{R^{-}(v)}^{R^{+}(v)}[E(v)-V(R)]^{1 / 2} d R
$$

onde $v$ é o número quântico vibracional, $\mu$ a massa reduzida, $\mathrm{R}$ são as distâncias internucleares correspondentes aos pontos de retorno (interno e externo) do potencial 
e $E(v)$ é a energia do nível vibracional $v$, o espaçamento entre os níveis vibracionais, ignorando-se rotações, ou seja, considerando-se $J=0$, pode ser dado pela seguinte expressão analítica [72]:

$$
\frac{d E_{v}}{d v}=K_{n}\left(D-E_{v}\right)^{(n+2) / 2 n}=K_{n}\left(\frac{C_{n}}{R^{n}}\right)^{(n+2) / 2 n}
$$

onde o coeficiente $K_{n}$ é dado por:

$$
K_{n}=\hbar\left(\frac{2 \pi}{\mu}\right)^{1 / 2} \frac{\Gamma(1+1 / n)}{\Gamma(1 / 2+1 / n)} \frac{n}{\left(C_{n}\right)^{1 / n}}
$$

A diferença entre as inclinações dos potenciais excitado e fundamental, no ponto de Condon $\left(\mathrm{R}=\mathrm{R}_{\mathrm{C}}\right)$, é dada por:

$$
\begin{gathered}
D_{C}=\left|\frac{d}{d R}\left(V_{e}(R)-V_{g}(R)\right)\right|_{R=R_{v^{+}}}=\left|\frac{d}{d R}\left(V^{\prime}(R)-V^{\prime}(R)\right)\right|_{R=R_{v^{+}}} \\
\approx\left|\frac{d}{d R}\left(V^{\prime}(R)\right)\right|_{R=R_{v+}} \\
=\frac{d}{d R}\left(D-\frac{C_{n}^{\prime}}{R_{v^{+}}^{n}}\right),
\end{gathered}
$$

e portanto, escrevemos

$$
D_{C}=\frac{n C_{n}}{R_{v^{+}}^{n+1}}
$$

onde supusemos o potencial fundamental como plano na região de longo alcance do potencial onde a transição ocorre. 
Para longas separações internucleares, as curvas de potencial associadas com a assíntota heteronuclear $n \mathrm{~S}+n \mathrm{~S}$, correspondendo a dois átomos distintos em seus estados fundamentais, podem ser expressas na seguinte forma [29]:

$$
V^{\prime}(R)=-\frac{C_{6}}{R^{6}}-\frac{C_{8}}{R^{8}}-\frac{C_{10}}{R^{10}}-\ldots
$$

onde os coeficientes $C_{n}$ para $n=6,8,10$ são os coeficientes de dispersão. Para a assíntota $n S+n^{\prime} P$ ( e também para $n S+n^{\prime} D$ ), as curvas de potencial excitadas de longo alcance são expressas por [29]:

$$
V^{\prime}(R)=-\frac{C_{6}}{R^{6}}-\frac{C_{8}}{R^{8}}-\ldots
$$

Contudo, os coeficientes do potencial fundamental são mais fracos do que aqueles do estado excitado. Por exemplo, para o par $\mathrm{K}-\mathrm{Rb}, C_{6}=4,105 \times 10^{3}$ u.a., enquanto que para o estado excitado $C_{6}=2,3247 \times 10^{5}$ u.a. Assim, considerando $V^{\prime}(R)=0$, podemos escrever os fatores de Franck-Condon da seguinte maneira:

$$
\begin{gathered}
F_{v}(R)=K_{n}\left(\frac{n C_{n}^{\prime}}{R_{v^{+}}^{n}}\right)^{(n+2) / 2 n} \frac{R_{v^{+}}^{n+1}}{n C_{n}}\left|\psi_{g}\left(R_{v^{+}}\right)\right|^{2} \\
F_{v}(R)=\left(\frac{2 \pi \hbar^{2}}{\mu}\right)^{1 / 2} \frac{\Gamma(1+1 / n)}{\Gamma(1 / 2+1 / n)}\left(\frac{R_{v^{+}}^{n}}{C_{n}}\right)^{1 / 2}\left|\psi_{g}\left(R_{v^{+}}\right)\right|^{2}
\end{gathered}
$$

Portanto, para o caso heteronuclear consideraremos $(n=6)$, e teremos:

$$
F_{v}(R)=\left(\frac{2 \pi \hbar^{2}}{\mu^{2}}\right) \frac{\Gamma(7 / 6)}{\Gamma(2 / 3)}\left(\frac{C_{6}}{R_{v^{+}}^{6}}\right)^{-1 / 2}\left|\psi_{g}\left(R_{v^{+}}\right)\right|^{2}
$$


Para colisões frias $(T<1 \mathrm{mK})$, ou seja, baixíssimas energias colisionais, podemos escrever a função de onda do estado fundamental, para a região de longo alcance, da seguinte maneira $[71,73]$ :

$$
\psi_{g}(R) \simeq e^{i \eta}\left(\frac{2 \mu}{\pi \hbar^{2} k_{\infty}}\right)^{1 / 2} k_{\infty}\left(R-a_{S}\right)
$$

Na equação acima a fase assintótica é:

$$
\eta=v_{\operatorname{máx}} \pi-k_{\infty} a_{S}
$$

e $\sqrt{2 \mu / \pi \hbar^{2} k_{\infty}}$ é o fator de normalização tal que $\left|\left\langle\psi_{g}^{+}(E) \mid \psi(E)\right\rangle\right|^{2}=\delta(E-E)$, $k_{\infty}=\sqrt{\frac{2 \mu K_{B} T}{\hbar^{2}}}$ é o vetor de onda térmico da colisão no estado fundamental, e $a_{S}$ é o comprimento de espalhamento de onda $\mathrm{s}$.

A energia cinética colisional assintótica é

$$
E=\hbar^{2} k_{\infty}^{2} / 2 \mu
$$

Assim, substituindo o quadrado da função de onda na eq. 2.17 , a reescrevemos da seguinte forma:

$$
F_{v}^{n}(R)=\left(\frac{8 \mu k_{\infty}^{2}}{\pi \hbar^{2}}\right)^{1 / 2} \frac{\Gamma(1+1 / n)}{\Gamma(1 / 2+1 / n)}\left(C_{n}^{\prime}\right)^{-1 / 2} R_{v^{+}}^{\left(\frac{n}{2}+2\right)}\left(1-\frac{a_{S}}{R_{v^{+}}}\right)^{2}
$$

Logo, para o caso heteronuclear, temos: 


$$
F_{v}^{n=6}(R)=\left(\frac{8 \mu k_{\infty}^{2}}{\pi \hbar^{2}}\right)^{1 / 2} \frac{\Gamma(7 / 6)}{\Gamma(2 / 3)}\left(C_{6}^{\prime}\right)^{-1 / 2} R_{v^{+}}^{5}\left(1-\frac{a_{S}}{R_{v^{+}}}\right)^{2}
$$

É importante observarmos que próximo à $R=a_{S}\left(a_{S}>0\right)$, temos um mínimo na intensidade no espectro de fotoassociação, o que fornece uma estimativa do comprimento de espalhamento.

Podemos notar que para $R$ grande, os fatores de Franck-Condon variam conforme $R^{5}$ para as moléculas heteronucleares $(n=6)$, enquanto com $R^{7 / 2}$ para homonucleares $(n=3)$. Portanto, em princípio isso nos indica que a fotoassociação heteronuclear seria mais favorecida com relação à associação de átomos de mesma espécie para a região de longo alcance dos potenciais, onde $R \gg a_{S}$.

Podemos, ainda, expressar os fatores de FC como função do número quântico vibracional $v$, usando a seguinte relação:

$$
\begin{aligned}
D-E_{v} & =X_{0}\left(v_{D}-v\right)^{2 n /(n-2)} \\
& =\frac{C_{n}}{R_{v^{+}}^{n}}
\end{aligned}
$$

Então, o ponto de retorno clássico externo pode ser escrito como:

$$
\begin{aligned}
R_{v^{+}} & =\left(\frac{C_{n}}{\bar{X}_{0}(n)}\right)^{1 / n}\left(v_{D}-v\right)^{2 /(2-n)} \\
& =\left(\frac{1}{\overline{X_{0}}(n)}\right)^{1 / n}\left(\mu C_{n}^{\prime}\right)^{1 /(n-2)}\left(v_{D}-v\right)^{2 /(2-n)} .
\end{aligned}
$$

onde $X_{0}(n)=\bar{X}_{0}(n)\left(\mu C_{n}^{2}\right)^{(1 / 2-n)}$, com a constante $\bar{X}_{0}(n)$ dependendo apenas do número $n$. 
Finalmente, os fatores de Franck-Condon heteronucleares ficam:

$$
F_{v}^{n=6}(R)=\frac{\Gamma(7 / 6)}{\Gamma(2 / 3)}\left(\frac{8 \mu^{7 / 2} k_{\infty}^{2}}{\pi \hbar^{2}}\right)^{1 / 2}\left[X_{0}(6)\right]^{-5 / 6}\left(1-\frac{a_{S}}{R_{v^{+}}}\right)^{2} C_{6}^{3 / 4}\left(v_{D}-v\right)^{-5 / 2}
$$

Podemos observar na eq. acima que para um dado $\left(v_{D}-v\right)$, os fatores de $\mathrm{FC}$ para transições ocorrendo a longo alcance e levando a fotoassociação heteronuclear são proporcionais a $\left(C_{6}\right)^{3 / 4}$, de modo que moléculas com maiores coeficientes da interação de longo alcance são as mais favorecidas. Ainda, devido ao fato do $k_{\infty}$ depender de $\mu^{1 / 2}$, estes fatores dependem da massa reduzida segundo $\mu^{9 / 4}$ de modo que são mais favorecidos os dímeros mais pesados.

Contudo, devido aos comprimentos de espalhamento para colisões heteronucleares ainda não serem conhecidos, valores absolutos para estes fatores não podem ser obtidos usando-se as equações analíticas acima. Nas Figs.2.4 (estados $\Sigma$ ) e 2.5 (estados П) podemos observar os fatores de FC relativos, correspondendo ao produto $C_{6}^{3 / 4} \mu^{9 / 4}$ para os diferentes dímeros alcalinos heteronucleares, para mesmos $\left(v_{D}-v\right)$, utilizandose os coeficientes calculados por Marinescu e Sadeghpour [29], e considerando-se os isótopos bosônicos: ${ }^{7} \mathrm{Li},{ }^{23} \mathrm{Na}$ (existe apenas um isótopo de $\mathrm{Na}$ ) $,{ }^{39} \mathrm{~K},{ }^{85} \mathrm{Rb}$ e ${ }^{133} \mathrm{Cs}$ (o único isótopo estável do $\mathrm{Cs}$ ).

$\mathrm{Na}$ Tabela 1 encontram-se listados os coeficientes de dispersão $C_{6}$ e $C_{8}$ do potencial de longo alcance de moléculas alcalinas heteronucleares calculados por Marinescu e Sadeghpour [29] para estados atrativos. As quantidades entre parênteses representam potências de dez. 


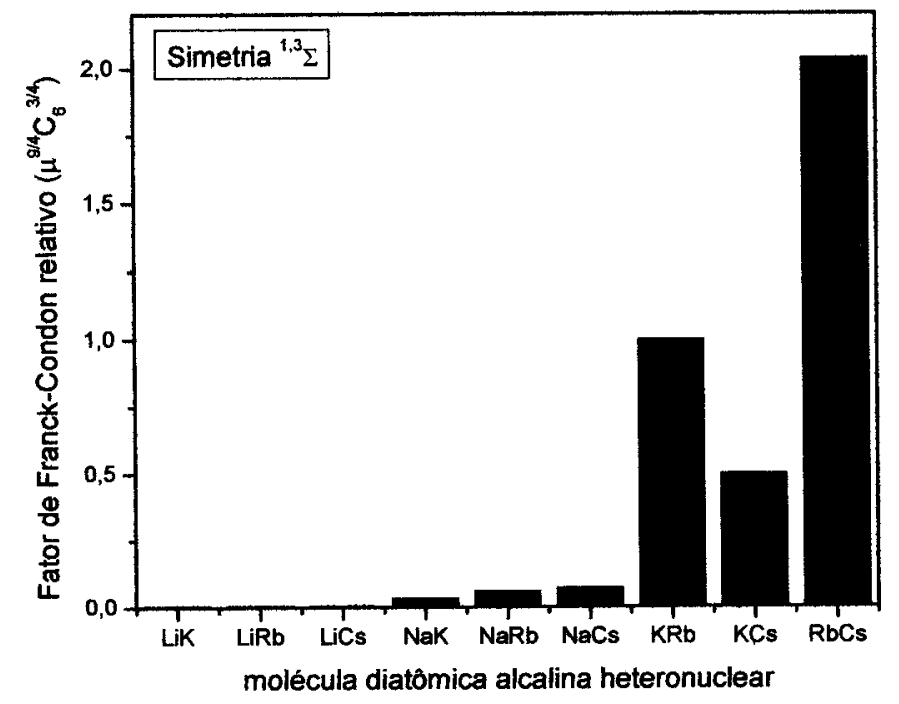

Figura 2.4: Fatores de Franck-Condon relativos representando as probabilidades de fotoassociação para diferentes moléculas heteronucleares considerando-se estados de simetria ${ }^{1,3} \Lambda^{+}=0$, com potenciais atrativos .

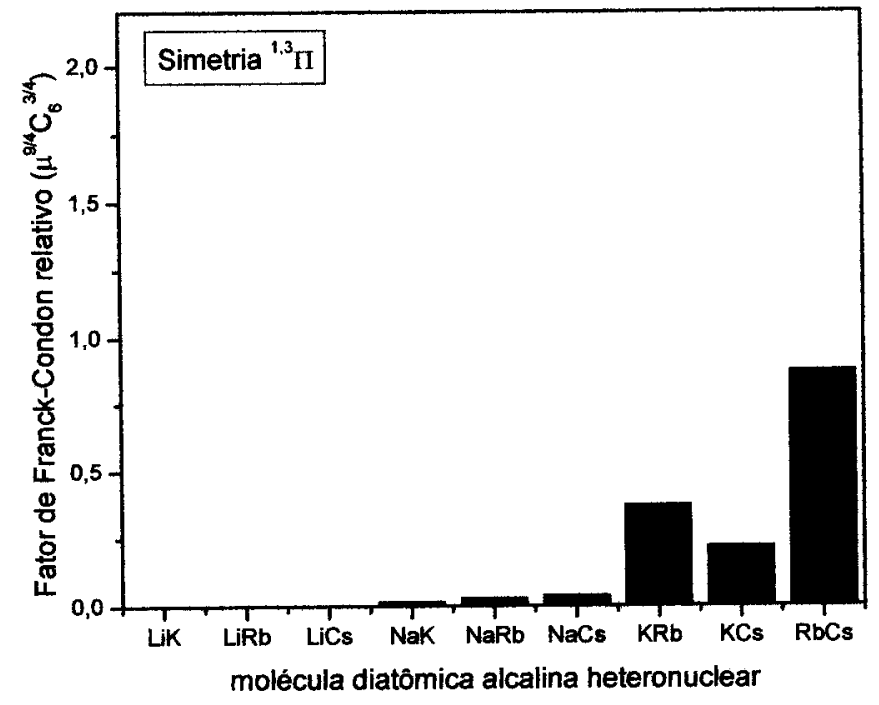

Figura 2.5: Fatores de Franck-Condon relativos para estados de simetria ${ }^{1,3} \Lambda=1$ com potencial atrativo . 
Podemos observar na tabela dos coeficientes de dispersão de dímeros heteronucleares (Tabela 1) que a combinação $\mathrm{K}(4 \mathrm{~S})+\mathrm{Rb}(5 \mathrm{P})$ apresenta o maior coeficiente $C_{6}$ (pricipalmente para os estados tripleto) com relação as demais moléculas alcalinas listadas. Outro fato importante é que a mesma molécula, porém em estados relacionados ao estado assintótico $\mathrm{K}(4 \mathrm{P})+\mathrm{Rb}(5 \mathrm{~S})$, é que apresenta os potenciais de caráter mais repulsivos dentre as moléculas heteronucleares. Assim, este fato nos indica que os canais repulsivos relacionados à assíntota $\mathrm{K}(4 \mathrm{P})+\mathrm{Rb}(5 \mathrm{~S})$ não devem participar da formação de KRb frias no estado fundamental por nós observadas.

\begin{tabular}{|c|c|c|c|c|}
\hline & $C_{6}\left(^{1,3} \Sigma^{+}\right)$ & $C_{8}\left({ }^{1,3} \Sigma^{+}\right)$ & $C_{6}(1,3 \Pi)$ & $C_{8}\left({ }^{1,3} \Pi\right)$ \\
\hline $\mathrm{Li}(2 \mathrm{~S})-\mathrm{K}(4 \mathrm{P})$ & $2,7751[4]$ & $2,2371[6]$ & $9,2765[3]$ & $1,58318[5]$ \\
\hline $\mathrm{Li}(2 \mathrm{~S})-\mathrm{Rb}(5 \mathrm{P})$ & $2,6744[4]$ & $2,8089[6]$ & $9,4312[3]$ & $1,7135[5]$ \\
\hline $\mathrm{Li}(2 \mathrm{~S})-\mathrm{Cs}(6 \mathrm{P})$ & $2,2416[4]$ & $3,6187[6]$ & $8,9016[3]$ & $1,8926[5]$ \\
\hline $\mathrm{Na}(3 \mathrm{~S})-\mathrm{Li}(2 \mathrm{P})$ & $1,6829[4]$ & $6,9559[5]$ & $5,1409[3]$ & $9,5887[4]$ \\
\hline $\mathrm{Na}(3 \mathrm{~S})-\mathrm{K}(4 \mathrm{P})$ & $1,7822[4]$ & $2,3743[6]$ & $6,8777[3]$ & $1,9560[5]$ \\
\hline $\mathrm{Na}(3 \mathrm{~S})-\mathrm{Rb}(5 \mathrm{P})$ & $1,8621[4]$ & $2,9641[6]$ & $7,4845[3]$ & $2,2030[5]$ \\
\hline $\mathrm{Na}(3 \mathrm{~S})-\mathrm{Cs}(6 \mathrm{P})$ & $1,8353[4]$ & $3,7927[6]$ & $7,9598[3]$ & $2,4778[5]$ \\
\hline $\mathbf{K}(\mathbf{4 S})-\mathbf{R b}(\mathbf{5 P})$ & $\mathbf{2 , 3 2 4 7}[\mathbf{5}]$ & $\mathbf{5 , 3 7 4 4}[\mathbf{6}]$ & $\mathbf{6 , 2 7 7 6 [ 4 ]}$ & $\mathbf{5 , 8 3 5 5}[\mathbf{5}]$ \\
\hline $\mathrm{K}(4 \mathrm{~S})-\mathrm{Cs}(6 \mathrm{P})$ & $6,4292[4]$ & $6,8132[6]$ & $2,1731[4]$ & $6,3629[5]$ \\
\hline $\mathrm{Rb}(5 \mathrm{~S})-\mathrm{Cs}(6 \mathrm{P})$ & $8,2377[4]$ & $7,6901[6]$ & $2,6721[4]$ & $8,3844[5]$ \\
\hline
\end{tabular}

Tabela 2.1: Coeficientes dos potenciais de longo alcance heteronucleares.

Nos restringimos, aqui, a uma discussão concernente à fotoassociação de dímeros heteronucleares inicialmente colidindo na assíntota $n \mathrm{~S}+n \mathrm{~S}$, em uma armadilha mista, baseadas nos fatores de Franck-Condon heteronucleares estimados pela teoria proposta por Wang e Stwalley [30].

A eficiência da formação de moléculas frias no estado fundamental por fotoassociação depende, no entanto, do produto da probabilidade de excitação e da probabi- 
lidade de decaimento espontâneo populando os níveis vibracionais do estado fundamental. Ambas probabilidades podem ser expressas por fatores de Franck-Condon. Contudo, a probabilidade de transição na região de pequenos $\mathrm{R}$ envolve o conhecimento das funções de onda moleculares para esta região, onde também já não mais vale a reflexion aproximation $[71,73]$, porém estes cálculos estão fora do escopo desta discussão.

\subsection{Moléculas Frias em Sistemas Homonucleares:}

\section{Breve Histórico}

O estudo de estados diatômicos excitados quasi-moleculares produzidos em experimentos de fotoassociação foi bastante abordado durante a última década. Após a proposta da realização de espectroscopia fotoassociativa, em 1989, por Thorshein, Weiner and Julienne [19] experimentos iniciaram a ser realizados para os vários átomos alcalinos aprisionáveis em MOTs [43, 44, 74].

Entretanto, os estados moleculares excitados, assintoticamente correlatos aos estados atômicos de dois átomos colidentes em seus estados $S+P$, são estados com curtos tempos de vida, referidos como short-lived, por apresentarem tempos de vida que variam em torno do valor atômico, de acordo com a simetria do estado [60]. Assim, após um determinado tempo, da ordem de poucas dezenas de nanossegundos as moléculas formadas através do encontro colisional na armadilha decaem espon-

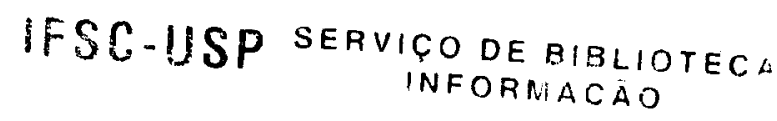


taneamente, podendo ser detectadas pela técnica de fluorescência ou por fotoinização, contínua ou pulsada.

Nos últimos quatro anos, moléculas frias estáveis, detectadas no estado fundamental, começaram a ser estudadas em MOTs a partir do experimento pioneiro do Laboratório Aimé-Cotton, na França.

A produção eficiente de moléculas frias homonucleares foi observada pela primeira vez por A. Fioretti et al. [45] através de fotoassociação, por um único passo, de um par de átomos frios de Cs, seguida por emissão espontânea. O mesmo processo foi observado em uma armadilha magneto-óptica de Rb [34] e em K [35]. Já, a observação de formação de moléculas $\mathrm{K}_{2}$ frias com eficiência comparável, demandou um esquema de fotoassociação via dois passos, por duas-cores [75], como reportado por Nikolov et al. [47]. Nos dois primeiros experimentos ( $\mathrm{Cs}$ e $\mathrm{Rb}$ ) a deteç̧ão foi realizada através de foto-ionização pulsada e no experimento com $\mathrm{K}$ a ionização foi realizada com laser(s) cw.

Recentemente, moléculas frias foram também produzidas em uma armadilha de Na [36], em um esquema geral similar aos demais alcalinos. Este último trabalho utilizou ionização por um laser cw (seletiva com relação às assíntotas colisionais hiperfinas $\left(f_{A}+f_{B}\right)$ dos átomos, $\mathrm{A}$ e $\mathrm{B}$, colidentes, devido à largura de linha da ordem de $\mathrm{MHz}$ ao contrário da largura de $\mathrm{GHz}$ dos lasers pulsados) mas a taxa de formação molecular não foi estimada. 


\subsection{Esquema Geral de Formação Molecular em Sis-}

\section{temas Homonucleares}

Em traços gerais, a produção de moléculas frias envolve dois principais passos:

(a) Fotoassociação de dois átomos colidindo em seus estados fundamentais, através da absorção de um fóton quase-ressonante, e (b) decaimento espontâneo no interior na janela de Franck-Condon onde a probabilidade de popular-se estados ligados do poço dos potenciais fundamentais seja favorável.

O segundo passo necessário à produção de dímeros estáveis, em geral envolve as características especiais de certos tipos de potenciais de interação, como os estados com duplo mínimo [76]. A importância dos estados com duplo poço de potencial se deve ao fato de que a população dos estados ligados do poço externo do estado excitado é muito favorável por causa da sobreposição de Franck-Condon com os estados ligados do potencial fundamental é aumentado pela amplitude da função de onda vibracional no poço duplo em separações internucleares mais intermediárias (região do poço mais externo)

- Basicamente, o primeiro passo de uma reação de fotoassociação (PA) entre um par de átomos frios colidindo no estado fundamental com energia cinética relativa $E=k_{B} T$ (para temperaturas da ordem de $10^{-4} \mathrm{~K}$ ) podendo levar à formação de moléculas em seus estados fundamentais, pode ser expresso da seguinte maneira: 


$$
A(n S)+A(n S)+\left(\omega_{0}-\Delta_{L}\right) \longrightarrow \mathrm{A}_{2}^{*}\left(\Omega_{u, g}(\mathrm{nS}+\mathrm{nPJ} ; \nu, \mathrm{J})\right)
$$

onde $\omega_{0}$ é a frequência de transição $n S_{1 / 2} \longrightarrow n P_{\mathrm{J}}(\mathrm{J}=1 / 2,3 / 2)$, e $\Delta_{L}$ é o detuning do laser, sintonizado para o vermelho da transição atômica. A reação descrita acima, pode ser entendida como uma transição vertical do contínuo do estado fundamental para um estado rovibracional $(\nu, J)$ do estado molecular excitado $\Omega_{u, g}$.

Devido ao fato do comportamento de longo alcance do potencial e das temperaturas ultrafrias dos átomos colidentes, esta transição ocorre principalmente a longas separações internucleares, $R_{L} \sim\left(C_{3} / \hbar \Delta_{L}\right)^{1 / 3}$ (no caso de colisões homonucleares, envolvendo dois átomos idênticos), e $R_{L} \sim\left(C_{6} / \hbar \Delta_{L}\right)^{1 / 6}$ (para colisões heteronucleares) correspondendo ao ponto de retorno externo do potencial excitado, onde a função de onda é mais localizada.

Na maioria dos casos, esta molécula formada por PA, de curto tempo de vida (quasi-molécula), decai por emissão espontânea. Dependendo da região onde ocorre o decaimento, se este ocorre na região de longo alcance ou na intermediária de separações internucleares, os átomos são em geral perdidos da armadilha (processo de trap-loss) resultando em um par de átomos quentes:

$$
A_{2}^{*} \longrightarrow A(n S)+A(n S)+\hbar \omega^{\prime}
$$

onde o ganho em energia cinética correspondendo à diferença de energia entre os fótons absorvido e emitido, $\hbar\left(\omega_{0}-\omega\right)$, é geralmente suficiente para que os átomos

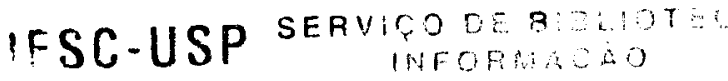


escapem da armadilha, resultando em um par de átomos livres.

A estabilização de uma molécula no estado fundamental, com uma determinada energia de ligação, acontece através do seguinte processo:

$$
A_{2}^{*}\left(\Lambda_{g, u}^{+/-}\right)-\hbar \omega_{s p o n t} \longrightarrow A_{2}\left(\Sigma_{g, u}^{+}(n S+n S ; v, J)\right)
$$

e requer a ocorrência do evento de decaimento na zona de curtas separações interatômicas, e além disso, a existência de um overlap favorável entre as funções de onda dos estados excitado excitado e fundamental.

Uma das dificuldades encontradas na produção de moléculas no estado fundamental deve-se ao fato que apenas uma pequena fração das moléculas no estado $S+P$ produzidas por fotoassociação decaem para o estado fundamental. A densidade de pares atômicos colidindo numa separação $R$ e $R+d R$ dada por:

$$
n_{A B}=n_{A} n_{B} 4 \pi R^{2} d R
$$

variando por tanto com a distância entre os núcleos ao quadrado, e assim, quanto maior for a separação internuclear no ponto de Condon, maior o número de pares colidindo excitados para níveis vibracionais de estados $\mathrm{S}+\mathrm{P}$. Por outro lado, a sobreposição do estado excitado com o estado fundamental é pequena, uma vez que a separação de equilíbrio do estado fundamental é de apenas poucos $a_{0}$, enquanto que o ponto de retorno interno dos potenciais excitados localizam-se em distâncias maiores. Logo, a maior parte das moléculas excitadas decai para o contínuo do estado fundamental, originando em geral dois átomos livres. Apenas um pequeno número de 
pares excitados alcança a região de curtas separações internucleares onde a emissão de um fóton irá popular principalmente os estados vibracionais mais excitados.

No caso geral, devido ao caráter assintótico de curto alcance do potencial fundamental, $-C_{6} / R_{6}$, apenas os estados rovibracionais mais excitados são populados através da reação acima descrita.

Entretanto, uma formação eficiente de moléculas no estado fundamental através de fotoassociação de dois átomos colidindo nos estados fundamentais atômicos seguida por decaimento espontâneo é mais provável em certos casos especiais. Mecanismos mais eficientes de produção de moléculas frias são propiciados por características especiais de determinados estados moleculares, como por exemplo a estrutura de duplo poço dos estados homonucleares $0_{g}^{+}$e $1_{u}$ do $\operatorname{Cs}_{2}\left(6 S_{1 / 2}+6 P_{3 / 2}\right)$ [45]. Uma alta taxa de formação de $\mathrm{Cs}_{2}, 10^{6} / \mathrm{s}$, foi observada provavelmente devido à estrutura especial destes estados. O que ocorre é que os pontos de retorno internos (do poço mais externo) nestes estados $\left(R \sim 16-30 a_{0}\right)$ correspondem aos pontos de retorno externos dos níveis vibracionais do estado fundamental. O decaimento a partir de transições partindo dos pontos de retorno internos do segundo poço popula os níveis vibracionais mais excitados do estado fundamental, enquanto que o decaimento a partir do poço interno, popula níveis mais baixos do potencial fundamental.

A figura abaixo representa o processo de formação molecular através de um estado de duplo mínimo. Na Fig.2.6 é esquematizada a formação de moléculas frias através de um estado de duplo-mínimo. 


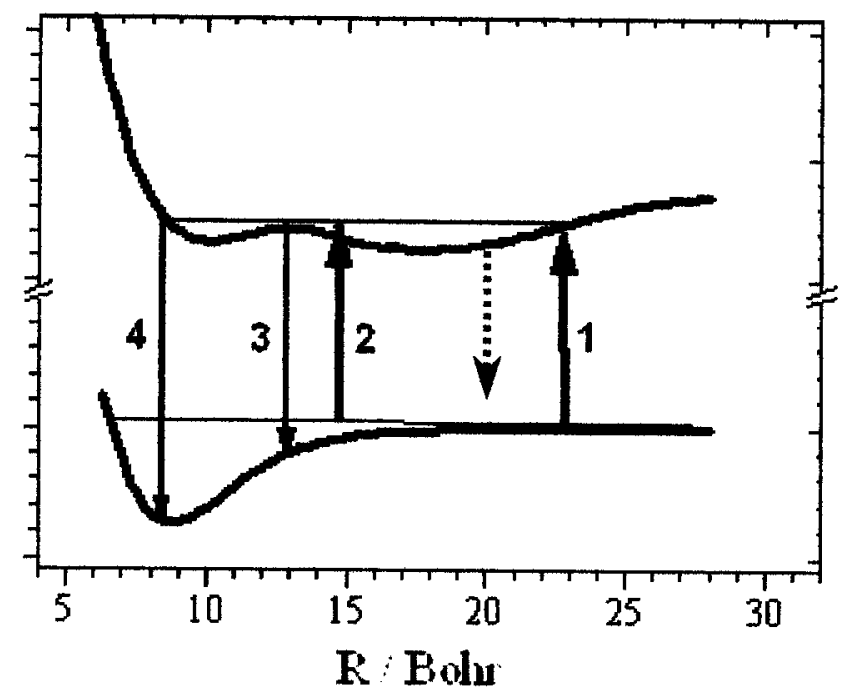

Figura 2.6: Esquema geral de formação de moléculas no estado fundamental através da fotoassociação de dois átomos nos estados atômicos fundamentais, em um estado excitado com duplo mínimo. A absorção de um fóton do laser de aprisionamento (a longo alcance, indicada pela transição eq.2.28) fotoassocia os átomos em estados ligados do poço externo. Uma transição feita por um fóton de um laser de prova bem mais dessintonizado pode fotoassociar o par a mais curto alcance (transição 2), contudo, o número de pares para menores separações internucleares é bem menor do que os acessados a longo alcance. Emissão espontânea para o estado fundamental pode popular os estados ligados mais excitados (transição 3) e mais profundos (transição 4) do estado molecular fundamental, dependendo da região onde ocorre o decaimento. 
Em um MOT de Rb [34], foi observada a produção de moléculas diatômicas frias ( $\mathrm{T}^{\sim} 90 \mathrm{mK}$ ) no estado fundamental tripleto, para ambos os isótopos, ${ }^{85} \mathrm{Rb} \mathrm{e}^{87} \mathrm{Rb}$. O mecanismo de PA em Rb é bastante similar ao observado em Cs, onde os estados de longo alcance $0_{g}^{+}$e $1_{u}$ são fotoexcitados, decaindo para o estado molecular fundamental tripleto. A detecção é realizada por ionização de dois fótons, através do estado ressonante intermediário $2^{3} \Pi_{g}$.

Outro mecanismo de formação de moléculas frias via fotoassociação, demonstrado para átomos de Cs [46], baseia-se nas consequências do acoplamento ressonante entre estados vibracionais dos estados $0_{u}^{+}\left(6 \mathrm{~S}_{1 / 2}+6 \mathrm{P}_{3 / 2}\right)$ e $0_{u}^{+}\left(6 \mathrm{~S}_{1 / 2}+6 \mathrm{P}_{1 / 2}\right)$, o que permite a formação de moléculas em estados vibracionais mais profundos do potencial fundamental, bem abaixo do limite de dissociação $6 \mathrm{~S}_{1 / 2}+6 \mathrm{~S}_{1 / 2}$. Os estados $0_{u}^{+}$dos dímeros homonucleares advêm da mistura dos estados do Hund's case $(\mathrm{a})^{1} \Sigma_{u}^{+} \mathrm{e}^{3} \Pi_{u}^{+}$. Tal esquema de acoplamento, pode em princípio ser observável em outros estados eletrônicos bem como em outras espécies atômicas. Estes estados no $\mathrm{Cs}_{2}$ apresentam um pseudo-cruzamento em aproximadamente $10 a_{0}$. Este acoplamento entre os dois estados produz um fenômeno de ressonância entre as duas séries vibracionais e -manisfesta-se através de um notável aumento na densidade de probabilidade da função de onda vibracional do estado correlacionado ao limite $6 \mathrm{~S}_{1 / 2}+6 \mathrm{P}_{1 / 2}$, na região de separação interatômica intermediária, bem como a longas separações internucleares. Em virtude disso, acontece um melhor acoplamento entre as funções de onda dos estados excitado e fundamental, favorecendo a produção de moléculas frias. Em dados expe- 
rimentais este tipo de acoplamento podem revelar-se além de intensas perturbações no espectro de fotoassociação, e através do alargamento por predissociação das linhas em espectroscopia fotoassociativa, entre os limites $\mathrm{S}_{1 / 2}+\mathrm{P}_{1 / 2}$ e $\mathrm{S}_{1 / 2}+\mathrm{P}_{3 / 2}[44,58]$. O acoplamento entre estes estados ocorre através da interação spin-órbita. Conforme discutiremos na próxima seção, este é o caso a que atribuímos a formação de KRb frias.

No caso de rubídio o estado $0_{g}^{+}$do $\mathrm{Rb}_{2}$ apresenta o poço mais externo com uma profundidade de ${ }^{\sim} 28 \mathrm{~cm}^{-1}$, com mínimo em $\mathrm{R}_{e} \sim 17 \mathrm{~A}$, e neste caso, uma vez que a barreira é muito alta, efeitos de tunelamento não podem ser apresentados. Contudo, a forma do potencial permite fatores de Franck-Condon significativos para o decaimento para o estado fundamental tripleto, como observado pelos autores. Neste trabalho, a dependência da taxa de formação molecular com a densidade atômica, obtida variando-se o gradiente do campo magnético, sugere um papel proeminente de processos colisionais envolvendo três corpos [34].

$\mathrm{O}$ esquema de fotoassociação de $\mathrm{K}_{2}$ em dois passos [47], produz moléculas frias ( $\mathrm{T}^{\sim} 500 \mathrm{mK}$ ) no estado singleto, com grande eficiência, da ordem de $10^{5}$ moléculas/s, . a uma taxa de produção molecular duas ordens de grandeza superior ao esquema de PA por uma único passo [35], e com uma distribuição vibracional que inclui apenas alguns dos nf́veis vibracionais mais baixos, incluindo provavelmente, o nível vibracional $v=0$, é reportado em [47], sendo conceitualmente similar ao esquema proposto por Band e Julienne em 1995 [75]. No primeiro passo, os átomos são fotoassociados 
de modo a formar moléculas de longo alcance em um nível vibracional alto do estado $1{ }^{1} \Pi_{g}$, correlato ao limite $4 \mathrm{~S}_{1 / 2}+4 \mathrm{P}_{3 / 2}$, com um ponto de retorno em $\sim 45 a_{0}$. No segundo passo, as moléculas são novamente excitadas, agora para um determinado nível vibracional de um estado de Rydberg de curto alcance, no caso dos estados $5^{1} \Pi_{g}$ ou $6^{1} \Pi_{g}$, correlacionados ao limite de dissociação $4 \mathrm{~S}_{1 / 2}+4 \mathrm{D}$, e $4 \mathrm{~S}_{1 / 2}+4 \mathrm{~F}$. Este segundo passo permite selecionar-se o decaimento para níveis vibracionais específicos do estado molecular fundamental. Além disso, devido ao fato da segunda transição ser do tipo bound-bound, propiciada pelo acoplamento satisfatório entre as funções de onda. Decaimento radiativo direto ou por cascata através dos estados singletos intermediários produz então moléculas no estado $\mathrm{X}^{1} \Sigma_{g}$, com uma distribuição vibracional que pode ser manipulada através da seleção do nível vibracional do estado mais excitado.

\subsection{Esquemas de Formação Molecular para o Sis- tema Heteronuclear KRb}

- Conforme já discutido, os estados intermediários excitados envolvidos na formação de KRb no estado fundamental em nossos experimentos, são aqueles relacionados à assíntota $\mathrm{K}\left(4 \mathrm{~S}_{1 / 2}\right)+\mathrm{Rb}\left(5 \mathrm{P}_{1 / 2}\right)$ devido ao caráter atrativo destes potenciais. Pode-se observar na Fig.2.3 que nehum dos estados moleculares relacionados a esta assíntota apresenta duplo-mínimo e não existe nenhum estado de puro-longo alcance. Até o 
presente momento, apenas nosso trabalho obteve sucesso na produção de moléculas frias heteronucleares, contudo existem algumas outras propostas para observação de tais dímeros.

Através da inspeção dos potenciais de longo alcance (Hund's case (c)) calculadas por Rousseau et al. [69], observa-se que o dímero KRb apresenta um estado de duplo poço $0^{+}$correlato à assíntota $\mathrm{K}\left(4 \mathrm{P}_{3 / 2}\right)+\mathrm{Rb}\left(5 \mathrm{~S}_{1 / 2}\right)$, em analogia ao estado homonuclear $0_{g}^{+}$

Em recente artigo da literatura [?], tal estado da molécula é cogitado de ser utilizado visando à formação de KRb frias por ser um estado de duplo mínimo, exibindo o segundo mínimo em separações internucleares intermediárias $\left(\approx 20 a_{0}\right)$. Este estado a longo alcance é repulsivo, e apresenta ambos os poços imersos no contínuo de dissociação $\mathrm{K}\left(4 \mathrm{P}_{3 / 2}\right)+\mathrm{Rb}\left(5 \mathrm{~S}_{1 / 2}\right)$.

Todos os dímeros homonucleares também apresentam, entre outros estados convergindo no primeiro limite de dissociação excitado $n \mathrm{~S}+n \mathrm{P}$, dois estados repulsivos a longo alcance, variando com $+C_{3} / R^{3}$ com simetrias ${ }^{1} \Sigma_{g}^{+} \mathrm{e}^{3} \Pi_{g}$ que devido à razão $C_{3}^{\Sigma} / C_{3}^{\Pi}=2$ e à intensa interação spin-órbita (exceto para os dímeros mais leves, $\mathrm{Li}$ e Na) estes estados se misturam para formar um par de estados $0_{g}^{+}$(um dissociando em $\mathrm{S}+\mathrm{P}_{3 / 2}$ e outro em $\left.\mathrm{S}+\mathrm{P}_{1 / 2}\right)$ que apresentam um cruzamento evitado no intervalo de $15-20 a_{0}$. No caso do KRb este estado também é repulsivo a longas separações internucleares, apresentando um poço em curtas separações internucleares e um poço externo em separações intermediárias, observe a Fig.2.7.

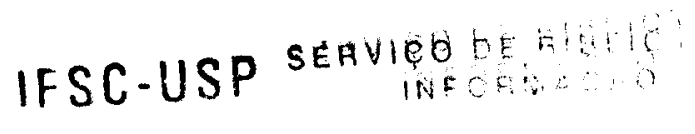




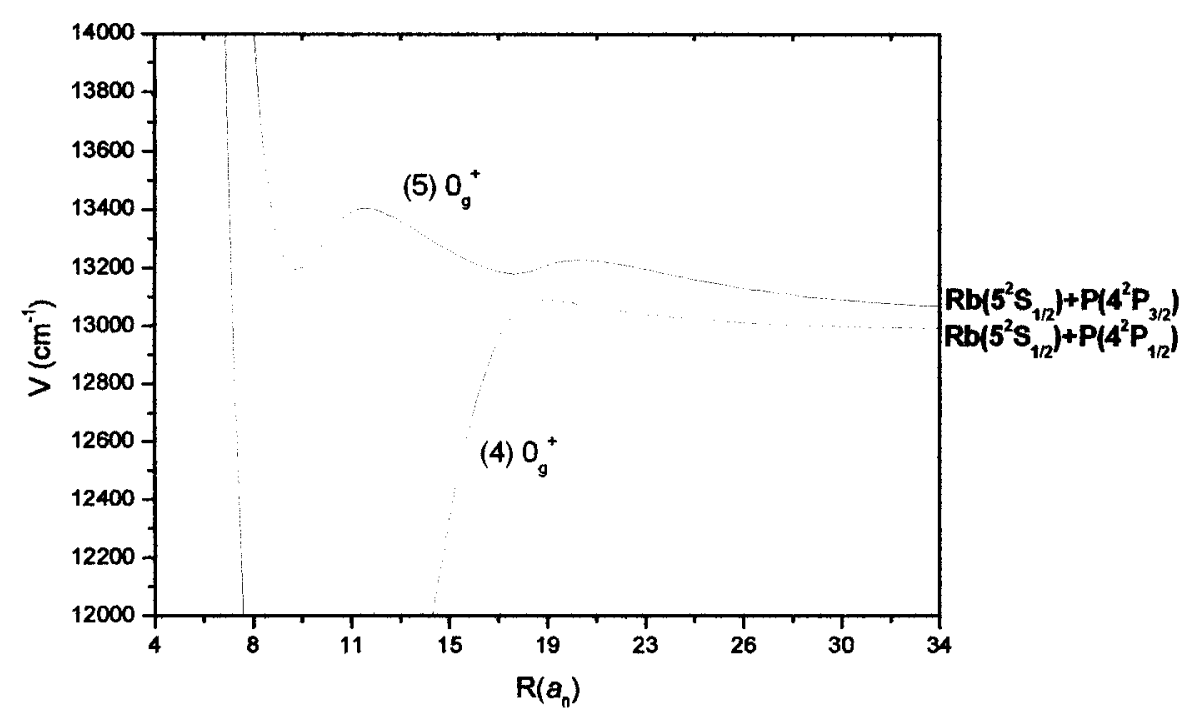

Figura 2.7: Curvas de potencial relativísticas (incluindo a interação spin-órbita) dos estados de simetria $0_{g}^{+}$do KRb. Uma das curvas $(5) 0_{g}^{+}$dissocia a longo-alcance em $4^{2} \mathrm{P}_{3 / 2}$ e a outra, (4) $0_{g}^{+}$em $4^{2} \mathrm{P}_{1 / 2}$.

A relevância deste tipo de estado nos alcalinos e a proposta de fotoassociação deste estado é discutida em $\mathrm{K}_{2}$ e $\mathrm{Rb}_{2}$ [77], e sua utilização para a formação de tais dímeros no estado fundamental $\mathrm{em} \mathrm{Rb}$ é realizada e discutida por Almazor et al.[76]. Ambos os poços são imersos no contínuo de dissociação, e portanto a proposta é de que a excitação deva ser realizada através da utilização de um laser dessintonizado para o azul, conforme proposto na Ref. [77].

No KRb o segundo poço (externo) é causado pelo pseudo-cruzamento, em aproximadamente $17 a_{0}$, deste (5) $0^{+}$com o estado (4) $0^{+}$correlacionado ao limite $\mathrm{K}\left(4 \mathrm{P}_{1 / 2}\right)+\mathrm{Rb}\left(5 \mathrm{~S}_{1 / 2}\right.$ Ao poço mais externo deste estado do KRb (suporta 4 estados vibracionais) nestes experimentos de absorção foi relacionada uma banda satélite detectada em 755,5 nm, resultante de uma transição em $\approx 17,6 a_{0}$ para o estado $(5) 0^{+}$. Resultados teóricos 
indicam que predissociação deste estado, $(5) 0^{+}$, através da interação com o (4) $0^{+}$é desprezível [78].

Segundo especulações teóricas este estado poderá ser utilizado visando-se à formação de KRb frias [78] baseadas em estimativas teóricas de formação de dímeros no estado fundamental produzidos pela fotoassociação em estados do segundo poço mais externo), i.e., probabilidades de transição entre estados moleculares excitados e fundamentais para a região de curto alcance populando estados vibracionais dos potenciais fundamentais $\left(a^{3} \Sigma^{+}\right.$e $\left.\mathrm{X}^{1} \Sigma^{+}\right)$por cálculos quânticos [78].

No caso de nosso experimento, onde a fotoassociação procede através dos fótons dos lasers de aprisionamento, que são dessintonizados para o vermelho das ressonâncias atômicas, o estado de duplo mínimo do KRb obviamente não é excitado. A energia dos fótons do laser de aprisionamento de $\mathrm{K}\left(13042,89 \mathrm{~cm}^{-1}\right.$ correspondentemente ao comprimento de onda de aprisionamento de 766,70 nm) é insuficiente para excitar o estado (5) $0_{g}^{+}$.

Assim, a formação de KRb frias em nosso experimento provavelmente procede via "acidentais" bons fatores de Franck-Condon para a população dos estados fun. damentais favorecidos pelo comportamento similar $-1 / R^{6}$ de ambos os potenciais, excitado e fundamental. Maiores investigações teóricas neste sentido deverão ser estimuladas por nossos experimentos procurando entender qual o canal(is) excitados predominantes na formação de KRb frias em nosso experimento.

As maiores probabilidades de transição concernentes à fotoassociação de átomos 
frios são aquelas entre as funções de onda na região próxima ao limite de dissociação devido à grande amplitude de oscilação da função de onda do estado excitado nesta região, onde oscila lentamente. Já na região próxima ao poço do potencial a função de onda oscila muito rapidamente devido à energia cinética ser alta nesta região. Também, a partir do fato de que a fotoassociação através do laser de aprisionamento ocorre a partir do contínuo do estado fundamental, em direção aos estados vibracionais mais altos do potencial excitado (próximos do limite de dissociação) podemos inferir que o decaimento espontâneo a partir deste estado populará, primariamente, os níveis vibracionais mais excitados dos estados fundamentais do $\mathrm{KRb}$, singleto e tripleto.

Se por um lado os estados heteronucleares do KRb excitados no nosso experimento (relacionados à assíntota $\mathrm{K}(4 \mathrm{~S})+\mathrm{Rb}\left(5 \mathrm{P}_{3 / 2}\right)$ ) não apresentam potenciais de duplo mínimo, os comportamentos "similares" entre os potenciais de Van der Waals dos estados excitado e fundamental (ambos variam com $-C_{6} / R^{6}$ ) parecem favorecer o decaimento espontâneo para estados ligados do estado fundamental através de uma sobreposição favorável entre as funções de onda radiais, propiciada talvez, pelo caráter dos potenciais.

Uma outra proposta para detecção de moléculas no estado fundamental é baseada no acoplamento ressonante entre estados de mesma simetria, correlatos aos limites $S_{1 / 2}+P_{1 / 2,3 / 2}[46]$. No Cs foi estudado o efeito do acoplamento ressonante entre estados do Hund's case (c) de mesma simetria $0_{u}^{+}\left(5 \mathrm{~S}+5 \mathrm{P}_{1 / 2,3 / 2}\right)$ [46]. A interação entre os dois estados resulta em um aumento na região de cruzamento das curvas 
de potencial, da amplitude da função de onda do estado correlato à $\mathrm{S}+\mathrm{P}_{1 / 2}$. Foi observado no trabalho da Ref. [46] um aumento na taxa de produção de moléculas $\mathrm{Cs}_{2}^{+}$detectadas no fundamental, devido a tal efeito.

No KRb tal tipo de acoplamento ocorre entre os estados $(4) 0^{+}$e $(5) 0^{+}$dos limites $\mathrm{K}\left(4 \mathrm{P}_{1 / 2,3 / 2}\right)+\mathrm{Rb}\left(5 \mathrm{~S}_{1 / 2}\right)$ e é responsável pelo poço externo do potencial. Os estados $(2) 0^{+}$e $(3) 0^{+}$assintoticamente conectados ao limite $\mathrm{K}\left(4 \mathrm{~S}_{1 / 2}\right)+\mathrm{Rb}\left(5 \mathrm{P}_{1 / 2}\right)$ e $\mathrm{K}\left(4 \mathrm{~S}_{1 / 2}\right)+\mathrm{Rb}\left(5 \mathrm{P}_{3 / 2}\right)$, respectivamente, também apresentam um pseudo-cruzamento em $\sim 6 a_{0}$. Outro pseudo-cruzamento é observado em $\sim 7 a_{0}$ entre os dois estados $0^{-}$, também correlacionados às assíntotas $\mathrm{K}\left(4 \mathrm{~S}_{1 / 2}\right)+\mathrm{Rb}\left(5 \mathrm{P}_{1 / 2}\right)$ e $\mathrm{K}\left(4 \mathrm{~S}_{1 / 2}\right)+\mathrm{Rb}\left(5 \mathrm{P}_{3 / 2}\right)$. Para estados de simetria 1, também dissociando neste mesmo limite, um cruzamento ocorre em $\sim 7 a_{0}$. Em todos estes casos é esperado que a magnificação na densidade de probabilidade da função de onda vibracional na região de alcance intermediário favoreça a sobreposição com a função de onda do estado fundamental, favorecendo assim o decaimento para os estados ligados do potencial fundamental do KRb e portanto a produção de moléculas no estado fundamental [79].

\subsection{Detecção de Moléculas no Estado Fundamen- tal através das Bandas Difusas}

A utilização de transições de detecção de moléculas frias baseia-se primariamente nas chamadas bandas difusas dos dímeros alcalinos. No início dos anos 80 as regiões 
espectrais relativas à estas bandas foram bastante estudadas em experimentos de ligth-induced fluorescence (LIF) e de absorção [80, 81], realizados em células de vapor contendo altas densidades de vapores alcalinos $\left(10^{17} \mathrm{~cm}^{-3}\right)$ aquecidas em heat-pipes. Tais bandas difusas consistem em um caso especial de interference continuum structure.

O estado superior relacionado à transição associada a tais estruturas é o $2^{3} \Pi_{g}$, o qual apresenta um caráter da primeira assíntota iônica excitada $A^{-}\left({ }^{3} P\right)+A^{+}\left({ }^{1} S\right)$ [80], onde A representa o átomo alcalino, partindo-se do estado molecular fundamental tripleto, ${ }^{3} \Sigma_{u}^{+}$. Este estado em todos os dímeros alcalinos tem caráter repulsivo apresentando um poço de potencial bastante raso. As bandas difusas estudadas em tais experimentos em células de vapor aparecem como estruturas espectralmente largas (com uma largura FWHM de aproximadamente $100 \mathrm{~cm}^{-1}$ ), com pronunciado pico principal e menores ondulações em direção à região de menores comprimentos de onda. $\mathrm{O}$ estado $2^{3} \Pi_{g}$ correlaciona-se às assíntotas $4 \mathrm{~S}+3 \mathrm{D}$ do $\mathrm{K}_{2}$ e $5 \mathrm{~S}+4 \mathrm{D}$ do $\mathrm{Rb}_{2}$.

As principais peculiaridades relacionadas às bandas difusas são atribuídas a duas características principais do estado superior [80]. Uma delas é que a função força . de oscilador de dipolo é "aumentada" devido à configuração de interação (mixing) com o estado $1^{3} \Pi_{g}$. Esta interação também influencia a curva diferença de potencial $2^{3} \Pi_{g}\left\llcorner^{3} \Sigma_{u}^{+}\right.$ocasionando um mínimo ou um ponto de inflexão, que aparentemente são responsáveis pelo aumento nos coeficientes de emissão e absorção medidos em células. Os máximos na função força de oscilador coincidem com os extremos na curva 
diferença de potencial. Outra característica peculiar do estado $2^{3} \Pi_{g}$ é o seu caráter iônico relativo à primeira assíntota iônica excitada. O caráter tripleto geralmente observado no espectro é atribuído a esta característica.

O caráter difuso destas bandas espectrais nos experimentos à altas temperaturas basicamente advém do raso estado fundamental tripleto, ${ }^{3} \Sigma_{u}^{+}$, devido ao fato de que nestas temperaturas a transição do estado fundamental para o mencionado estado excitado é do tipo free-bound, uma vez que os estados vibracionais do estado tripleto no regime de altas temperaturas encontram-se quase vazios, e a absorção então procede a partir de estados livres para estados ligados, acarretando o caráter difuso dos espectros. No caso de moléculas frias as ressonâncias são estreitas devido ao fato de termos transições do tipo bound-bound, conforme poderá ser observado para o Rb mais a seguir na seção dos resultados.

Nos dímeros homonucleares [80], tais estruturas de caráter difuso são associadas a transições com o mencionado alto momento de dipolo, do estado fundamental tripleto ${ }^{3} \Sigma_{u}^{+}$para o estado ${ }^{3} \Pi_{g}$. Assim, a utilização de transições de ionização envolvendo os estados intermediários das bandas difusas para detecção de dímeros no estado - fundamental constitui uma estratégia bastante interessante.

Experimentos de deteç̧̃̃o de moléculas frias $\mathrm{Rb}_{2}$ [34] (banda difusa em 600-610 $\mathrm{nm})$ e $\mathrm{Cs}_{2}[42]$ (700-720 nm) baseiam-se em tal estratégia de detecção de moléculas no estado molecular fundamental, observe esquema mostrado na Fig.2.8 para formação de $\mathrm{Rb}_{2}$. As melhores eficiências de ionização de moléculas frias, isto é, maiores sinais 


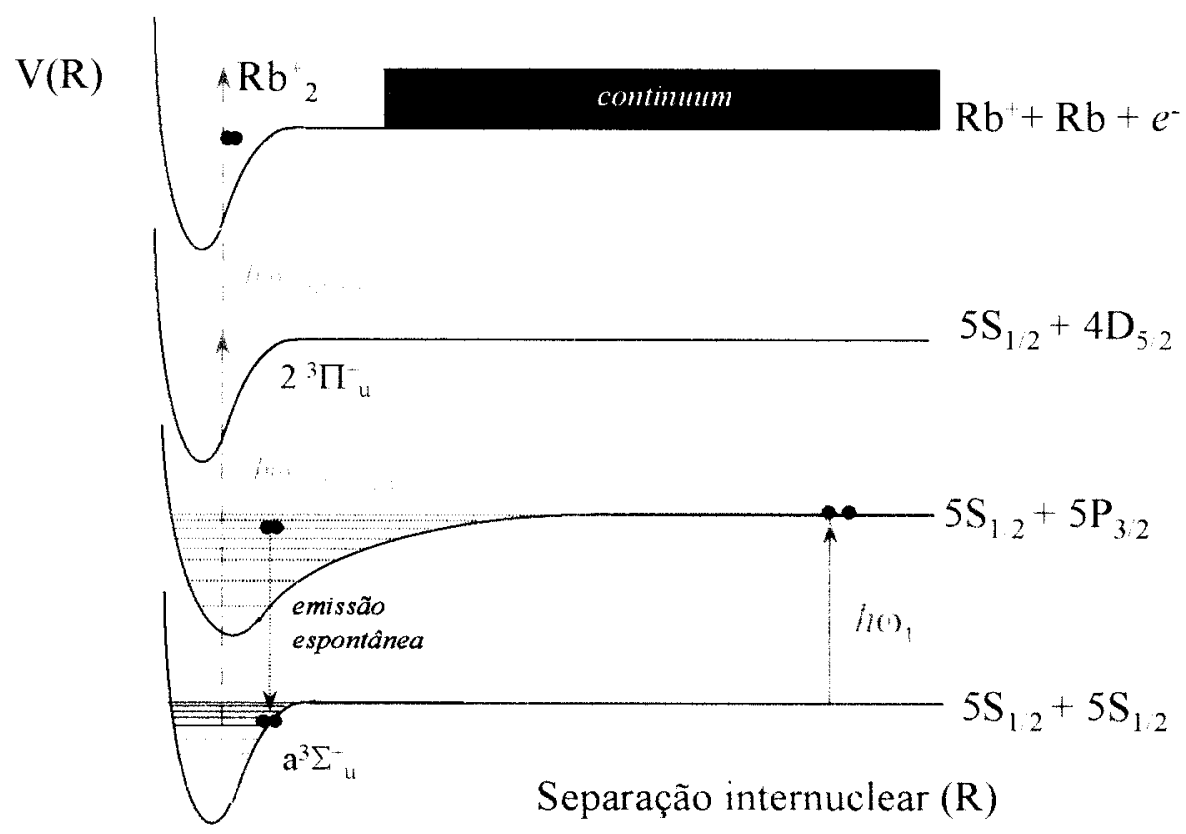

Figura 2.8: Representação esquemática dos potenciais envolvidos na produção de $R b_{2}$ frias.

de íons, correspondem à regiões em energia de máximos no coeficiente de absorção em energias térmicas [42]. Na Fig.2.9 são mostradas as energias dos fótons das bandas difusas comparadas com a metade da energia necessária para ionizar um átomo.

O processo de REMPI no primeiro passo pode ser descrito pela seguinte equação:

$$
A_{2}\left(a^{3} \Sigma\right)+h \nu_{d i f f . b a n d} \longrightarrow A_{2}^{* *}\left(2^{3} \Pi\right)
$$

onde o estado $2^{3} \Pi$ se "divide" nos estados $2_{g}, 1_{g}$, e os quase-degenerados $0_{g}^{+}$and $0_{g}^{-}$, no caso dos dímeros homonucleares.

O segundo fóton produz diretamente um dímero homonuclear iônico, em determinados níveis ro-vibracionais: 


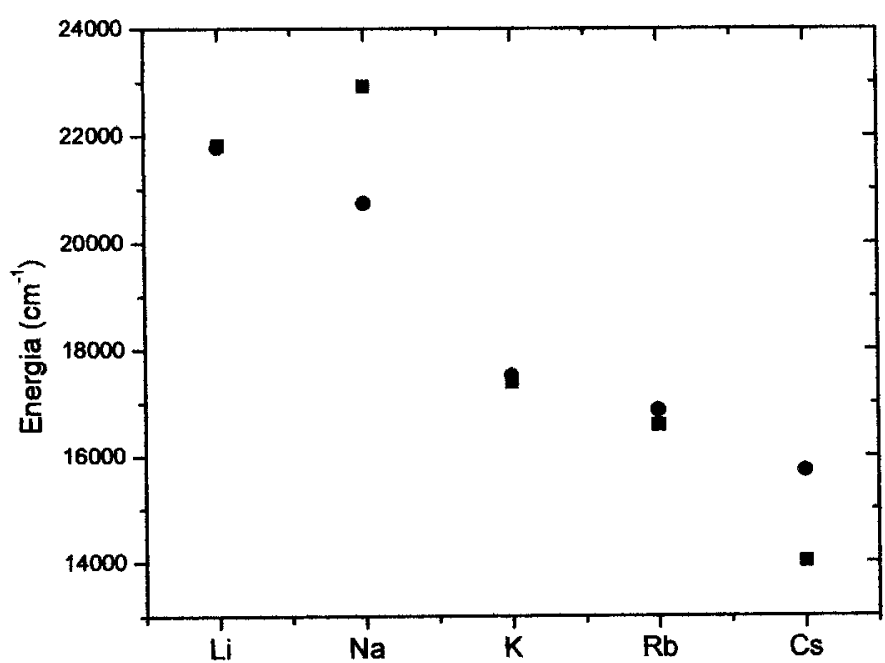

Figura 2.9: Energias dos fótons das bandas difusas (quadrados) comparadas com a metade da energia de ionização (círculos) para todos os alcalinos.

$$
A_{2}^{* *}\left(2^{3} \Pi\right)+h \nu_{\text {diff.band }} \longrightarrow A_{2}^{+}\left(X^{2} \Sigma_{g}^{+}\right)+e^{-}\left(E_{k i n} \approx 0\right)
$$

onde consideramos que a energia do elétron ejetado é próxima de zero. Portanto, para que REMPI eficiente seja aplicado, a seguinte equação deve ser satisfeita:

$$
2 x h \nu_{\text {diff.band }}<I . P .(\text { átomo })
$$

onde $\nu_{\text {diff.band }}$ é a frequência da transição para os estados da banda difusa e I.P. é a energia de ionização atômica. É considerada aqui uma fraca energia de ligação no estado $\Sigma_{u}^{+}$.

Se graficarmos a energia dos fótons da banda difusa de todos os alcalinos comparandoas com a metade do valor correspondente à energia de ionização [82], podemos logo concluir que que o dímero de $\mathrm{CS}_{2}$ é o mais favorecido, seguido pelo $\mathrm{Rb}_{2}$. No caso do 
$\mathrm{Rb}_{2}$, Fioretti et al. também observaram que o estado $2^{3} \Sigma_{g}^{+}$também pode ser utilizado com a proposta de deteç̧ão [42], o que foi confirmado também para o caso do $\mathrm{Cs}_{2}$ [46]. Mesmo que a energia $2 h \nu_{\text {diff.band }}$ seja maior do que a energia de ionização do átomo ainda é possível formar-se um dímero. Entretanto, neste caso o elétron ejetado carrega consigo uma quantidade de energia cinética de modo a deixar o dímero iônico no estado fundamental [82].

No caso heteronuclear, temos uma analogia entre o estado $2^{3} \Pi$ e os estados hetero ${ }^{3} \Pi$ [83]. Bandas difusas do sistema KRb foram observadas em experimentos de LIF e absorção [83] em $569 \mathrm{~nm}, 586,7 \mathrm{~nm}$ e $597 \mathrm{~nm}$, onde foi abordada a região espectral situada no intervalo de 560-610 nm. A segunda, e mais intensa banda, resulta da transição $4^{3} \Pi<1^{3} \Sigma$, e a terceira, da $3^{3} \Pi<1^{3} \Sigma$, respectivamente, sendo que a transição $4^{3} \Pi<1^{3} \Sigma$ tem uma força de oscilador mais intensa do que a $3^{3} \Pi<1^{3} \Sigma$. A transição $4^{3} \Pi<1^{3} \Sigma$ corresponde à $2^{3} \Pi_{g}-{ }^{3} \Sigma_{u}^{+}$do caso homonuclear.

Em nosso experimento também utilizamos tal estratégia de detecção usando fótons fazendo transições para bandas difusas para detectarmos $\mathrm{KRb}$, na banda difusa do $\mathrm{Rb}_{2}$. Termos obtido sucesso na detecção provavelmente então deve-se ao fato que o fóton de $602,58 \mathrm{~nm}$ respeitar a relação $2 \mathrm{~h} \nu<I . P \cdot \mathrm{Rb}$, ou seja, $2 h \nu=33180,03<$ $33691,02 \mathrm{~cm}^{-1}$.

Conforme pode ser observado no Capítulo 4, utilizamos a detecção de KRb frias no estado fundamental em uma região espectral estreita situada na região da banda difusa do $\mathrm{Rb}_{2}$. Em breve deveremos proceder à tentativa de deteção na região em 
torno de $\lambda=586 \mathrm{~nm}$, onde supostamente deveremos ter uma amplificação de nosso sinal iônico.

Conforme proposto em um recente artigo da literatura [78], uma outra estratégia proposta para a detecção de KRb frias é através da banda satélite (blue satelite band) destas moléculas. Naquele trabalho, a formação de KRb térmicas é atribuída ao estado de duplo mínimo (5) $0^{+}$do $\mathrm{KRb}$, o qual correlaciona-se à assíntota $\mathrm{K}\left(4 \mathrm{P}_{3 / 2}\right)+\mathrm{Rb}\left(5 \mathrm{~S}_{/ 12}\right)$. Este estado do dímero hetero corresponde ao estado $0_{g}^{+}$correlacionado aos estados $\mathrm{K}\left(4 \mathrm{~S}_{1 / 2}\right)+\mathrm{Rb}\left(4 \mathrm{P}_{3 / 2}\right)$ e $\mathrm{Rb}\left(5 \mathrm{~S}_{1 / 2}\right)+\mathrm{Rb}\left(5 \mathrm{P}_{3 / 2}\right)$ dos dímeros homonucleares.

Segundo G. Pichler [82], o sucesso do nosso trabalho estaria associado intimamente à detecção de KRb usando bandas difusas. Esta estratégia aumentaria a eficiência no passo de ionização atravês da optimização da primeira transição ressonante da transição de dois fótons, favorecendo assim a detecção das moléculas KRb formadas em nossa armadilha.

\subsection{Mecanismos de Formação de Moléculas Estáveis}

Faremos aqui uma breve discussão qualitativa acerca da formação de dímeros estáveis no estado fundamental. Para dois átomos colidindo, a remoção de energia necessária para a estabilização da molécula pode ocorrer, basicamente, de duas maneiras [68].

Uma delas é através de uma colisão com um terceiro corpo (recombinação por colisão de três corpos, ou simplesmente recombinação de três corpos) e a segunda é 
por emissão espontânea de radiação em uma colisão binária a partir de um estado excitado [68].

a recombinação de três corpos é o processo onde duas partículas formam um dímero estável através da interação com uma terceira partícula, sendo de importância geral em sistemas de muitos corpos e altas densidades [68].

No segundo caso, a transição radiativa ocorre principalmente no ponto de retorno clássico interno do potencial excitado em direção aos estados vibracionais cujos pontos de retorno externos localizem-se verticalmente abaixo do ponto de retorno interno, seguindo o princípio de Franck-Condon [68, 84], segundo o qual uma transição não deve ser acompanhada de movimento radial, isto é, os núcleos, durante uma transição, permanecem aproximadamente parados [68]

Se os dois átomos se aproximam num potencial do estado fundamental, a formação molecular por uma colisão binária radiativa é praticamente impossível, uma vez que a probabilidade para uma transição vibracional levando a uma remoção de energia é muito menor do que para uma transição eletrônica. Em meios densos, a recombinação de três corpos é o mecanismo muito mais freqüente de formação molecular.

- Para que ocorra recombinação de dois átomos em uma molécula diatômica em uma colisão de dois corpos, é necessário que a colisão ocorra em um potencial excitado, por exemplo, o do tipo S+P. Em colisões ordinárias ocorrendo a altas temperaturas a recombinação em uma colisão de dois corpos é um processo raro, uma vez que o tempo característico dos estados moleculares excitados, tipicamente da ordem de 
$10^{-8} \mathrm{~s}$, é muito maior se comparado ao tempo de duração de uma colisão $10^{-13} \mathrm{~s}$, durante o qual o elétron deve emitir espontaneamente. Entretanto, numa colisão fria, os tempos colisionais são maiores do que os tempos de vida e transições para o estado fundamental têm tempo de ocorrer durante a colisão.

Moléculas frias são formadas em MOTs a partir de dois átomos frios colidindo na assíntota $\mathrm{S}+\mathrm{P}$, tanto para os vários casos homonucleares relatados na literatura, quanto para o caso heteronuclear comforme evidenciado em nosso trabalho.

Conforme mostrado nos vários experimentos homonucleares e no heteronuclear $\mathrm{KRb}$, as moléculas alcalinas frias são detectadas mesmo após tempos bastante superiores aos tempos de vida de estados moleculares excitados populados pelo laser de aprisionamento ou pelo laser de fotoassociação (prova). Dessa maneira as moléculas frias no estado fundamental podem ser consideradas como estáveis, em contraposição às short lived molecules no estado excitado, que são criadas durante os experimentos de fotoassociação.

Entretanto, de acordo A. Fioretti, as moléculas de Rb [34] formadas no estado fundadental são devidas principalmente à recombinação de três corpos. Esta afirmação não é corroborada por nossa medida para a taxa de formação, que apresenta comportamento linear com relação à densidade da amostra atômica, o que indica que a formação molecular se dá por colisões binárias e não por colisões de três corpos. Contudo, maiores investigações ainda devem ser realizadas sobre este tópico. 


\section{Capítulo 3}

\section{Montagem e Procedimento}

\section{Experimental para Produção e}

\section{Detecção de KRb Frias}

Descreveremos abaixo o nosso sistema experimental para produção de moléculas heteronucleares frias detectadas no estado fundamental, consistindo da armadilha magneto-óptica mista carregada a partir de uma célula de vapor, o sistema de lasers - de aprisionamento e de deteç̧ão, e os sistemas de deteç̧ão e aquisição de dados. 


\subsection{Aprisionamento de ${ }^{39} \mathrm{~K} \mathrm{e}^{85} \mathrm{Rb}$}

Nossa armadilha magneto-optica mista para aprisionamento simultâneo de duas espécies atômicas distintas opera em uma câmara de aço inoxidável fechada de formato cilíndrico contendo 14 janelas, das quais 10 são para o acesso óptico dos feixes de aprisionamento e prova, enquanto as demais são utilizadas para observação e detecção de íons e da fluorescência emitida pelos átomos aprisionados a partir do vapor [85]. A câmara principal de aprisionamento contém junto a ela acoplados reservátorios de K, $\mathrm{Na}$, Rb e Cs. A pressão em seu interior é da ordem de $10^{-8}$ torr, mantida por duas bombas turbo-molecular e uma bomba iônica que funcionam independentemente.

Os átomos escolhidos para serem utilizados neste experimento em especial, correspondem ambos aos isótopos bosônicos mais abundantes do potássio e do rubídio, ${ }^{39} \mathrm{~K}(\mathrm{I}=3 / 2$, abundância $93,26 \%) \mathrm{e}{ }^{85} \mathrm{Rb}(\mathrm{I}=5 / 2$, abundância $72,17 \%)$. Esta escolha baseou-se nos argumentos teóricos já comentados anteriormente e na disponibilidade dos lasers em nosso laboratório para aprisionamento destas duas espécies.

O campo magnético quadrupolar necessário para a abertura dos níveis de energia Zeeman dos átomos necessário para o aprisionamento é gerado por um par de bobinas montadas na configuração anti-Helmholtz, situadas externamente à câmara. A corrente que circula nas bobinas é da ordem de $10 \mathrm{~A}$, produzindo um gradiente de campo na região central da câmara de aproximadamente 10 gauss/cm na direção vertical (z) e 5 gauss/cm no plano (xy).

Três pares de feixes laser para cada uma das espécies a serem aprisionadas e res- 
friadas mutuamente ortogonais, retrorefletidos e com polarizações circulares opostas, $\sigma^{+}$e $\sigma^{-}$, interceptam-se na região central da câmara, onde o campo magnético varia linearmente com a posição. As polarizações corretas são obtidas utilizando-se lâminas $\lambda / 4$ nos braços da armadilha localizados no plano xy e rombos de Fresnel nos acessos do eixo z. As armadilhas são carregadas a partir da captura, na região central de intercruzamento dos feixes, dos átomos com velocidades mais baixas da distribuição de Maxwell-Boltzmann, e o carregamento procede segundo uma constante de tempo de poucos segundos. Com este sistema produzimos amostras com aproximadamente $10^{7}$ átomos e densidades típicas da ordem de $10^{10}$ átomos $/ \mathrm{cm}^{3}$. Os mesmos valores de gradientes de campo são utilizados para aprisionar ambas as espécies. As densidades máximas obtidas em MOTs carregados a partir de células de vapor, tipicamente da ordem de $10^{10}$ átomos $/ \mathrm{cm}^{3}$, são limitadas por colisões com o gás residual de fundo, colisões inelásticas frias e pelo re-espalhamento de fótons no interior da amostra.

A força sentida pelos átomos no mínimo do campo pode ser expandida na velocidade (associada ao resfriamento) e na posição (relacionada ao aprisiomanento): $F_{M O T}=-\alpha v-k r[1]$, de maneira que os átomos são resfriados sob ação da componente viscosa da força e comprimidos pela componente restauradora no centro do campo magnético quadrupolar. As amostras atômicas frias distribuem-se espacialmente segundo distribuições aproximadamente gaussianas, podendo portanto ser expressas da seguinte maneira:

$$
n(\mathbf{r})=n_{0} e^{-\frac{r^{2}}{2 \sigma_{r}^{2}}}
$$




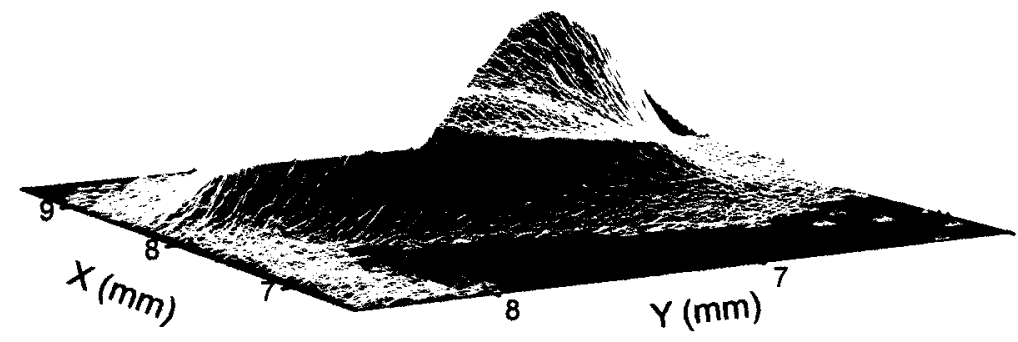

Figura 3.1: Distribuições espaciais das amostras atômicas de rubídio $\left({ }^{85} \mathrm{Rb}\right)$ e potássio $\left({ }^{39} \mathrm{~K}\right)$, mostrando a sobreposição entre elas.

onde $n_{0}$ é a densidade de pico da amostra, $r=\sqrt{x^{2}+y^{2}+z^{2}}$, e $\sigma_{r}$ é a largura da distribuição (denominada cintura gaussiana), a qual nos fornece o raio da amostra atômica.

Na Fig.3.1 observamos as distribuições espaciais das duas amostras. A amostra de potássio (colorizada em azul) é menos densa, a nuvem de rubídio é mais densa (em cinza), observe a a maior intensidade do perfil de densidades.

Nos experimentos realizados neste trabalho de formação e detecção de moléculas KRb frias foram utilizados dois lasers Ti:Safira (Coherent - 899), um para o aprisionamento e resfriamento de cada espécie atômica, $\mathrm{K}$ e Rb.

O laser para aprisionamento de Potássio é opticamente bombeado por um laser 
de argônio (INNOVA-Coherent). O segundo Ti:Safira, para o aprisionamento de Rubídio, o bombeio é realizado por um laser de estado sólido bombeado por diodos e duplicado em frequência (Verdi-V10 - Coherent) que apresenta uma potência efetiva de saída de $10 \mathrm{~W}$.

Componentes ópticos independentes são utilizados para cada comprimento de onda, isto é, para o aprisionamento das duas espéicies, e espelhos dicróicos são utilizados para o acesso óptico dos feixes ao eixo $\mathrm{z}$ da armadilha, onde ambos os feixes seguem conjuntamente.

O laser Ti:Safira para o K opera em $\lambda=766,70 \mathrm{~nm}\left(12816,56 \mathrm{~cm}^{-1}\right)$ e é dessintonizado segundo $\Delta=-40 \mathrm{MHz}(\simeq 6,5 \Gamma)$ da transição atômica $4 \mathrm{~S}_{1 / 2}(\mathrm{~F}=2) \Longrightarrow$ $5 \mathrm{P}_{3 / 2}\left(\mathrm{~F}^{\prime}=3\right)$. O segundo laser Ti:Safira, operando em $\lambda=780,24 \mathrm{~nm}(12816,56$ $\mathrm{cm}^{-1}$ ) fornece a frequência de aprisionamento de $\mathrm{Rb}$, com um detuning $\Delta=-10$ $\mathrm{MHz}(\simeq 1,6 \Gamma)$ da transição de aprisionamento $5 \mathrm{~S}_{1 / 2}(\mathrm{~F}=3) \Longrightarrow 5 \mathrm{P}_{3 / 2}\left(\mathrm{~F}^{\prime}=4\right)$. A largura de linha destes lasers é da ordem de $1 \mathrm{MHz}$.

A partir das freqüências principais de aprisionamento são geradas as freqüências de rebombeio, para previnir o bombeamento óptico para o subnível hiperfino funda.mental não interagente com o laser de aprisionamento, e portanto perdas de átomos da transição de resfriamento. Isto é feito através da passagem da luz por um modulador eletro-óptico (EOM) no caminho do laser para a câmara de aprisionamento. As frequências de rebombeio correspondem às transições $4 \mathrm{~S}_{1 / 2}(\mathrm{~F}=2) \Longrightarrow 5 \mathrm{P}_{3 / 2}\left(\mathrm{~F}^{\prime}=4\right) \mathrm{e}$ $5 \mathrm{~S}_{1 / 2}(\mathrm{~F}=1) \Longrightarrow 5 \mathrm{P}_{3 / 2}\left(\mathrm{~F}^{\prime}=2\right)$, para o ${ }^{39} \mathrm{~K}$ e ${ }^{85} \mathrm{Rb}$, respectivamente. No caso do $\mathrm{K}$, a 
frequência de rebombeio também é dessintonizada $40 \mathrm{MHz}$ para o vermelho da referida transição acima.

Na Fig.3.2 podemos observar uma representação esquemática dos feixes laser usados no experimento (aprisionamento e de ionização), o detector de íons (CEM) e as bobinas de aprisionamento na configuração anti-Helmholtz, responsáveis pelo campo magnético quadrupolar responsável em quebrar a degenerescência dos níveis Zeeman dos átomos a serem aprisionados.

Os esquemas dos níveis de energia envolvidos no aprisonamento das duas espécies atômicas podem ser observados na Fig.3.3. Note que para o potássio a estrutura hiperfina do estado excitado é quase-degenerada. Consequentemente, as linhas referentes à estrutura hiperfina deste estado não podem ser resolvidas por espectroscopia de saturação. O ajuste da frequência dos lasers de aprisionamento é realizado por esta técnica de espectroscopia atômica, onde é medida a absorção do feixe quando este atravessa uma célula de vidro contendo vapor do alcalino que desejamos aprisionar, à medida que o laser varre uma faixa de frequência que pré-estabelecemos. Selecionamos entre os picos de absorção referentes à transições dos estados hiperfinos -fundamentais $F$ para os estados hiperfinos excitados $F^{v}$ as quais correspondem a transição de aprisionamento, e que queremos que seja promovida, e fixamos o laser em uma frequência que corresponde à frequência de ressonância subtraída do detuning $\Delta$, da ordem de poucas larguras de linha natural da transição.

O fato do laser ter que ser sintonizado, no caso do potássio, abaixo de manifold de 


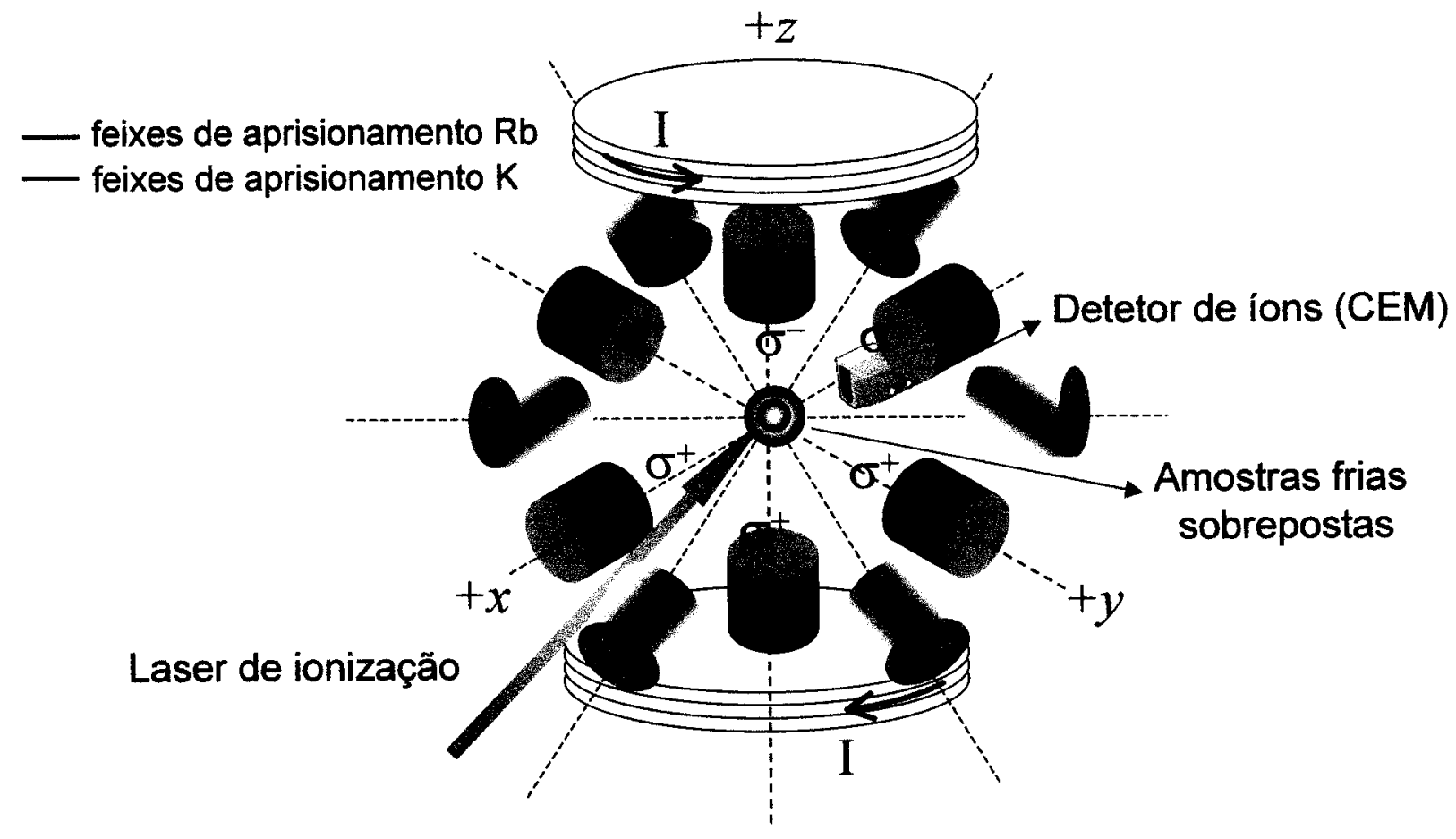

Figura 3.2: Representação dos feixes de aprisionamento de $\mathrm{K}$ e $\mathrm{Rb}$ e das bobinas responsáveis pelo campo magnético dos MOTs na armadilha mista. Na direção z ambos os feixes, do K e do Rb são combinados. Nas demais direções, o acesso ao centro da armadilha é feito por acessos ópticos distintos, como mostra a figura. Também pode ser observado o feixe do laser de deteç̧ão (corante pulsado) que é incidido - sobre a região de sobreposição entre as amostras frias. O detector de íons (CEM) quando no interior da câmara de aprisionamento, fica posicionado a uma distância de aproximadamente $10 \mathrm{~cm}$ do centro da armadilha, e portanto das amostras. 


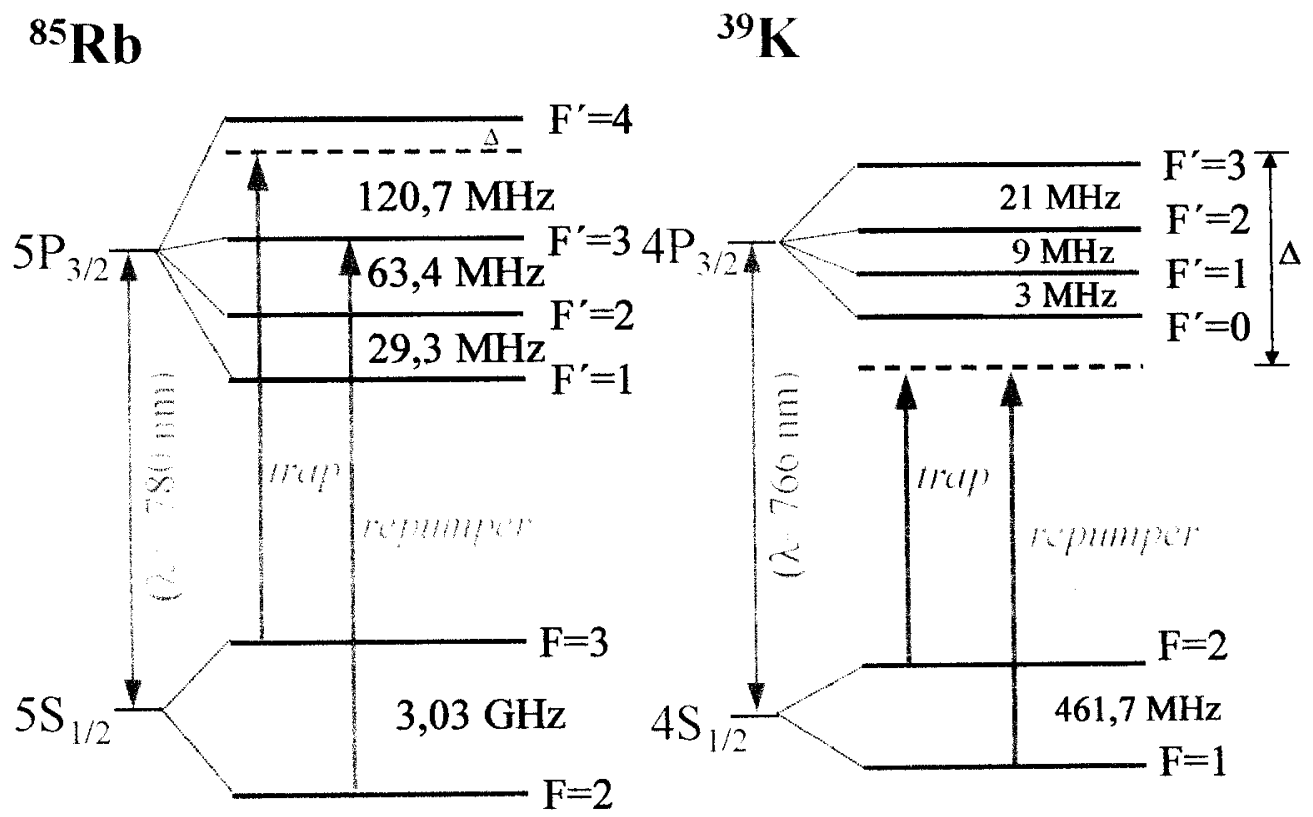

Figura 3.3: Representação esquemática dos níveis atômicos hiperfinos dos estados fundamentais $\mathrm{Rb}\left(5^{2} \mathrm{~S}_{1 / 2}\right)$ e $\mathrm{K}\left(4^{2} \mathrm{~S}_{1 / 2}\right)$ e dos primeiros estados excitados $\mathrm{Rb}\left(5^{2} \mathrm{P}_{3 / 2}\right)$ e $\mathrm{K}\left(4^{2} \mathrm{P}_{3 / 2}\right)$ envolvidos no aprisionamento de ${ }^{85} \mathrm{Rb}$ e ${ }^{39} \mathrm{~K}$ (correspondentemente às linhas D2), onde podemos observar as transições de aprisionamento e de rebombeio. $\mathrm{O}$ detuning do laser de aprisionamento do $\mathrm{Rb}$ é $\Delta_{\mathrm{Rb}}=-10 \mathrm{MHz}$ e ambas as frequências (aprisionamento e rebombeio) do $\mathrm{K}$ são dessintonizadas por $\Delta_{\mathrm{K}}=-36 \mathrm{MHz}$. 
estados hiperfinos excitados, e não logo abaixo do estado hiperfino de maior energia (maior $F^{\prime}$ ) faz com que a transição de resfriamento não seja intensa, ocorrendo uma maior população do estado hiperfino fundamental $(F)$ mais baixo com relação aos demais alcalinos.

A transição com maior força de escilador no caso de utilização de luz circularmente polarizada é a $F \rightarrow F+1$, como no caso dos demais alcalinos (o lítio também é exceção juntamente ao potássio). A frequência do laser de aprisionamento deve ser sintonizada logo abaixo desta transição, caso contrário, um detuning para o azul gera uma força de repulsão entre os átomos. Como os níveis excitados do K são muito próximos, coforme pode ser observado na Fig.3.3, o detuning para o vermelho do estado de maior $F^{\prime}$ fica muito próximo do estado situado subsequentemente abaixo, gerando uma força repulsiva. Daí a necessidade do detuning ser bem maior que o usual e abaixo do estado hiperfino $F^{\prime}=0$ no caso do ${ }^{39} \mathrm{~K}$, e o aprisionamento deste alcalino não ser tão eficiente e a armadilha de $\mathrm{K}$ não tão robusta quanto a de $\mathrm{Rb}$.

Um laser de diodo operado próximo à frequência de ressonância do Rb (linha D2) $(\lambda=780,24 \mathrm{~nm})$, foi utilizado como laser de fotoassociação (ou laser de prova). Esta escolha foi devida ao fato de termos optado em utilizar os lasers de Ti:Safira para o aprisionamento das duas espécies pela maior estabilidade que este tipo de laser apresenta frente aos lasers de diodo, e amostras bastante estáveis eram um requisito fundamental para nossos experimentos. Anteriomente à aquisição de um segundo modulador EOM, para o laser do $\mathrm{Rb}$, o rebombeio dos átomos era realizado por este 
laser de diodo.

A fluorescência emitida pelas amostras aprisionadas é medida por uma fotomultiplicadora (PMT) calibrada. As nuvens são focalizadas no interior deste dispositivo através de um sistema de lentes situado diante de uma das janelas de observação. Imagens das amostras são captadas, através desta mesma janela, por uma das câmaras CCD, também calibrada, através da inserção de um divisor de feixe no sistema óptico de focalização das imagens das amostras na PMT.

Uma representação esquemática da nossa montagem experimental pode ser observada na Fig.3.4, onde podemos observar os lasers de aprisionamento, detecção e de prova, as indicações das montagens para realização de espectroscopia de saturação para o locking das frequências de aprisionamento. São representadas também as duas câmeras CCDs, a fotomultiplicadora (PMT) e o detector de íons (CEM). Outra CCD é posicionada diante de outra janela de observação para monitorarmos as posições relativas entre os dois MOTs durante o alinhamento das amostras.

A fotografia mostrada na Fig.3.5, mostra a armadilha (câmara de aprisionamento, bobinas do campo magnético situadas externamente a ela, a óptica de retroreflexão .dos feixes de aprisionamento, e o sistema de diagnóstico das amostras (PMT e CCD). A foto seguinte, Fig.3.6 mostra o laser de Ti:Safira de aprisionamento de Rb sendo bombeado pelo laser VERDI-V10. Na Fig.3.7 mostramos o sistema de translado do detector de íons, que fica para fora da câmara principal enquanto não é utilizado. $\mathrm{Na}$ foto subsequente, Fig.3.8, observamos junto ao laser de aprisionamento de Rb o 


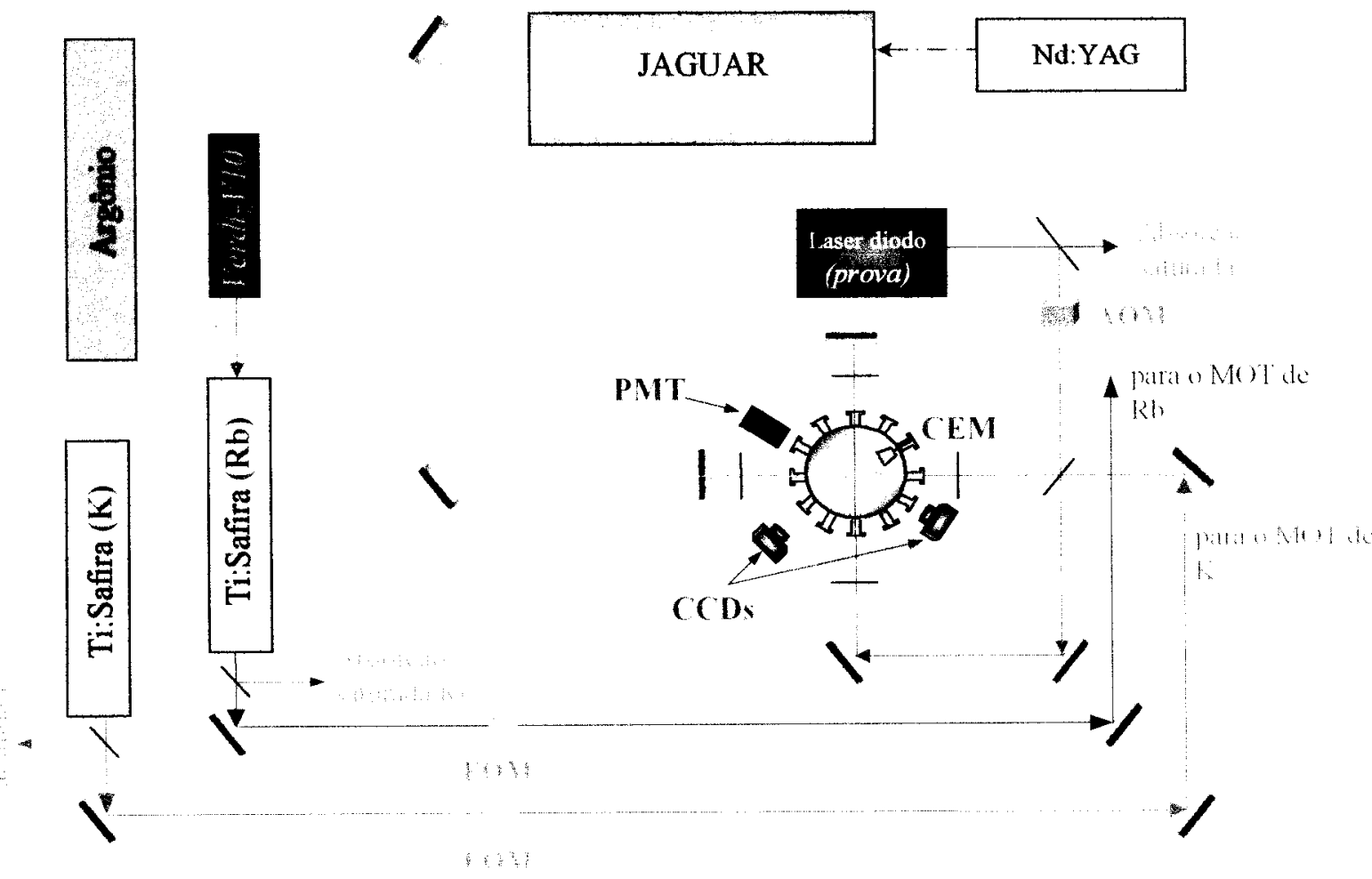

Figura 3.4: Representação esquemática da montagem experimental empregada na produção de moléculas KRb frias. Podem ser observados os lasers de Ti:Safira usados para aprisionamento de ${ }^{85} \mathrm{Rb}$ e ${ }^{39} \mathrm{~K}$, e o laser de detecção (laser de corante pulsado), que é bombeado por um laser Nd:YAG. Moduladores eletro-ópticos (EOM), acoplados a chaves de RF, são utilizados para desligar/ligar a frequência de rebombeio para ambas as espécies atômicas.

sistema experimental para realização de espectroscopia de absorção saturada e para o desligamento dos MOTs. A foto a seguir, Fig.3.9, apresenta uma visão geral do laboratório.

\subsection{Sistemas de Detecção e Aquisição de Dados}






Figura 3.5: Visão parcial da montagem experimental: detalhe mostrando a câmara de aprisionamento, as bobinas responsáveis pelo campo magnético quadrupolar, a janela de acesso óptico para observação da fluorescência (tubo fotomultiplicador) e para o sistema de imagem das armadilhas (câmara CCD). São mostrados também os reservatórios de $\mathrm{K}$ e $\mathrm{Rb}$ acoplados à câmara principal. 


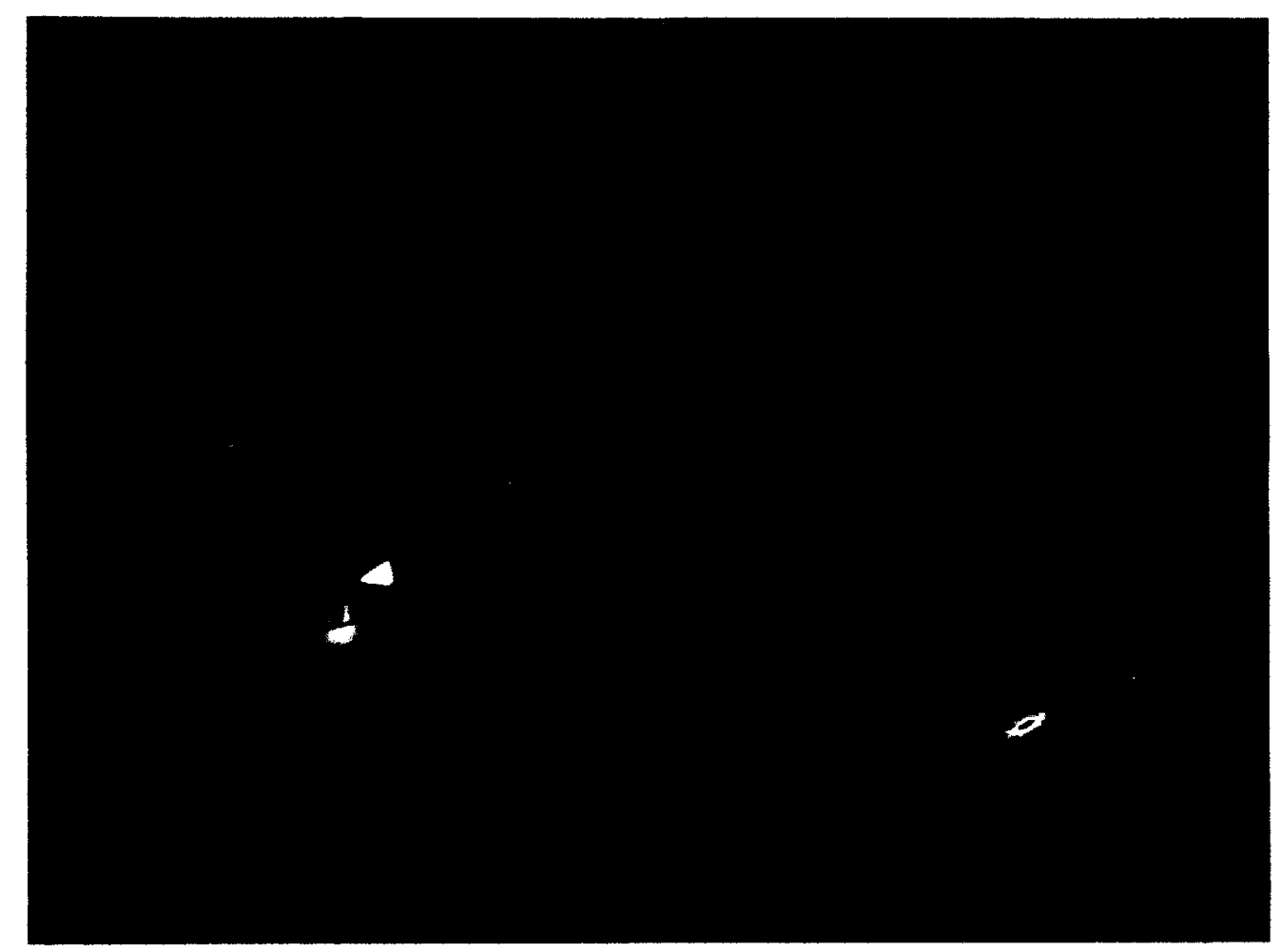

Figura 3.6: Visão parcial da montagem experimental mostrando o bombeamento do laser Ti:Safira (aprisionamento $\mathrm{Rb}$ ) pelo laser de estado sólido Verdi. 


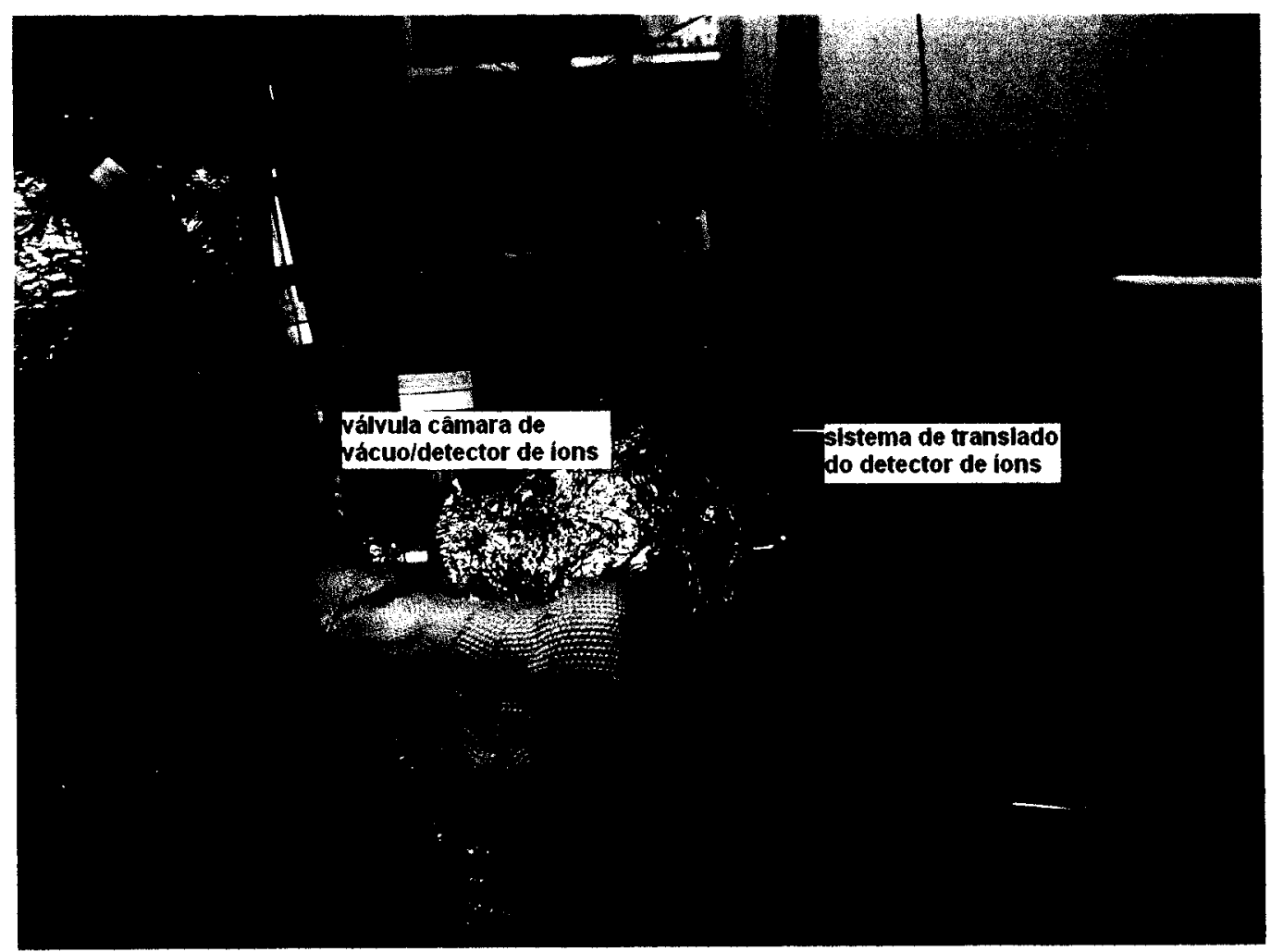

Figura 3.7: Detalhe mostrando o sistema de translado do detector de íons. Quando fora da câmara de aprisionamento, o CEM fica separado da mesma, e uma válvula mantém o detector livre de vapores alcalinos presentes na câmara. 


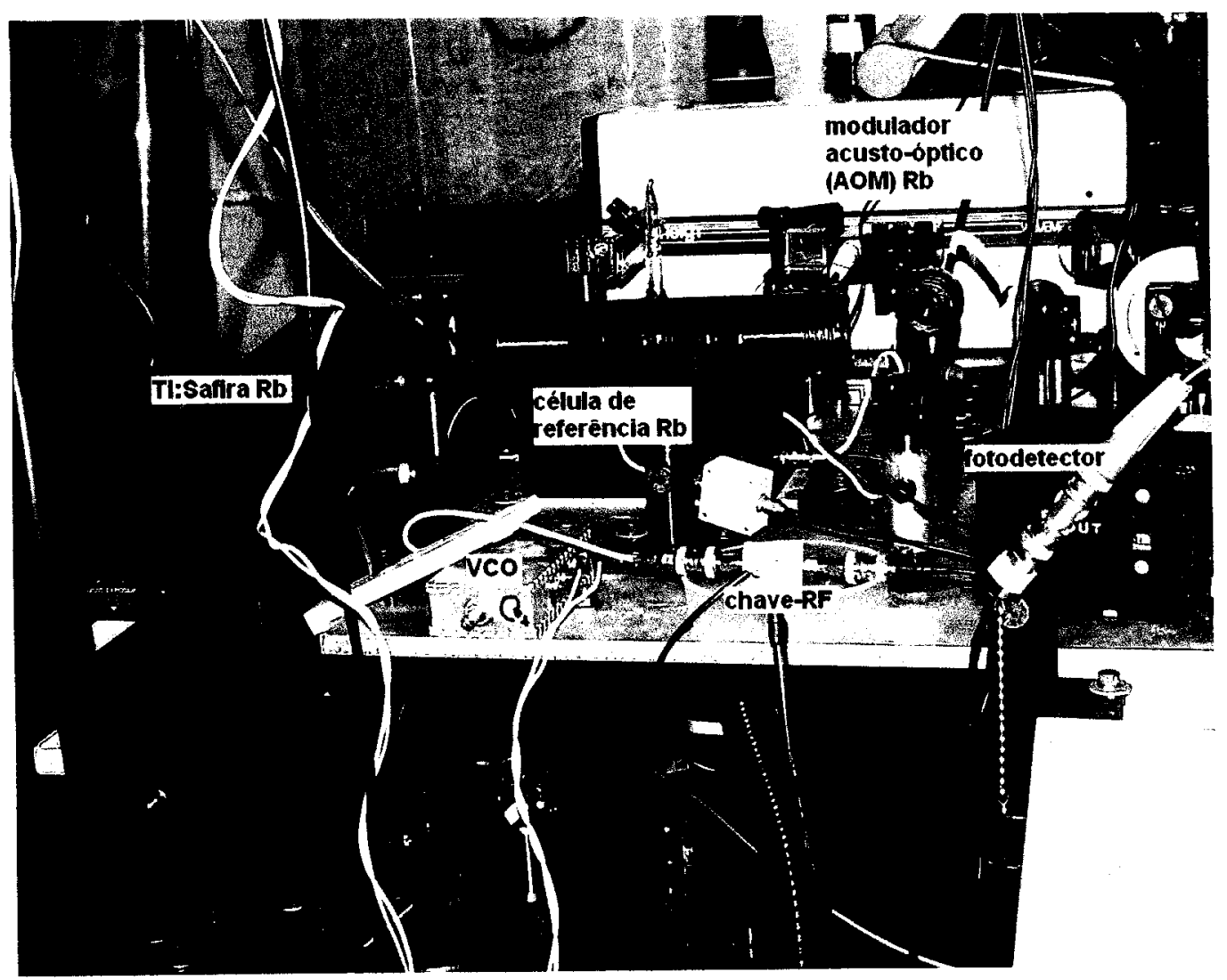

Figura 3.8: Detalhe do sistema experimental: sistema de absorção saturada do Rb. É mostrado o laser de aprisionamento de $\mathrm{Rb}$, a célula de referência deste alcalino, o modulador acusto-óptico (AOM), e o VCO (que sintoniza a rádio-frequência injetada no $\mathrm{AOM}$ ). A chave de rádio-freqüencia (RF) acoplada junto ao AOM é usada para desligar/ligar a armadilha, comandada pelo gerador de função/delay. Também aparece nesta figura o fotodetector que comandas a aquisição do sinal de íons pela captação da luz do laser de corante. O modulador eletro-óptico (EOM) não aparece nesta foto. 


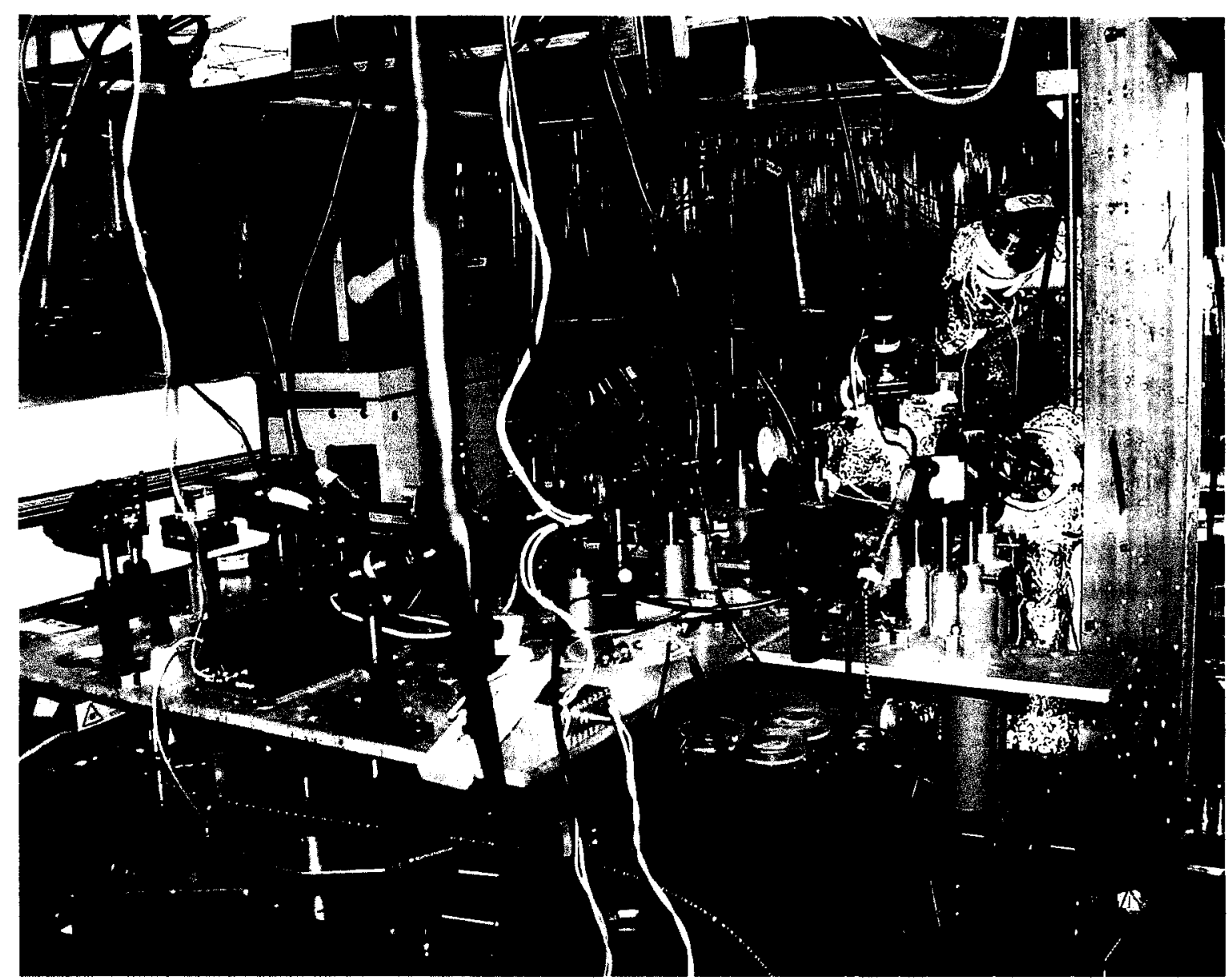

Figura 3.9: Visão geral do sistema experimental: ao fundo o laser de corante pulsado, - bombeado pelo laser pulsado de nanosegundos Nd:YAG. Sobre a mesa elevada, a óptica de aprisionamento de $\mathrm{K}$ e de $\mathrm{Rb}$. À frente, o laser de aprisionamento de $\mathrm{Rb}$ e o sistema de espectroscopia de saturação. $\grave{A}$ direita, a câmara de aprisionamento e o sistema óptico de detecção de imagem e fluorescência (situados do lado oposto da parede vertical).

$$
\begin{aligned}
& \text { IFSO-USP SERVICODE PBBLIOTEUM } \\
& \text { INFORMACAOO }
\end{aligned}
$$


Nas seções sequintes, discutiremos sobre os nossos sistemas de detecção das moléculas frias e de aquisição dos dados, e também sobre o esquema temporal dos experimentos.

\subsection{Deteç̧ão}

Nosso sistema de deteç̧ão de íons atômicos e moleculares é constituído por um laser de corante pulsado (JAGUAR-Continuum) responsável pela fotoionização de átomos e moléculas formados em nosso MOT, por um detector de íons do tipo channel electron multiplier (CEM) (modelo: KBL 408 - Dr. Sjultz) localizado no interior da câmera de aprisionamento, e por integrador boxcar (gated integrator and boxcar averager, modelo: SR250 - Stanford Research Systems).

De maneira a implementarmos a contagem dos íons moleculares, tanto homonucleares quanto heteronucleares, utilizamos uma janela temporal de contagem através do posicionamento da gate de um integrador do tipo boxcar na região de interesse da contagem.

O laser de corante pulsado (JAGUAR) é bombeado pelo segundo harmônico de um laser Nd:YAG ( $\lambda=532 \mathrm{~nm}$, duração temporal dos pulsos de $9 \mathrm{~ns}$, taxa de repetição entre $10 \mathrm{~Hz}$ e $20 \mathrm{~Hz}$, energia/pulso: $25 \mathrm{~mJ}$ ). A potência na saída do Nd:YAG é de $3 \mathrm{~W}$, e após a passagem do feixe pelo gerador de segundo harmônico a potência medida é aproximadamente $800 \mathrm{~mW}(80 \mathrm{~mJ} /$ pulso de energia para uma taxa de repetição de $10 \mathrm{~Hz}$ ou $40 \mathrm{~mJ} /$ pulso para operação do laser em $20 \mathrm{~Hz}$ ). Anteriormente à aquisição 
deste laser (início de 2002) contávamos com um laser de corante caseiro, o qual foi utilizado nos experimentos em outras misturas. Embora o princípio básico de operação entre eles seja o mesmo (a cavidade é formada por uma grade de difração, responsável pela sintonizabilidade do laser e um espelho de saída, o comercial fornece energias superiores ao caseiro bem como outras vantagens adicionais. Os lasers de corante pulsados contam com dois estágios (duas cubetas de corante e óptica relacionada), sendo o primeiro de oscilação onde se estabelece a ação laser, e o segundo de amplificação desta.

Para operação no intervalo de comprimentos de onda referentes à banda difusa do $\mathrm{Rb}_{2}(600-610 \mathrm{~nm})$ o laser de corante apresentou $7 \mathrm{~mJ} /$ pulso, equivalentemente a uma potência média de $70 \mathrm{~mW}$ para uma taxa de repetição igual a $10 \mathrm{~Hz}$. Para o caso de operação do laser a $20 \mathrm{~Hz}$ a energia/pulso é aproximadamente igual a 3,5 mJ. Esta energia é bastante satisfatória comparada à fornecida por nosso laser de corante caseiro, $1 \mathrm{~mJ} /$ pulso, usado para deteç̧ão iônica nas misturas anteriores (KCs, $\mathrm{NaRb}$, $\mathrm{LiCs})$.

Para o caso de sintonização no intervalo $600-610 \mathrm{~nm}$, foi utilizada uma combinação de dois diferentes corantes: Rhodamina 610 para o estágio do oscilador (concentração: 271,51 mg para $500 \mathrm{ml}$ de solvente) e Rhodamina 640 no estágio de amplificação (concentração: 26,95 mg para $1200 \mathrm{ml}$ de solvente) para ambos diluídos em etanol, de modo a obtermos ação laser no intervalo $595-611 \mathrm{~nm}$. Ambos os corantes usados são da marca Exciton. 
Este laser sintonizável comercial (JAGUAR) é controlado por um software que permite selecionar-se o comprimento de onda de operação. Este programa também controla a varredura do laser permitindo que seja escolhido o intervalo de frequiências a ser varrido e a velocidade de varredura. Esta característica do laser comercial, controle fino do comprimento de onda e da velocidade de varredura, nos pareceu essencial para a deteç̧ão das moléculas heteronucleares. A utilização de um laser de detecção altamente controlável é portanto singular para o sucesso da detecção das moléculas heteronucleares, uma vez que estas são detectáveis apenas em uma região bastante restrita dentro do intervalo de $\lambda$ 's mencionado.

Nosso detector de f́ons é um channel electron multiplier (CEM) alimentado por uma tensão da ordem de $3 \mathrm{KV}$. O detector é acoplado a um sistema de translado que o mantêm fora da câmara de vácuo quando este não está sendo utilizado. Quando em operação, este dispositivo é localizado a uma distância de $10 \mathrm{~cm}$ com relação ao centro da armadilha, e portanto das amostras. Um procedimento de retirada do detector do interior da câmara é feito diariamente com o intuito de evitar-se os frequientes problemas advindos da contaminação das paredes internas do mesmo pela deposição de vapores dos metais alcalinos. A deposição de alcalinos no interior do detector deteriora o sinal de íons aumentando o ruído e comprometendo assim a confiabilidade do sinal obtido.

A obtenção de amostras densas e uma sobreposição bastante optimizada entre as amostras, juntamente com a optimização da incidência do laser pulsado na região de 


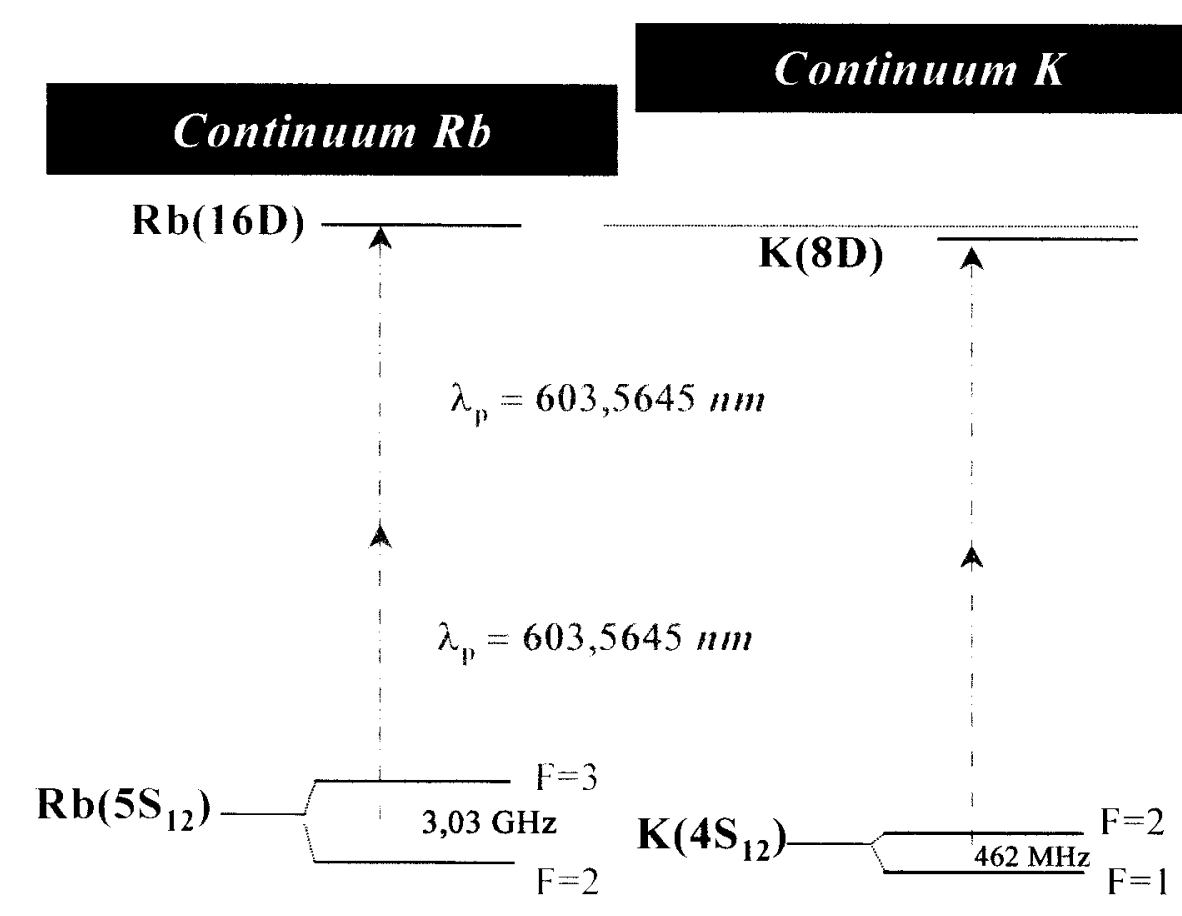

Figura 3.10: Transição de detecção realizada pelo laser de corante pulsado, a partir do estado fundamental. Os dois fótons levam à excitação dos estados $8 \mathrm{D}_{3 / 2,5 / 2}$ do $\mathrm{Rb}$ e $16 \mathrm{D}_{3 / 2,5 / 2}$ do K. O limite de ionização do $\mathrm{Rb}$ é $33691,02 \mathrm{~cm}^{-1}$ e o do $\mathrm{K}$ é 34991,2 $\mathrm{cm}^{-1}$. A energia do estado $\mathrm{Rb}(16 \mathrm{D})$ é $33180,03 \mathrm{~cm}^{-1}$, e $\mathrm{K}(8 \mathrm{D})$ é $33178,36 \mathrm{~cm}^{-1}$.

sobreposição das amostras, é imprescindível à observação da formação das moléculas heteronucleares. A focalização e a intensidade deste laser sobre esta região de sobreposição, também alteram a intensidade e forma do sinal molecular. Após termos ajustado estes parâmentros, procedíamos, já na presença do sinal iônico heteronuclear, a um ajuste fino no comprimento de onda do laser de corante para torná-lo o mais intenso possível.

Os estados acessados pelo laser pulsado no experimento de produção de moléculas KRb frias $\left(\lambda_{\text {puls }} \sim 602,6 \mathrm{~nm}\right)$ encontram-se representados na Fig.3.10. 


\subsection{Aquisição de dados}

Conjuntamente ao sinal de íons, os sinais de fluorescência e o sinal de referência advindo dos sistemas de absorções saturadas também são obtidos através de uma placa de aquisição de dados (National Instruments), que é a parte responsável pela comunicação com o software de aquisição dos dados por programas em linguagem Labview. A placa de aquisição de dados permite a comunicação entre os equipamentos de aquisição dos sinais medidos e o computador (PC).

A Fig.3.11 mostra uma representação esquemática do sistema de detecção e aquisição de dados do nosso experimento. O sinal de "trigger", ou sinal de sincronismo, para toda a sequência experimental de detecção molcular é fornecido pelo gerador de função/delay, ao laser pulsado (Nd:YAG) e para a chave de rádio-frequência ou RF, que irá comandar o desligamento/religamento dos MOTs. Os íons, que são detectados durante os períodos de desligamento dos MOTs são detectados pelo channeltron. O espectro de TOF é aquisicionado no osciloscópio e processado pelo boxcar. O sinal proveniente de um fotodiodo que capta a luz do laser de corante serve de trigger para a aquisição dos sinais pelo osciloscópio, placa de aquisição (DAQ) de dados, e o boxcar. Os sinais de fons (provenientes do osciloscópio e do boxcar) e da fluorescência, advindos da PMT, podem então ser observados e salvos pelos programas de aquisição dos dados, para subsequientemente serem analizados.

O sinal proveniente do detector de íons é aquisicionado por um osciloscópio digital (TEKTRONIKS - 2430), que é conectado ao integrador boxcar, responsável por 


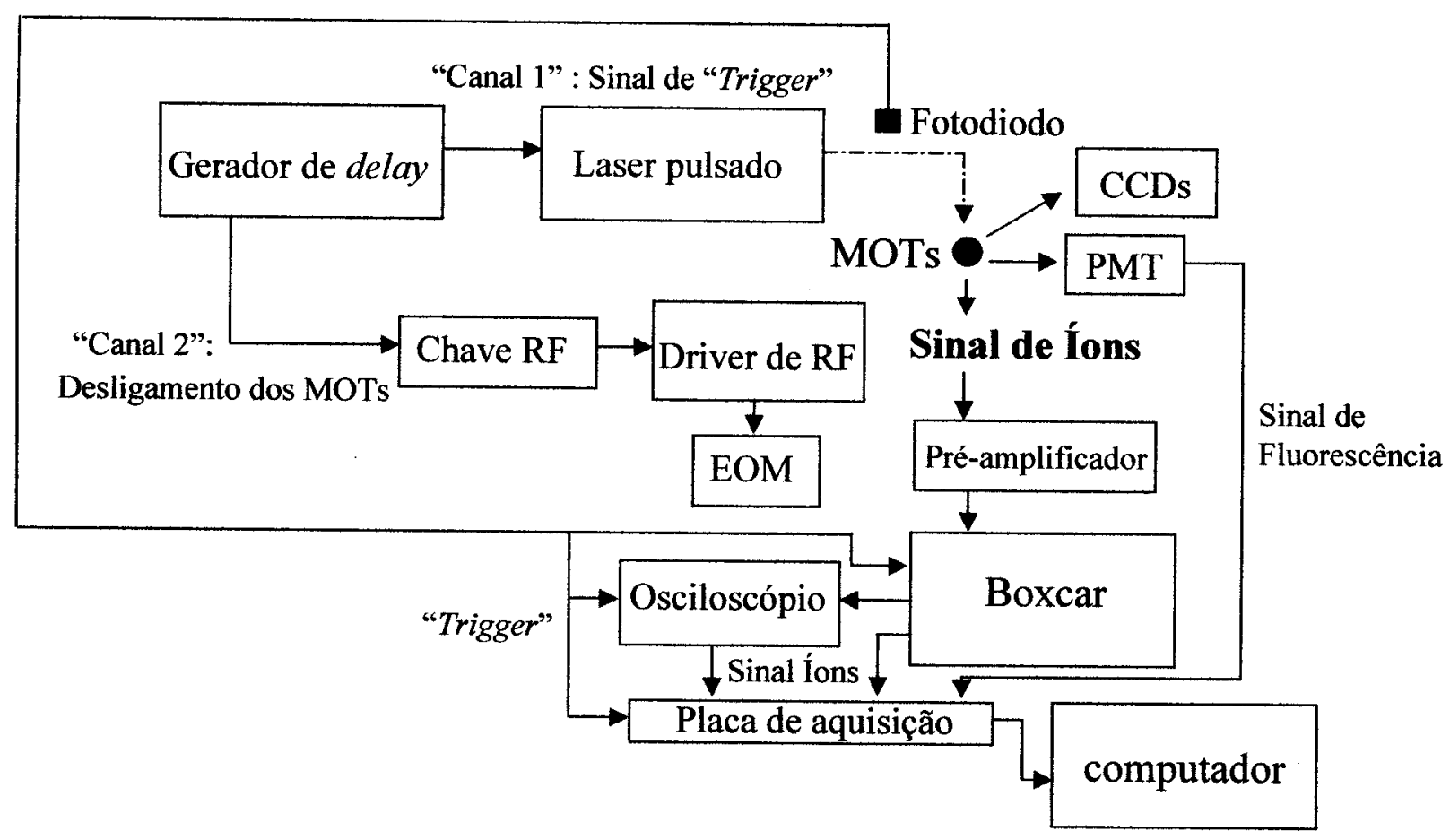

Figura 3.11: Esquema dos sistemas de deteç̧ão e aquisição de dados.

realizar médias, amplificar o sinal e integrá-lo, que já fora previamente amplificado por um pré-amplificador ligado ao detector, e também a uma placa GPIB através da qual podemos aquisicionar os dados em um PC para serem então analisados.

\subsection{Esquema Temporal}

O esquema temporal do nosso experimento é esquematizado na Fig.3.12. A detecção das moléculas no estado fundamental é realizada no "escuro", em intervalos temporais durante os quais as armadilhas são desligadas. Este desligamento é realizado para que apenas as moléculas que estejam no estado fundamental, e não também 
as excitadas, sejam detectadas.

Ambas as armadilhas são desligadas através do desligamento da frequência de rebombeio por meio de um modulador eletro-óptico (EOM) acoplado a uma chave de rádio-frequência e a um gerador de pulso e delay (DG535 - 4 channel digital delay / pulse generator - Stanford Research Systems).

Toda a sequência temporal é sincronizada pelo sinal captado por um fotodetector da luz do laser de corante, constituindo o sinal de trigger, que é basicamente um sinal TTL baixo de $5 \mathrm{~V}$ para $0 \mathrm{~V}$, permanecendo em $0 \mathrm{~V}$ durante $20 \mu$ s e se repetindo a uma taxa de 10 a $20 \mathrm{~Hz}$, que é o limite do laser Nd:YAG. A partir daí, há um atraso aproximado de $180 \mu$ s até que o pulso laser seja emitido e atinja as amostras frias, produzindo os íons moleculares que demoram cerca de $12 \mu s,\left(\mathrm{~K}_{2}^{+}\right), 15 \mu s\left(\mathrm{KRb}^{+}\right) \mathrm{e}$ $20 \mu s\left(\mathrm{Rb}_{2}^{+}\right)$, respectivamente para atingirem o detector de íons (CEM).

A chegada do pulso de ionização com relação ao momento de desligamento das armadilhas, e o desligamento das mesmas, são eventos comandados através do gerador de função e delay, sempre através de pulsos TTL. 


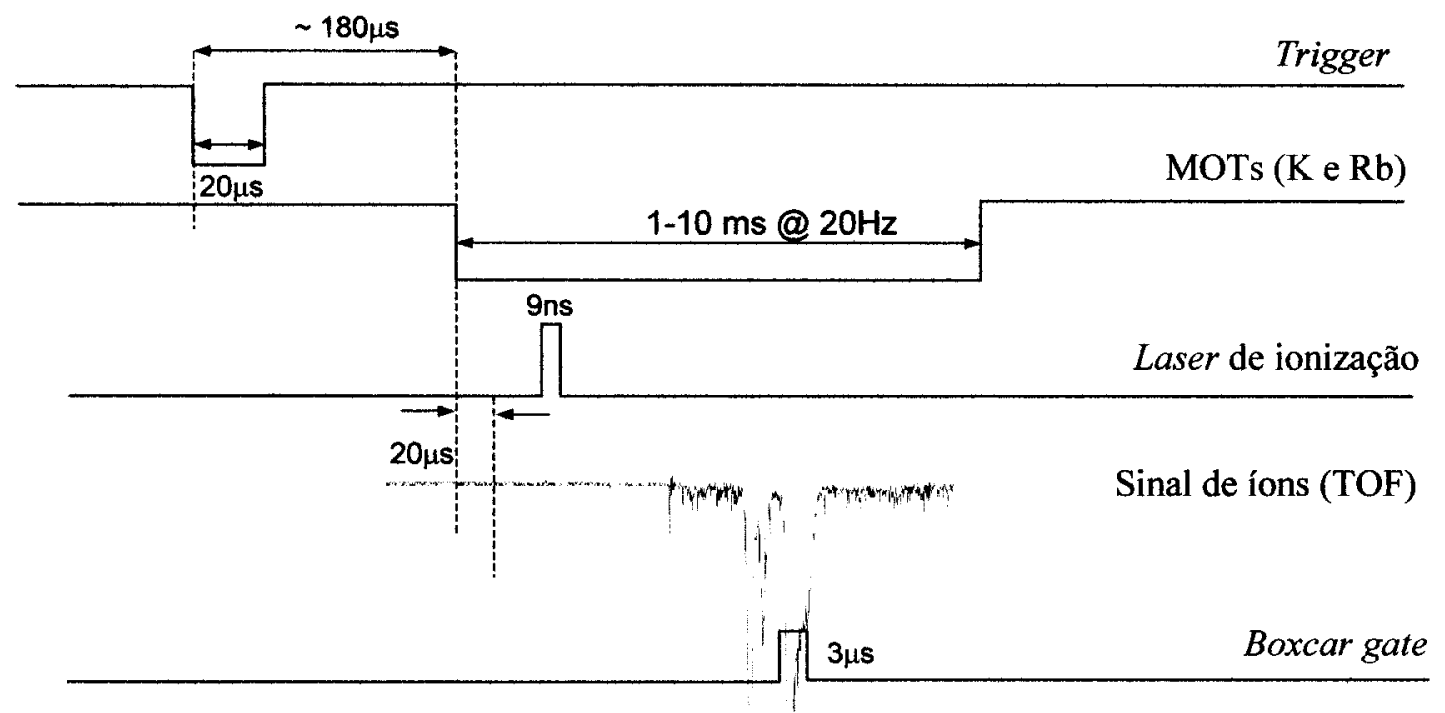

Figura 3.12: Esquema temporal dos experimentos envolvendo produção de moléculas frias no estado fundamental. A ionização e a detecção do sinal iônico ocorrem em fases de desligamento das duas armadilhas. 


\section{Capítulo 4}

\section{Resultados Experimentais}

\subsection{Detecção de Moléculas KRb Frias}

A deteç̧ão das moléculas formadas em nossa armadilha é realizada por espectrometria de massa, técnica baseada no espectro de tempo-de-vôo das espécies ionizadas, que no nosso caso são átomos e as moléculas diatômicas.

Quando o laser de corante é sintonizado ressonantemente (ou quase-ressonantemente) com um estado intermediário, por exemplo, em uma transição de dois fótons para o contínuo atômico e/ou para um estado ligado do potencial da molécula ionizada $\mathrm{A}_{2}^{+}$, um segundo pico aparece no espectro de tempo de vôo em uma posição aproximada de $\sqrt{2} t$ com relação ao tempo de chegada dos íons atômicos $\mathrm{A}^{+}$ao detector $\left(t_{A}\right)$, relativo à detecção dos dímeros homonucleares, dependente da razão entre as massas das espécias atômico-moleculares: 


$$
t_{A_{2}}=\sqrt{m_{A_{2}} / m_{A}} t_{A} \simeq \sqrt{2} t_{A}
$$

Estes tempos, $t_{A} \mathrm{e} t_{A_{2}}$ correspondem à distância percorrida pelas partículas ionizadas (átomos ou moléculas) no interior da câmara de aprisionamento até o detector de íons. O processo de deteç̧ão é optimizado quando da utilização de REMPI (resonant multi-photon ionization). Quando o primeiro fóton conecta o estado fundamental a um estado intermediário ressonantemente, a força da transição de detecção e, portanto, o sinal iônico atingem as melhores condições.

No caso de um dímero heteronuclear, a sua detecção é indicada no espectro de tempo de vôo pelo surgimento de um pico iônico em uma posição que também depende da razão entre as massas das espécies detectadas:

$$
t_{A B}=\sqrt{\frac{m_{A B}}{m_{A_{2}}}} t_{A_{2}}=\sqrt{\frac{m_{A B}}{m_{B_{2}}}} t_{B_{2}} .
$$

Por exemplo, nos espectros que podem ser observados abaixo, podemos verificar que o pico correspondente à produção de KRb obedece à relação entre as massas das moléculas hetero e homonucleares:

$$
t_{K R b}=\sqrt{\frac{m_{K R b}}{m_{R b_{2}}}} t_{R b_{2}} \simeq 0,854 t_{R b_{2}} .
$$

O pico relativo à detecção de dímeros heteronucleares desaparece prontamente se bloqueamos qualquer uma das amostras, corroborando o fato de que as moléculas 
KRb são formadas em nosso MOT a partir de átomos frios e não de átomos térmicos presentes no vapor de fundo da câmara de aprisionamento.

Abaixo podemos observar os gráficos mostrando a evolução dos espectros de tempo-de-vôo obtidos, desde a primeira deteç̧ão de KRb térmicas (Fig.4.1), originadas a partir de átomos térmicos do vapor de fundo em uma situação em que a câmara de aprisionamento estava tomada por grande quantidade de vapores alcalinos liberados pelo aquecimento da câmara de aço inoxidável e dos reservatórios de $\mathrm{K}$ e $\mathrm{Rb}$ a ela acoplados. A seguir então é apresentado um espectro de TOF (obtido em setembro de 2002) mostrando resultados preliminares de evidência de moléculas heteronucleares frias em nosso MOT, na Fig.4.2. Finalmente, a seguir, pode ser observado um TOF mostrando inequivocamente a detecção de $\mathrm{KRb}$ frias em nosso sistema, Fig.4.3. A assimetria observada no pico referente ao $\mathrm{Rb}_{2}$ deve-se à geometria da amostra atômica.

A grande melhoria observada na qualidade do espectro (Fig.4.4) mostrando um incremento na produção de $\mathrm{KRb}$ frias adveio principalmente de melhorias experimentais em nosso sistema. Entre as principais melhorias implementadas podem ser ressaltadas - a melhoria nas condições de vácuo (redução dos vapores alcalinos de fundo), o procedimento de limpeza do detector de íons, e a optimização do alinhamento das cavidades dos lasers de aprisionamento, o que levou ao fornecimento de potências mais altas e maior estabilidade das freqüências de aprisionamento, etc. Na Fig.4.3, a relação entre as posições temporais dos picos referentes a $\mathrm{KRb}$ e a $\mathrm{Rb}_{2}$ corresponde à razão 


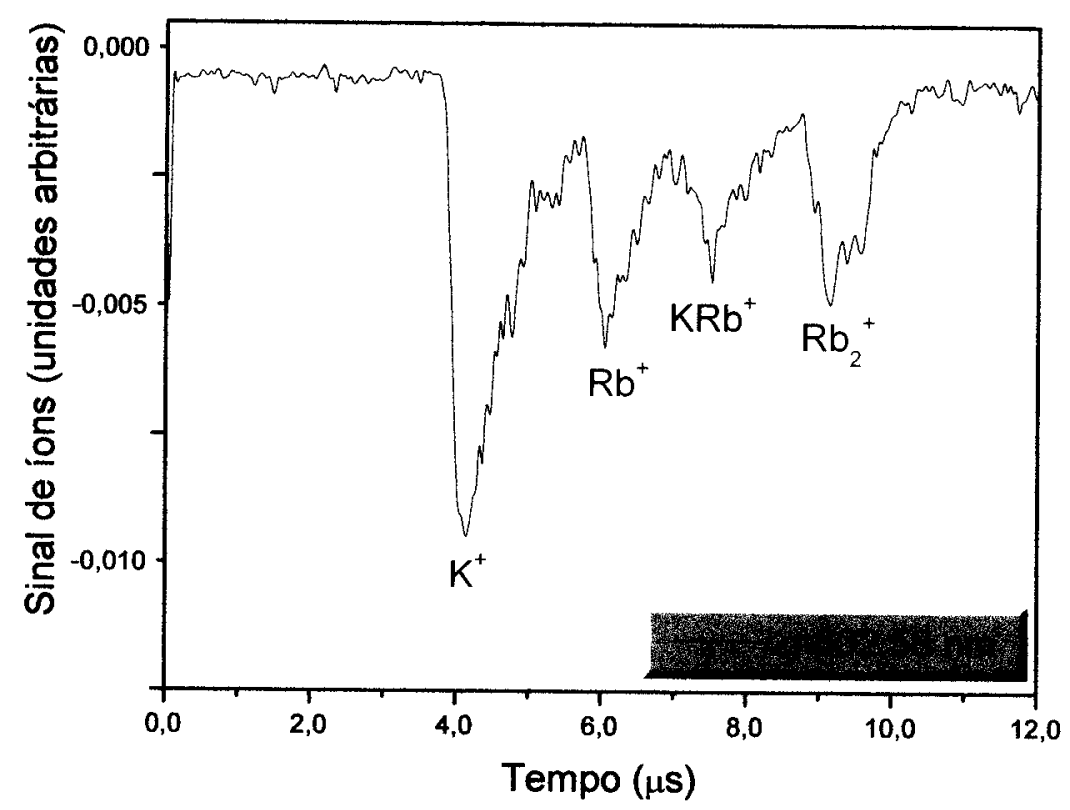

Figura 4.1: Espectro de tempo-de-vôo onde são observados picos de formação de moléculas homonucleares frias conjuntamente à formação de KRb térmicas.

$t_{K R b} / t_{R b 2}=0,826$, e na Fig.4.4 esta razão é igual à 0,805 , mostrando uma ótima concordância com a predição teórica para a posição do pico heteronuclear no espectro de tempo-de-vôo (TOF).

É importante ressaltar que as intensidades relativas entre os picos iônicos homonucleares e heteronuclear dependem fortemente do comprimento de onda do laser pulsado, e no caso heteronuclear depende crucialmente da condição de densidade e de sobreposição entre as amostras, e da optimização da incidência do feixe do laser pulsado na região de interseção.

$\mathrm{Na}$ região da banda difusa do $\mathrm{Rb}_{2}$ onde detectamos a formação de $\mathrm{KRb}$, a produção dessas moléculas ocorre quando o comprimento de onda deste laser em 602,5645 $\mathrm{nm}$, correspondentemente a uma transição de dois fótons quase-ressonante referente 


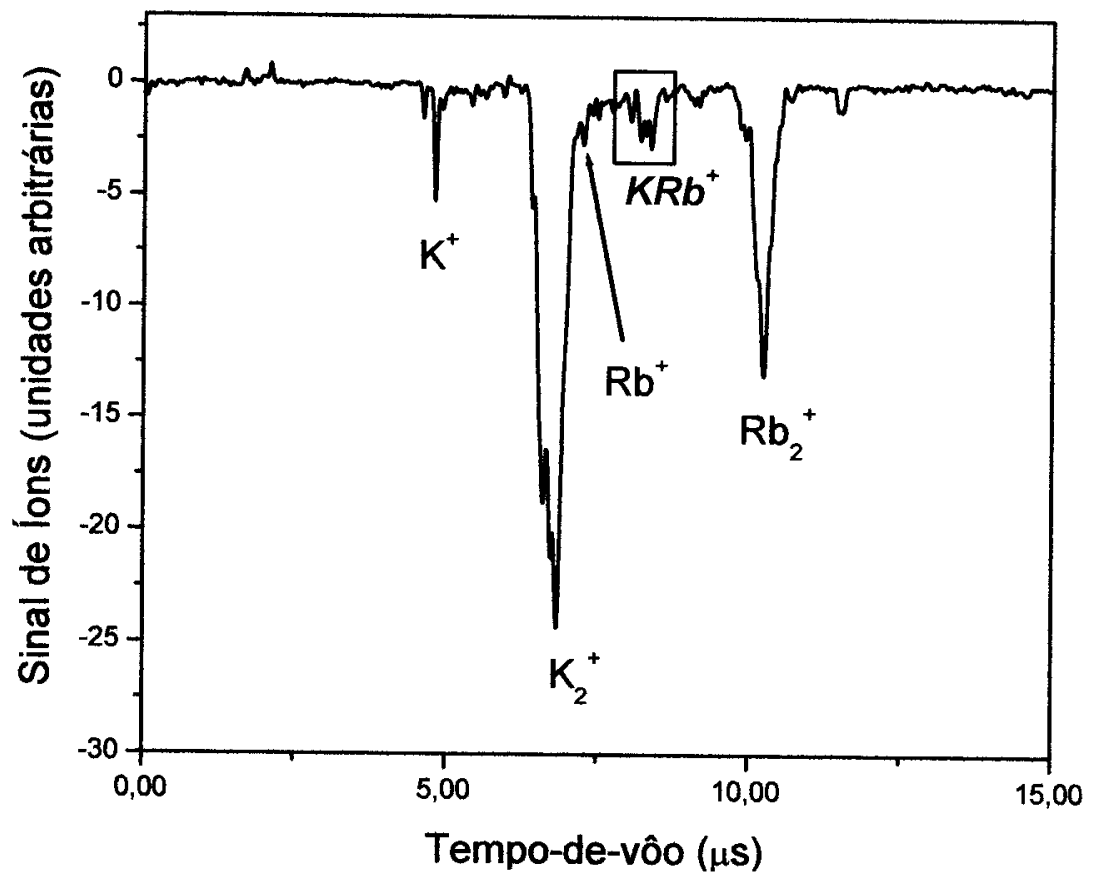

Figura 4.2: Evidência da formação de $\mathrm{KRb}^{+}$frias. Resultados preliminares onde ainda não havia sido comprovada a natureza dos átomos (frios ou térmicos) a partir dos quais se originou neste caso a formação molecular heteronuclear. 


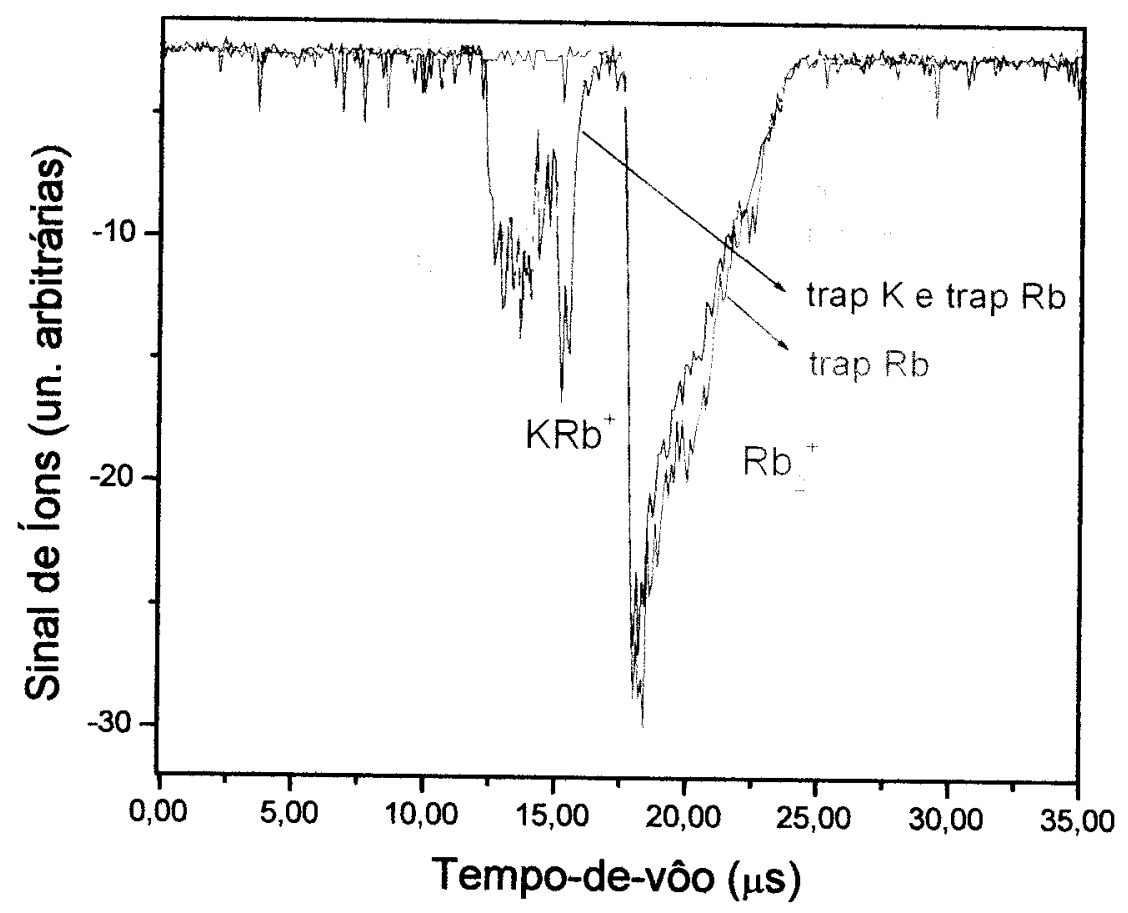

Figura 4.3: Espectro de tempo-de-vôo apresentando os picos iônicos homonucleares $\mathrm{K}_{2}^{+}$e $\mathrm{Rb}_{2}^{+}$e o pico heteronuclear $\mathrm{KRb}^{+}$, que só é observado na presença de ambas as armadilhas, evidenciando o fato de que o sinal é proveniente dos átomos frios de $\mathrm{K} \mathrm{e}$ Rb.

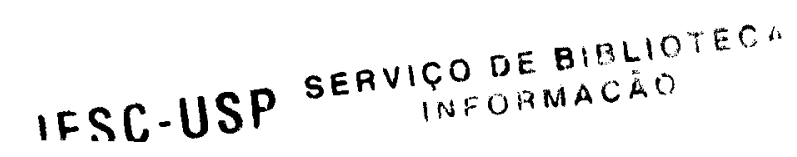




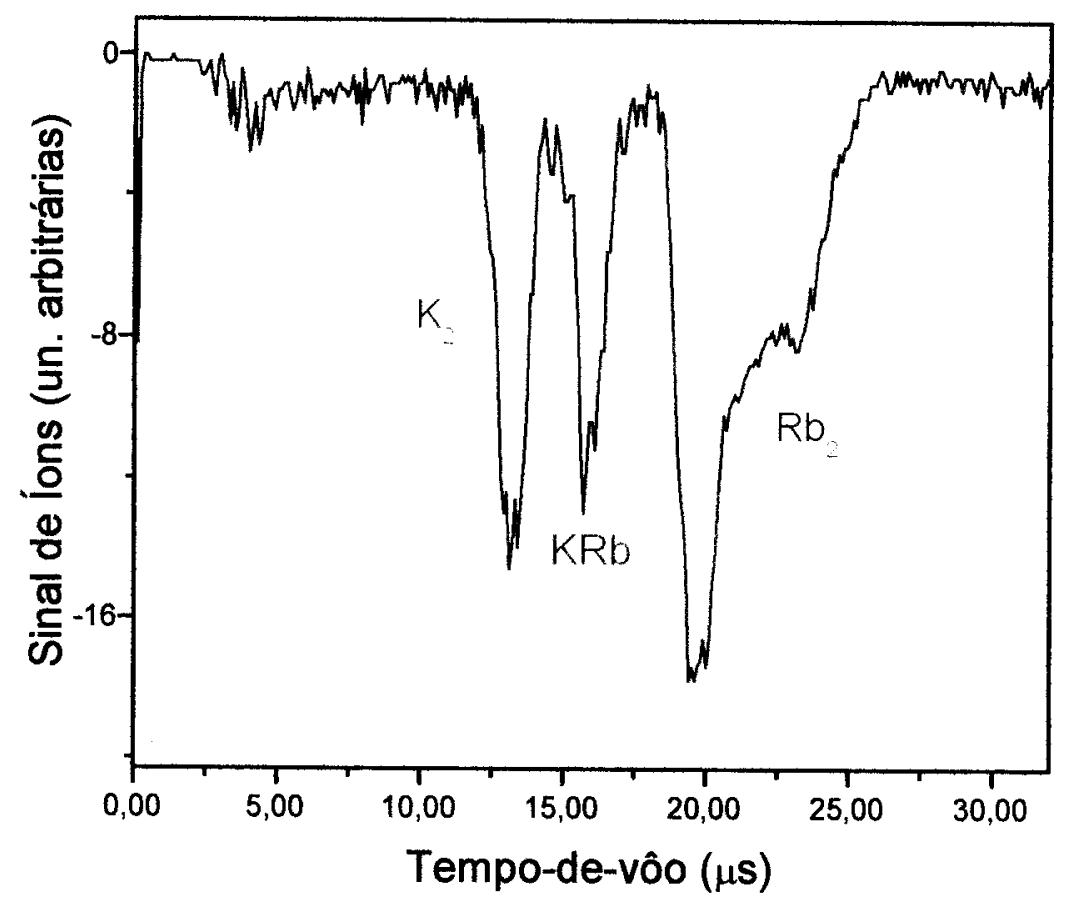

Figura 4.4: Espectro de tempo-de-vôo onde podemos observar claramente o pico iônico heteronuclear $\mathrm{KRb}^{+}$com relação aos homonucleares $\mathrm{K}_{2}^{+}$e $\mathrm{Rb}_{2}^{+}$. 
à transição $5 S_{1 / 2} \rightarrow 16 D_{3 / 2,5 / 2}\left(33180,03 \mathrm{~cm}^{-1}\right)$ do $\mathrm{Rb}$ e $4 S_{1 / 2} \rightarrow 8 D_{3 / 2,5 / 2}$ do $\mathrm{K}$ $\left(33178,36 \mathrm{~cm}^{-1}\right)$.

\subsection{Espectroscopia Molecular na Região da Banda}

\section{Difusa do $\mathbf{R b}_{2}$}

O comprimento de onda para o qual é observada a deteç̧ão de KRb corresponde a aproximadamente $602,6 \mathrm{~nm}$, e foi localizado através da varredura do laser de deteç̧ão na região $600-610 \mathrm{~nm}$.

Abaixo na Fig.4.6, observamos os espectros na região da banda difusa do $\mathrm{Rb}_{2}$ para o próprio $\mathrm{Rb}_{2}$ (para ambos os isótopos, 85 e 87) bem como para $\mathrm{K}_{2}$ e $\mathrm{KRb}$, respectivamente, apenas na região de deteç̧ão de KRb. O pico do KRb corresponde à transição de dois fótons do $\mathrm{Rb} 5 \mathrm{~S}_{1 / 2} \rightarrow 16 \mathrm{D}$ e a do $\mathrm{K} 4 S_{1 / 2} \rightarrow 8 D$.

As ressonâncias observadas nos espectros de íons (Fig.4.5) correspondem aos estados intermediários acessados pela transição de dois fótons de deteç̧ão dos dímeros no estado fundamental molecular. Nos experimentos de absorção realizados em amostras

alcalinas térmicas estes estados são associados à banda difusa dos dímeros alcalinos.

Podemos identificar no espectro abaixo para o rubídio, da esquerda para a direita, as seguintes transições de dois fótons a partir do estado $5 \mathrm{~S}_{1 / 2}$ para os estados de Rydberg: 18D, 17D, 16D, 15D, 14D (da esquerda para a direita). O sexto pico corresponde à transição $5 \mathrm{P}_{3 / 2} \rightarrow 5 \mathrm{~F}$. Na Fig.4.7 temos o espectro de íons para ${ }^{87} \mathrm{Rb}_{2}$. 


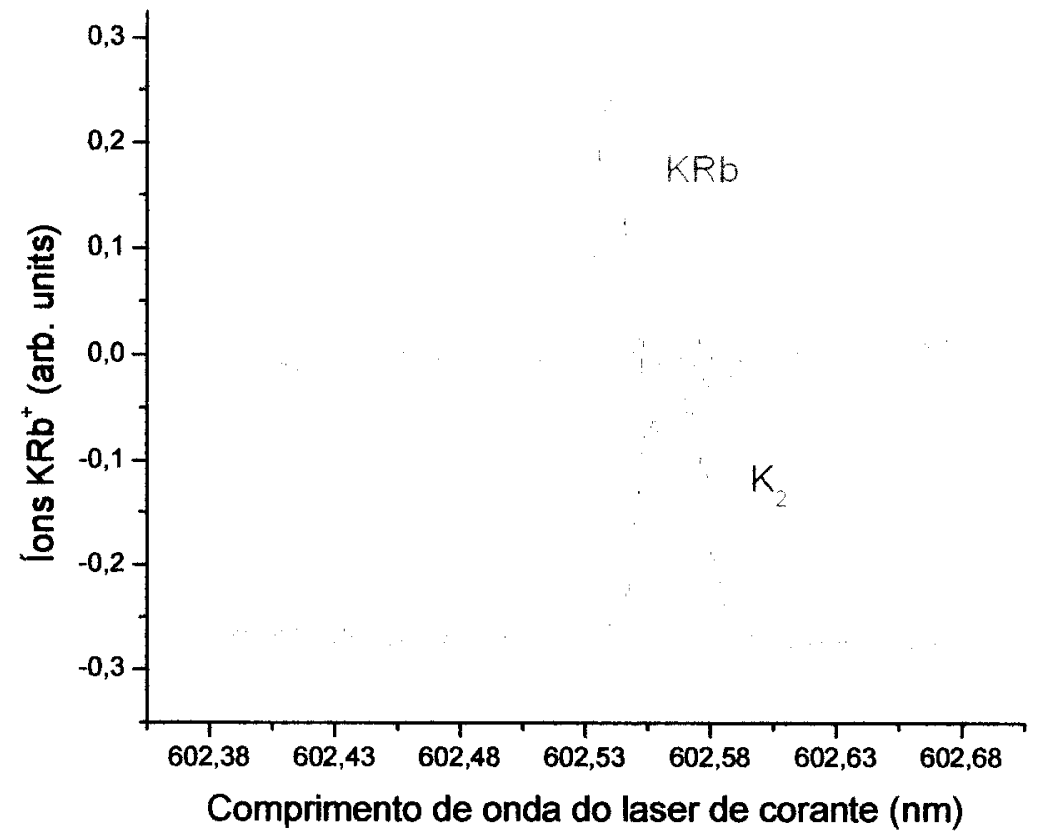

Figura 4.5: Espectro dos estados excitados na banda difusa do $\mathrm{Rb}_{2}$ das moléculas frias $\mathrm{KRb}$ e $\mathrm{K}_{2}$. A energia do estado $\mathrm{K}(8 \mathrm{D})$ é $33178,36 \mathrm{~cm}^{-1}$ e a do estado $\mathrm{Rb}(16 \mathrm{D})$ é $33180,03 \mathrm{~cm}^{-1}$. 




Figura 4.6: Espectro na região da banda difusa do $\mathrm{Rb}_{2}$, para o isótopo ${ }^{85} \mathrm{Rb}$. Na parte superior do gráfico observamos as ressonâncias do sinal iônico, e abaixo, o sinal de fluorescência.

Na Fig.4.9 mostramos os espectros para ${ }^{87} \mathrm{Rb}^{+} \mathrm{e}{ }^{87} \mathrm{Rb}_{2}^{+}$. No trabalho da Ref.[34] os autores mencionam que os íons moleculares ${ }^{87} \mathrm{Rb}_{2}$ só eram observados na presença de um laser de fotoassociação em adição ao de aprisionamento. Outra peculiaridade observada em nossos espectros em comparação ao do grupo italiano, é o fato de que as ressonâncias em nossos espectros moleculares são bem mais estreitas, sendo comparáveis às ressonâncias atômicas no caso do experimento deles. Provavelmente, isto ocorre devido ao nosso laser pulsado ser mais estreito espectralmente comparado ao deles.

Na Fig.4.8 mostramos um esquema de deteção das moléculas de Rb, bem como o esquema de níveis para o aprisionamento de ambos os isótopos, em nosso experimento 




Figura 4.7: Espectro na região da banda difusa do $\mathrm{Rb}_{2}$, para o isótopo ${ }^{87} \mathrm{Rb}$.

de reprodução dos resultados de Gabbanini et al. [34].

$\mathrm{Na}$ ocasião da realização deste experimento, anterior ao de detecção dos dímeros $\mathrm{KRb}$, o aprisionamento de Rubídio, para ambos os isótopos, era realizado por um dos lasers Ti:Safira e o rebombeio pelo segundo Ti:Safira (que viria a ser usado para aprisionar Potássio), sintonizado na linha D1, conforme no experimento dos italianos.

- Um fato bastante interessante e curioso com relação a comparação entre os nossos resultados e aqueles obtidos por Gabbanini e colaboradores é o fato de que o espectro para o caso do ${ }^{87} \mathrm{Rb}$ foi no caso deles apenas observado em presença do laser de fotoassociação (prova). Em nosso experimento moléculas ${ }^{87} \mathrm{Rb}_{2}$ podem ser observadas mesmo apenas na presença do laser de aprisionamento, sendo portanto fotoassociadas 


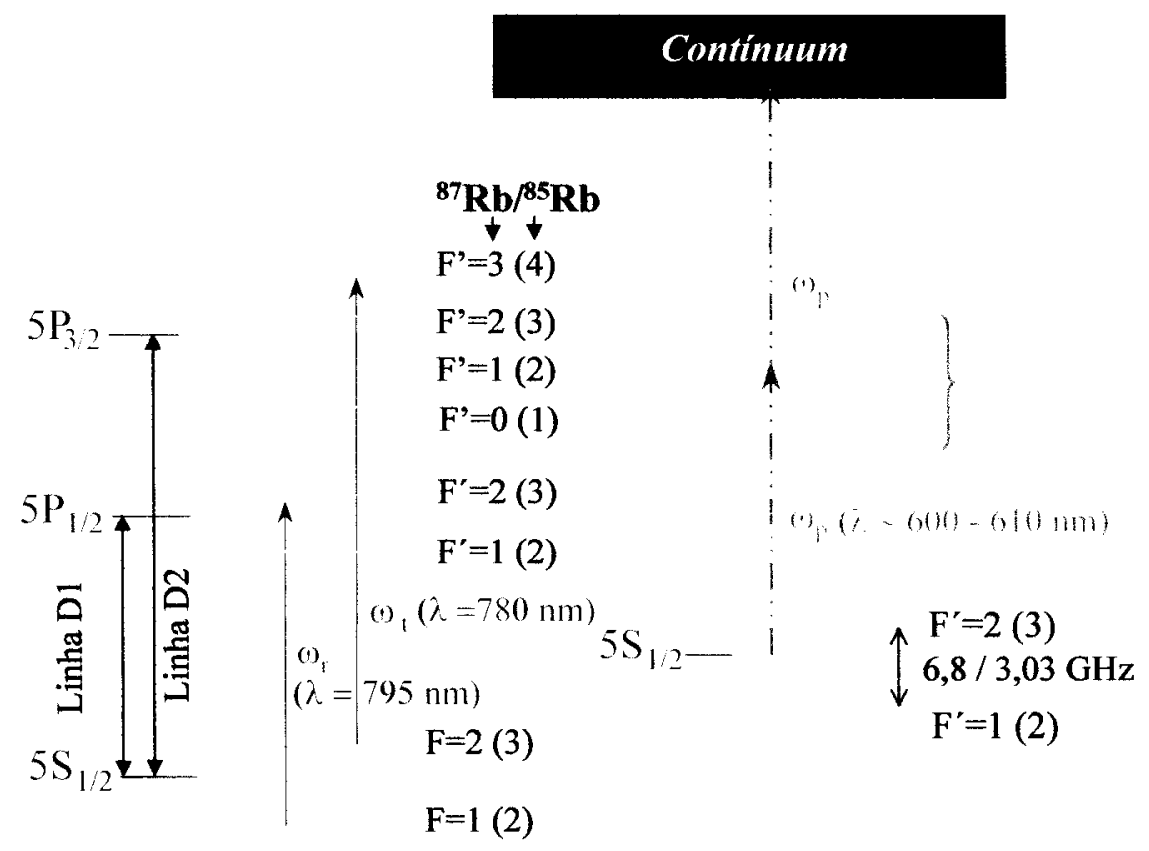

Figura 4.8: Esquema de aprisionamento de ${ }^{85} \mathrm{Rb}^{87} \mathrm{Rb}$ e de deteç̧ão de $\mathrm{Rb}_{2}$ a partir do estado fundamental $5 \mathrm{~S}_{1 / 2}$.

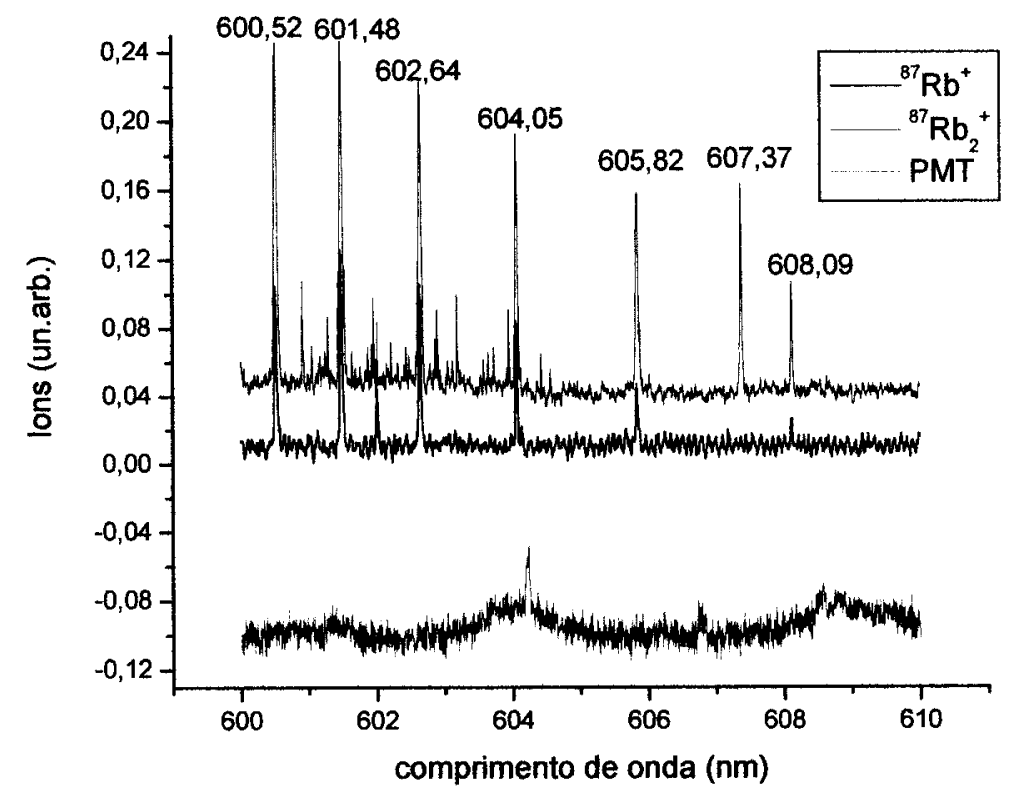

Figura 4.9: Gráfico mostrando a comparação entre os espectros moleculares contendo as ressonâncias relativas aos estados excitados da banda difusa do ${ }^{87} \mathrm{Rb}_{2},{ }^{87} \mathrm{Rb}$. 
pela freqüencia fornecida por este laser. A diferença básica entre nosso experimento e o dos italianos reside nas potências de aprisionamento. No caso deles, bastante moderada $(50 \mathrm{~mW})$ fornecida por um laser de diodo, enquanto nosso Ti:Safira fornecia neste experimento $500 \mathrm{~mW}$ disponíveis para aprisionamento.

Neste trabalho no qual estudamos formação de moléculas heteronucleares KRb frias no estado fundamental formadas a partir da fotoassociação de átomos de ${ }^{85} \mathrm{Rb} e$ ${ }^{39} \mathrm{~K}$ colidindo em uma armadilha magneto-óptica mista bem como as homonucleares, $\mathrm{K}_{2}$ e $\mathrm{Rb}_{2}$, caracterizamos-as referentemente ao estado molecular no qual são formadas, com relação à sua temperatura translacional, e a taxa de formação. Vejamos nas seções abaixo os procedimentos utilizados.

Nas seções abaixo, poderão ser observados os resultados concernentes à caracterização das moléculas hetero e homonucleares frias em nosso MOT misto de $\mathrm{K}$ e $\mathrm{Rb}$.

\subsection{Medida da Temperatura Translacional Mole-}

\section{cular}

Nesta seção são apresentados os resultados experimentais que comprovam que as moléculas KRb produzidas em nossos experimentos são frias, apresentando temperaturas compatíveis com as temperaturas dos átomos aprisionados.

A temperatura das moléculas foi determinada a partir de medidas experimen- 
tais da expansão da nuvem molecular como função do tempo de desligamento das armadilhas. As moléculas formadas não entram no esquema de aprisionamento e saem da região de aprisionamento atômico pela expansão da amostra na presença da gravidade.

Nossa técnica de medida da temperatura molecular é similar a que pode ser utilizada para determinar a temperatura dos átomos aprisionados. Existem também outras técnicas de medida da temperatura de uma amostra atômica, como por exemplo, utilizando a técnica de imagens por absorção da nuvem de átomos frios, muito utilizada em armadilhas magnéticas e puramente ópticas. A técnica de imagem por absorção consiste na aquisição da imagem em uma CCD da sombra impressa pela amostra num feixe quase-ressonante. Para o nosso caso utilizamos a técnica de imagem por fluorescência, onde necessitamos apenas de uma câmara CCD. As resoluções de ambos os métodos são similares. Evidentemente, entretanto, a técnica de imagem por absorção não pode ser utilizada para medir a temperatura de moléculas.

Os resultados experimentais da expansão da amostra foram ajustados por resultados teóricos fornecidos por uma simulação numérica simples. Na simulação, os átomos . na amostra apresentam distribuições espaciais e de velocidades (Maxwell-Boltzmann) gaussianas. Aos átomos são atribuídas posições e velocidades aleatoriamente. A expansão balística da nuvem molecular é então assumida como acontecendo dentro de uma região compatível com o tamanho dos MOTs acessados pelo laser de deteç̧ão. Esta simulação não leva em consideração a queda das moléculas pela ação da gravi- 
dade. Os resultados podem ser observados nos gráficos mostrados nas Figs.4.10, 4.11, 4.12, 4.13 abaixo, para as moléculas $\mathrm{K}_{2}, \mathrm{Rb}_{2}$, e $\mathrm{KRb}$, respectivamente.

A temperatura da nuvem molecular também foi inferida através do ajuste dos dados experimentais por uma expressão [86] originalmente obtida para determinar a temperatura atômica de átomos aprisionados, e pudemos prontamente adaptá-la para o nosso caso.

Na expressão utilizada, é considerada a expansão balística das moléculas e também a queda das moléculas na região dos MOTs pela ação da aceleração da gravidade. A expressão que utilizamos para ajustar teoricamente os nossos dados tem a seguinte forma:

$$
C(t)=C(0) \frac{\tau_{r}^{2}}{\tau_{r}^{2}+t^{2}} \exp \left[-\frac{t^{4}}{\tau_{g}^{2}\left(\tau_{r}^{2}+t^{2}\right)}\right]
$$

A expansão balística da amostra é representada por uma função Lorentziana, e o efeito da gravidade é descrito através de uma função exponencial. O tempo característico $\tau_{r}$ é o tempo que as moléculas com temperatura $\mathrm{T}_{m}$ e velocidade média $\sigma_{v}=\sqrt{k_{B} T_{m} / m}$, levam para "voar" através da amostra de raio $\sigma_{r}$ dado por:

$$
\tau_{r}=\frac{\sigma_{r}}{\sigma_{v}}
$$

O segundo tempo característico da expressão, correspondente ao tempo gasto pelas moléculas caindo sob a ação da aceleração da gravidade para adquirirem uma velocidade igual a $2 \sqrt{2}$ da velocidade inicial, é: 


$$
\tau_{g}=\frac{2 \sqrt{2} \sigma_{v}}{g}
$$

onde a aceleração da gravidade é $\mathrm{g}=9,80665 \mathrm{~m} \mathrm{~s}^{-1}$. Os resultados do ajuste pela expressão acima podem ser observados na Fig.4.14. Através destes ajustes foram determinadas as seguintes temperaturas: $T_{K_{2}} \approx 200 \mu K, T_{R b_{2}} \approx 60 \mu K$ e $T_{K R b} \approx$ $150 \mu K$.Os resultados obtidos utilizando-se os dois métodos para inferir a temperatura, obviamente diferem, conforme pode ser observado dos resultados.

É muito importante ressaltar que o procedimento de medida da temperatura é fortemente dependente do alinhamento dos feixes dos lasers de aprisionamento, conforme podemos observar nos resultados para a temperatura das moléculas KRb. Isto também foi observado pelo grupo do NIST, nas medidas de temperatura em optical molasses [87]. Após realizarmos uma série de medidas, para diferentes condições de alinhamento, pudemos observar que no caso das moléculas $\mathrm{K}_{2}$ e $\mathrm{Rb}_{2}$, quanto mais regular a amostra, melhor a curva de decaimento e a temperatura determinada.

Em especial, quando realizamos a medida da temperatura das nuvens moleculares homonucleares, notamos que quando obtínhamos a curva de decaimento quando am-

- bas as amostras estavam presentes (amostras menos esféricas devido ao procedimento de overlap das mesmas), a temperatura fornecida era mais alta do que para amostras sozinhas e bastante esféricas, que apresentaram temperaturas bem mais frias. Isto nos indica que em amostras mais esféricas, o processo de resfriamento (força dissipativa do MOT) é mais eficiente, devido ao alinhamento mais balanceado em todas as 
direções de aprisionamento.

Os íons moleculares (dados experimentais) que aparecem nos gráficos abaixo, Figs.4.10, 4.11, 4.12, 4.13, referentes às medidas da temperatura molecular são resultado da integração do sinal de íons na região relativa ao pico de interesse, $\mathrm{KRb}^{+}$. O procedimento de análise dos dados influencia fortemente tanto na qualidade quanto na confiabilidade dos resultados. O procedimento de análise através do sinal de íons nos espectros de tempos de vôo foram feitos através de três diferentes formas: (a) considerando os valores fornecidos pelo boxcar para o número de íons (fornecido em un. arbitrárias); (b) considerando a intensidade dos picos moleculares; e (c) pela área, obtida pela integração do sinal iônico na região de interesse.

O procedimento utilizando integração do sinal iônico forneceu melhores resultados para o KRb se comparado aos valores fornecidos diretamente pelo boxcar, que são resultantes de médias e integração do sinal compreendido na região temporal da gate do integrador e aqueles tomando apenas a intensidade (amplitude) do sinal iônico. Com relação ao procedimento utilizando integração do sinal, observamos que quanto mais estreita for a "janela temporal" que escolhermos para calcular a área, resultados . mais confiáveis são obtidos. Isto devido ao fato que assim não estaríamos contando a contribuição dos sinais iônicos homonucleares do espectro de tempo-de-vôo quando por exemplo selecionávamos a região no espectro compreendida pelo pico do KRb. Assim, escolhendo sempre uma região temporal estreita e fixa, a partir da posição central do pico heteronuclear, obtínhamos um resultado em que podíamos confiar. 
Podemos notar que no caso da curva de decaimento para as moléculas heteronucleares, o tempo de desligamento das armadilhas é menor que o tempo que podíamos desligar as armadilhas para o caso em que medíamos as temperaturas das moléculas homonucleares. Isso ocorre pois devido ao sinal referente às moléculas KRb depender bastante de densidades bastante razoáveis dos dois traps, de modo que desligando-se as armadilhas a intensidade do pico referente no espectro de tempo de vôo rapidamente diminuía até tornar-se um sinal bastante pequeno e com variações quase imperceptíveis. Estamos atualmente construindo uma nova montagem experimental onde será possível obter-se melhores condições de vácuo que nos permitam a obtenção de amostras mais densas, uma vez que um grande limitante a maiores densidades são as colisões com o gás residual de fundo presente na câmara de aprisionamento.

Para que no caso das amostras homonucleares tempos de desligamento das armadilhas mais longos fossem obtidos, ótimas condições de alinhamento para assegurar-se as melhores densidades possíveis eram requeridas. Procedemos ao alinhamento visando ótimas densidades observando as amostras em uma CCD de alta resolução que permite que o tempo de exposição seja variado. Quanto melhor alinhamos os feixes de aprisionamento para baixos tempos de exposição da câmara (tempos de apenas 30 $\mathrm{ms}$ ), conseguimos os melhores resultados com relação às densidades e sobreposições e portanto dos dados experimentais obtidos. No caso das amostras homonucleares, as curvas de decaimento apresentadas nas Figs.4.10 e 4.11 utilizamos o procedimento de análise dos resultados baseado nos valores do número de íons fornecidos pelo boxcar. 


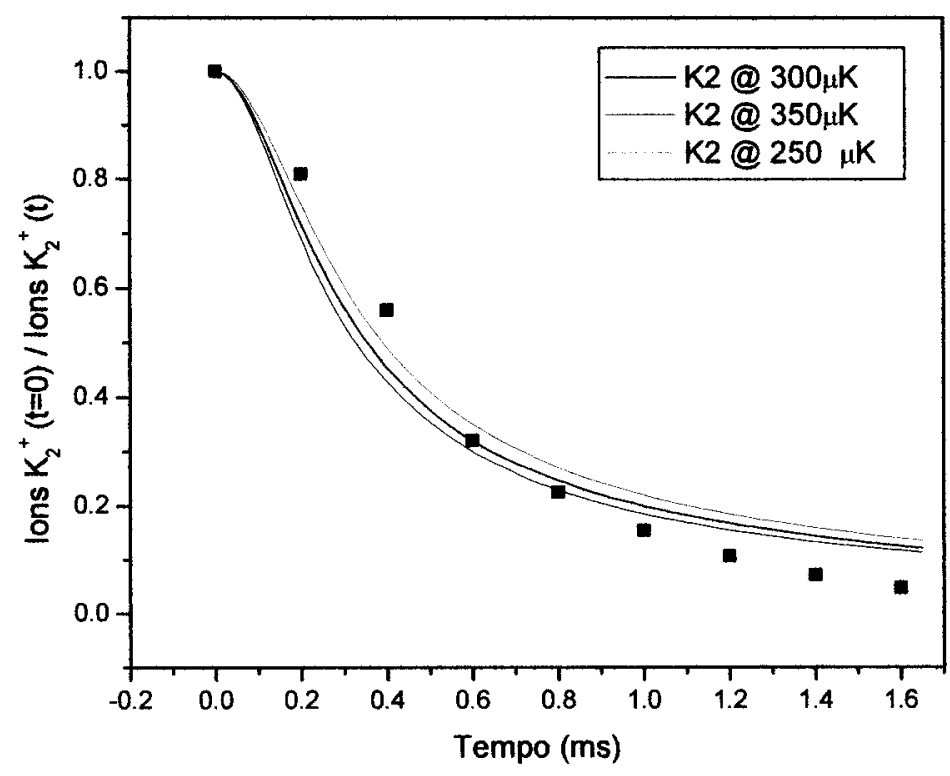

Figura 4.10: Íons moleculares $\mathrm{K}_{2}^{+}$como função do tempo de atraso entre o pulso de detecção e o desligamento da armadilha. As linhas contínuas são resultados de uma simulação numérica.

Os procedimentos acima levam a resultados similares quando o sinal de íons é grande.

Isto foi observado claramente para o caso das amostras homonucleares.

A partir das temperaturas translacionais obtidas para as moléculas formadas em nossa armadilha, podemos inferir as velocidades quadráticas médias a elas associadas, com a qual deixam a região onde são formadas,

$$
\bar{v}=\sqrt{\frac{3 k_{B} T}{m_{A B}}} .
$$

Obtemos então as seguintes velocidades médias: $v_{K R b}(150 \mu \mathrm{K}) \simeq 17,4 \mathrm{~cm} / \mathrm{s}$, $v_{R b_{2}}(90 \mu \mathrm{K}) \simeq 11,5 \mathrm{~cm} / \mathrm{s}$, e $v_{K 2}(250 \mu \mathrm{K}) \simeq 28,3 \mathrm{~cm} / \mathrm{s}$. Note que a molécula mais leve é mais veloz do que as mais pesadas, como deveria ser.

A fim de checarmos a validade dos resultados experimentais obtidos para as tem- 


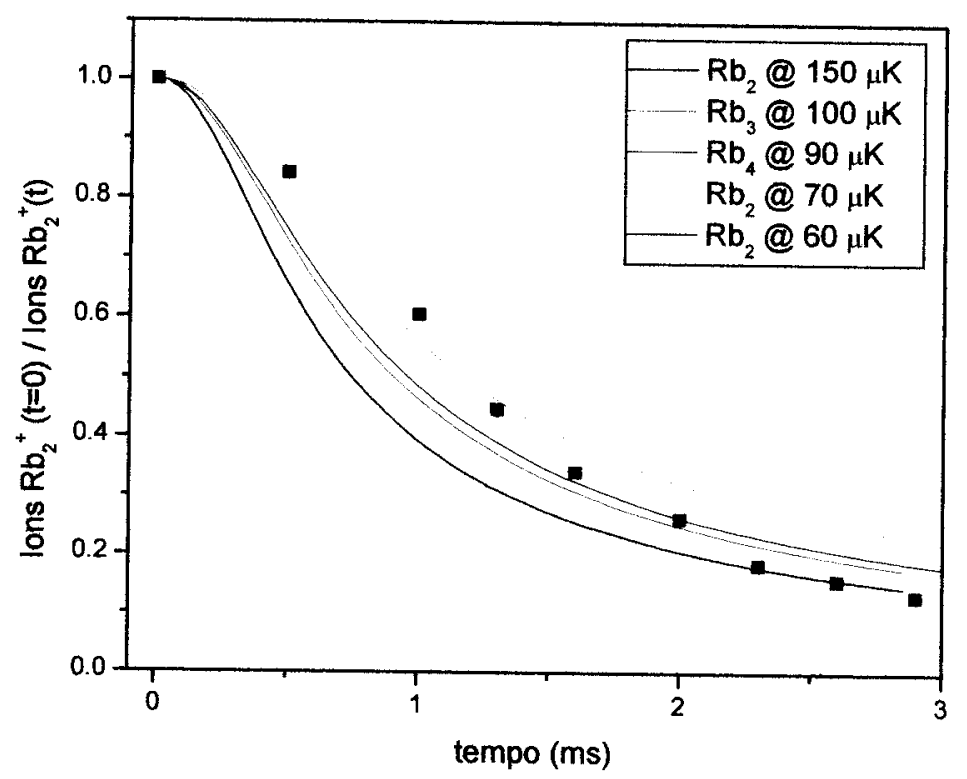

Figura 4.11: Íons moleculares $\mathrm{Rb}_{2}^{+}$como função do tempo de atraso entre o pulso de detecção e o desligamento da armadilha. As linhas contínuas são resultados de uma simulação numérica para várias temperaturas.

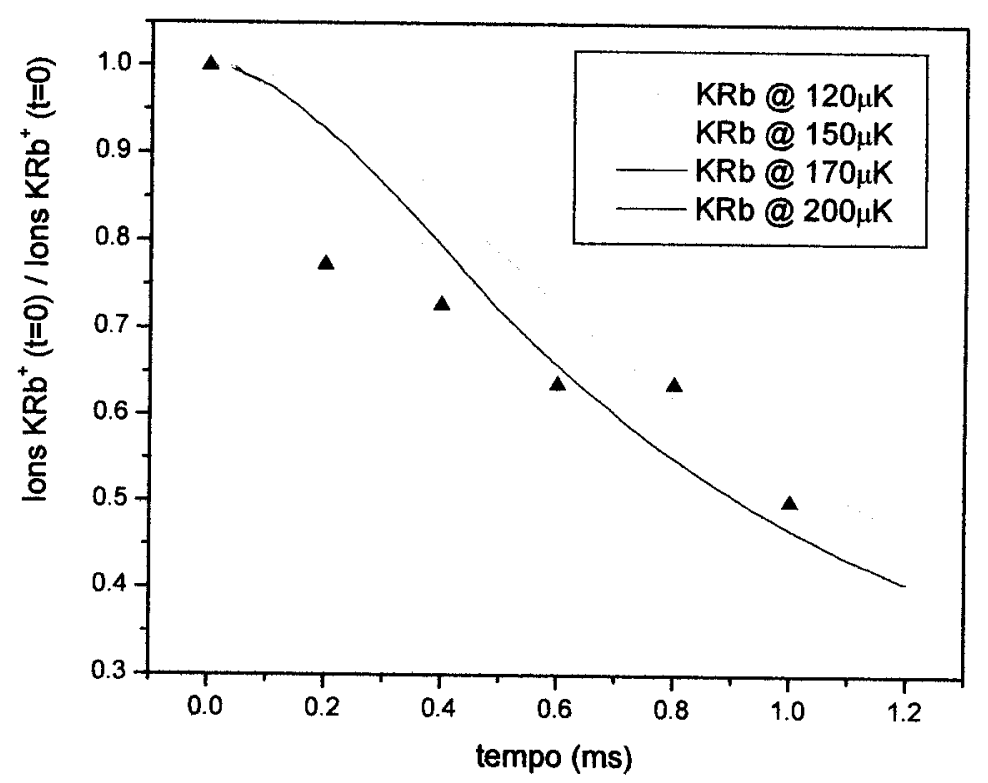

Figura 4.12: Íons moleculares $\mathrm{KRb}^{+}$como função do tempo de atraso entre o pulso de ionização e o desligamento das armadilhas de $\mathrm{K}$ e $\mathrm{Rb}$. As linhas contínuas são resultados de uma simulação numérica. 


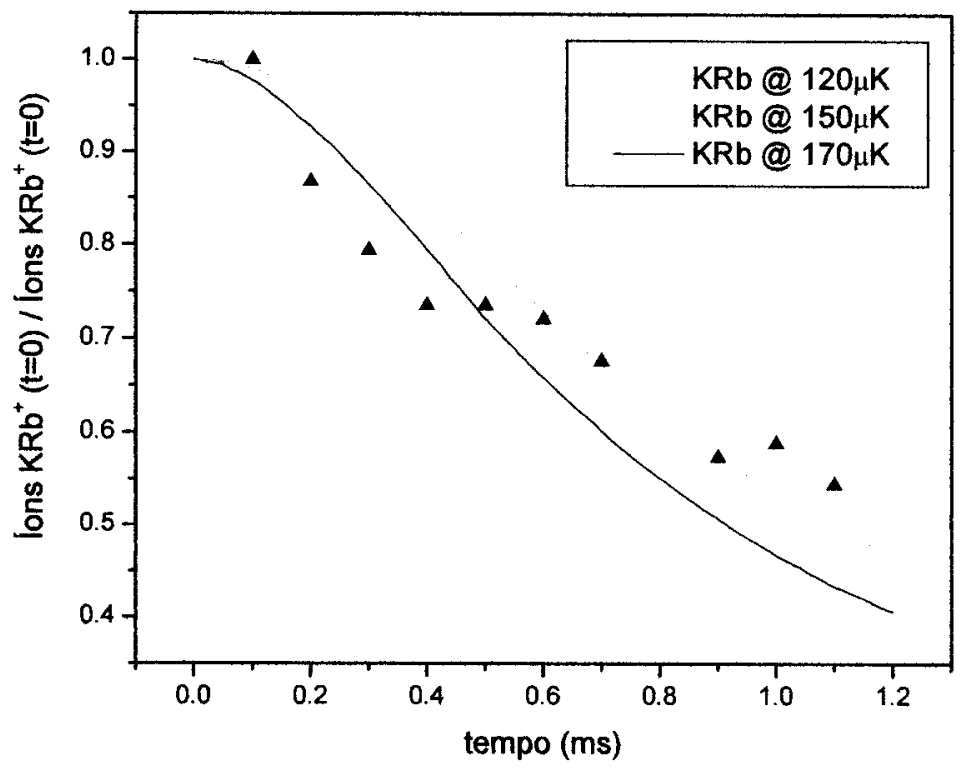

Figura 4.13: Íons moleculares $\mathrm{KRb}^{+}$como função do tempo de atraso entre o pulso de ionização e o desligamento das armadilhas de $\mathrm{K}$ e $\mathrm{Rb}$ para outra medida, em uma diferente condição de overlap. Podemos observar que distintas condições de alinhamento produzem diferentes resultados para a medida da temperatura molecular. 


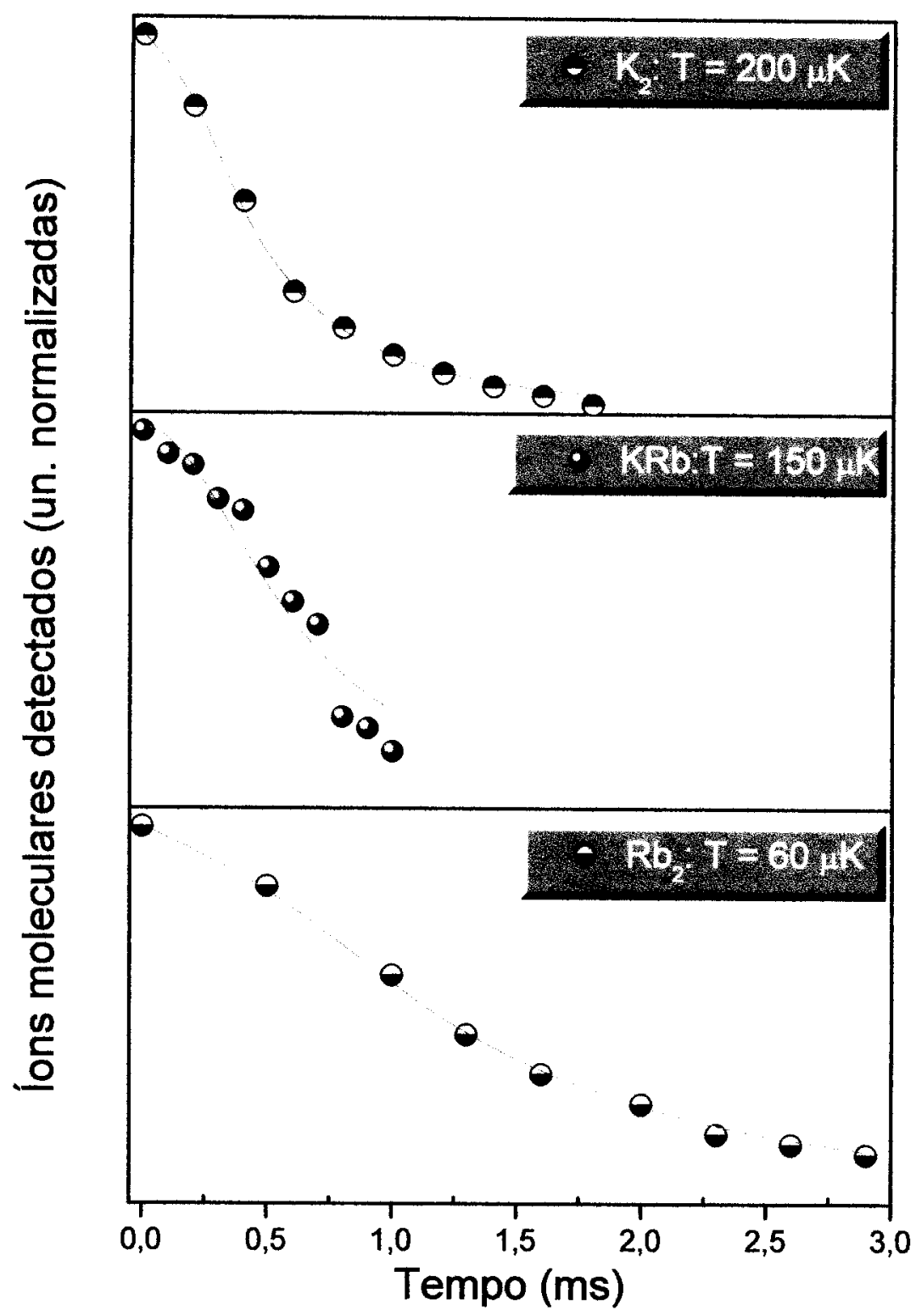

Figura 4.14: Íons moleculares homonucleares $\mathrm{K}_{2}^{+}$e $\mathrm{Rb}_{2}^{+}$e hetronucleares $\mathrm{KRb}^{+}$como função do tempo de desligamento das armadilhas. As linhas contínuas correspondem ao ajuste pela expressão analítica de Lambrecht et al. 
peraturas tranlacionais das moléculas frias produzidas em nosso MOT, podemos estimar teoricamente este valor considerando uma colisão onde um átomo de $\mathrm{Rb}$ e um átomo de $\mathrm{K}$ colidem inelasticamente formando uma molécula KRb. A temperatura estimada utilizando conservação do momentum em tal colisão nos fornece para o par KRb a temperatura $T_{K R b} \simeq 280 \mu \mathrm{K}$, em concordância satisfatória com a temperatura estimada experimentalmente, $T_{K R b} \simeq 150 \mu \mathrm{K}$, por tratar-se de um cálculo simples, usando para os valores das temperaturas atômicas os valores das respectivas temperaturas moleculares.

\subsection{Mecanismo de Formação Molecular Homonu- clear}

Apresentamos nesta seção, resultados para a formação de moléculas frias homonucleares, $\mathrm{K}_{2}$ e $\mathrm{Rb}_{2}$ em nossa armadilha, detectadas conjuntamente às moléculas $\mathrm{KRb}$. Nos gráficos abaixo observamos os resultados obtidos para as amostras homonucleares concernentemente às medidas experimentais do número de íons moleculares com re- lação à intensidade do laser de deteção (Figs.4.15 e 4.16) e variando a densidade atômica, Figs.4.17 e 4.18.

Utilizamos nestes experimentos de detecção das moléculas homonucleares o mesmo comprimento de onda de deteção do $\operatorname{KRb}(\lambda=602,56 \mathrm{~nm})$. Obviamente, se selecionarmos o comprimento de onda do corante ressonantemente com as transições 


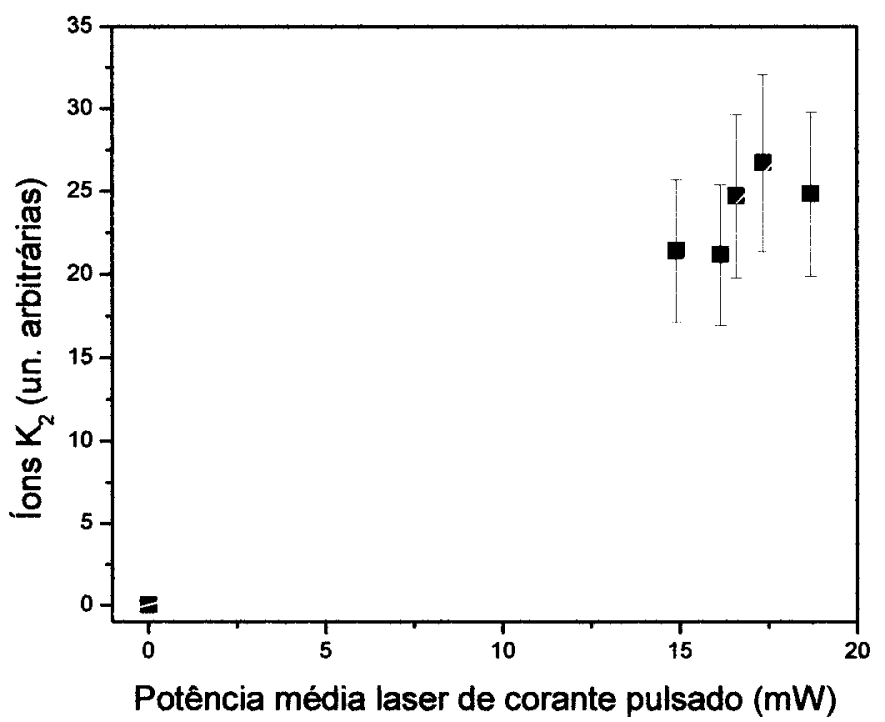

Figura 4.15: Íons moleculares $\mathrm{K}_{2}^{+}$como função da intensidade do laser de corante pulsado. Acima da potência média de $18 \mathrm{~mW} / \mathrm{cm}^{2}$ podemos notar que ocorre saturação.

moleculares mais intensas destes dois alcalinos, obtemos maiores sinais iônicos, principalmente para o caso do potássio. Podemos observar nos gráficos da Fig.4.15 $\left(\mathrm{K}_{2}\right)$ e Fig.4.16 $\left(\mathrm{Rb}_{2}\right)$ a dependência quadrática do sinal iônico com a potência do laser de corante, indicando que os dímeros $\mathrm{K}_{2}$ e $\mathrm{Rb}_{2}$ são detectados no estado fundamental, sendo portanto a transição de deteç̧ão uma transição de dois fótons e desta maneira o sinal de íons moleculares apresenta um comportamento quadrático com a intensidade . do laser pulsado.

No gráfico da Fig.4.17 mostramos a variação do sinal iônico $\mathrm{K}_{2}^{+}$com a densidade $\mathrm{n}_{K}$. O comportamento linear dos dados nos confirma que as moléculas advêm de colisões binárias. Na Fig.4.18 também podemos observar a variação do sinal iônico $\mathrm{Rb}_{2}^{+}$com a densidade $\mathrm{n}_{R b}$. O coeficiente também é linear. 


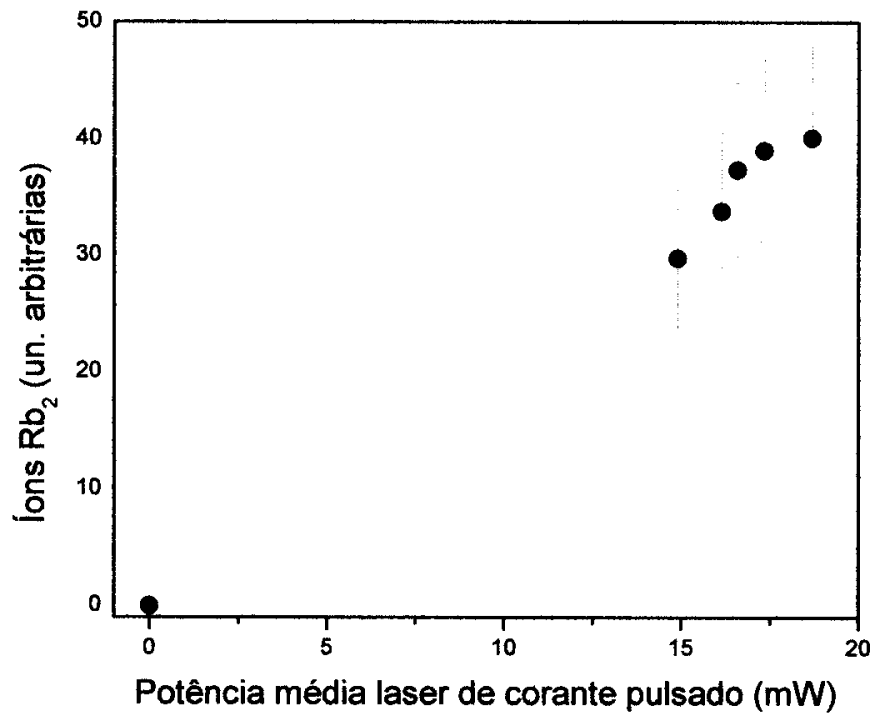

Figura 4.16: fons moleculares $\mathrm{Rb}_{2}^{+}$como função da intensidade do laser de corante pulsado. Podemos observar a dependência quadrática, a qual indica a ionização como sendo um processo de dois fótons a partir do estado fundamental.Acima da potência média de $18 \mathrm{~mW} / \mathrm{cm}^{2}$ podemos notar que ocorre saturação.

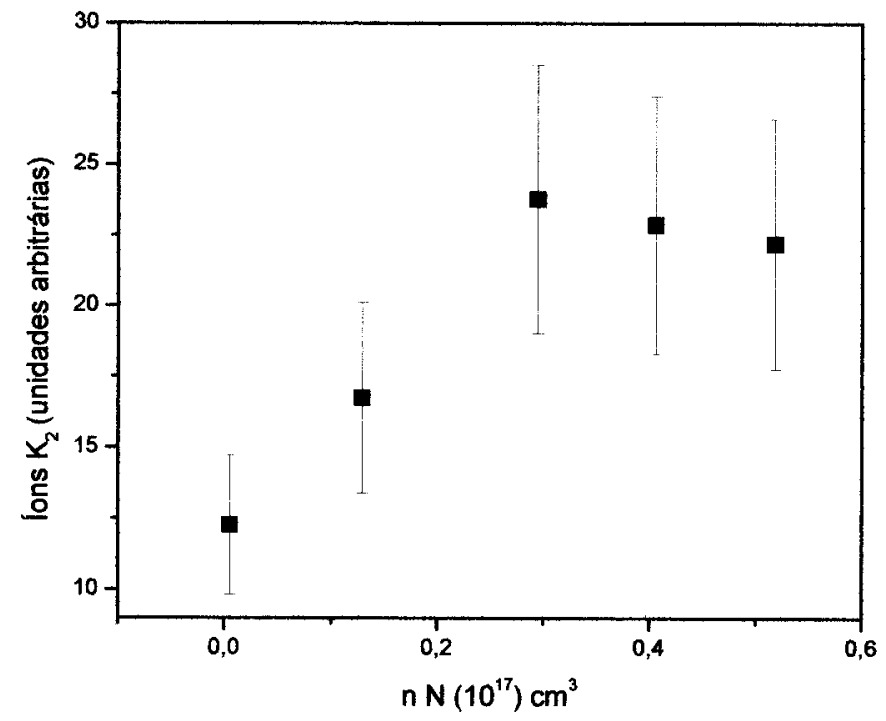

Figura 4.17: Íons moleculares $\mathrm{K}_{2}^{+}$como função da densidade atômica de pico da armadilha de $\mathrm{K}$. 


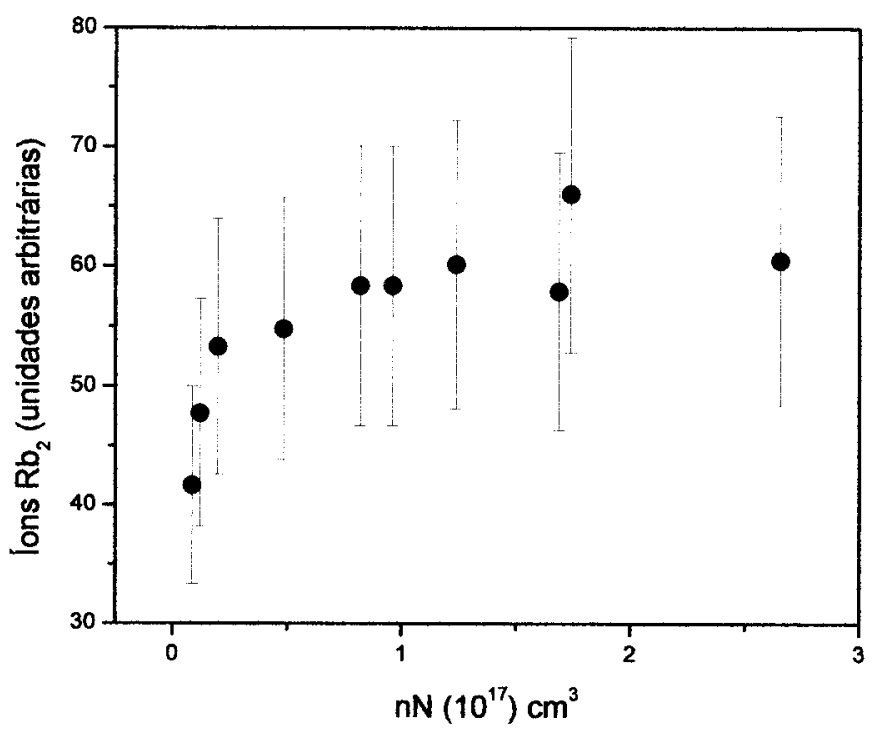

Figura 4.18: Íons moleculares $\mathrm{Rb}_{2}^{+}$como função da densidade atômica da armadilha de Rb.

\subsection{Taxas de Formação Homonucleares}

Partindo da hipótese de formação molecular via colisões binárias evidenciada pelos resultados mostrados acima, podemos propor que o processo de formação molecular que estamos estudando seja governado pela seguinte equação de taxa:

$$
\frac{1}{V} \frac{d n}{d t}=R n^{2}
$$

onde $n$ é a densidade de íons moleculares, $V$ é o volume efetivo de ionização (correspondente à porção da amostra acessada pelo laser de ionização) e $R$ é a constante de taxa.

Para o K a largura do pico iônico é aproximadamente 1,3 $\mu$ s (observe a Fig.4.4), o tempo de interação com o laser de ionização é 3ms, portanto temos a deteç̧ão de 
aproximadamente 9 moléculas/pulso, e obtemos a seguinte taxa de formação:

$$
\dot{K}_{2}^{+} \approx 1,12 \times 10^{4} \mathrm{~s}^{-1}
$$

Para o Rb, considerando a largura do pico iônico de $3,2 \mu$ s e um tempo de interação com o laser pulsado de $3 \mathrm{~ms}$, obtemos 20 moléculas/pulso, seguindo a taxa de formação molecular abaixo:

$$
\dot{R} b_{2}^{+} \approx 1,40 \times 10^{4} \mathrm{~s}^{-1}
$$

Considerando-se a formação das moléculas através de colisões binárias, determinamos a constante de formação das moléculas homonucleares utilizando a seguinte equação:

$$
\frac{1}{V} \frac{d I\left(A_{2}^{+}\right)}{d t}=R_{A} n_{A}^{2}
$$

onde o índice A representa a espécie atômica para a qual queremos determinar a constante de formação molecular.

A constante de formação homonucleares para $\mathrm{Rb}_{2}$ e para $\mathrm{K}_{2}$ ficam portanto:

$$
\begin{aligned}
& R_{R b 2} \simeq 4,5 \times 10^{-13} \mathrm{~cm}^{3} / \mathrm{s} . \\
& R_{K_{2}} \simeq 3,5 \times 10^{-13} \mathrm{~cm}^{3} / \mathrm{s} .
\end{aligned}
$$

A comparação dos valores para as taxas de formação de moléculas diatômicas homonucleares com os valores da literaura é satisfatória [35, 34]. 


\subsection{Mecanismos de Formação Molecular Heteronu-} clear

Nesta seção, apresentaremos os resultados que mostram que as moléculas frias KRb originadas por fotoassociação são detectadas no estado fundamental. Isto foi comprovado pelo fato que o sinal relativo às moléculas heteronucleares ionizadas, $\mathrm{KRb}^{+}$, apresentam um comportamento quadrático com a intensidade do laser de detecção (laser de corante pulsado), e também pelo fato de podermos desligar as armadilhas durante longos tempos, da ordem de vários ms (observe os gráficos da temperatura) e ainda observarmos o sinal iônico molecular. Caso contrário, se as moléculas estivessem no estado excitado, que apresentam tempos de vida da ordem de poucas dezenas de nanossegundos, não teríamos a observação de sinal iônico por tanto tempo após o desligamento dos MOTs.

A detecção das moléculas é realizada durante os intervalos de tempo durante os quais as armadilhas eram desligadas. O desligamento dos MOTs no experimento é realizado através do desligamento do laser de rebombeio durante intervalos da ordem de ms, o que faz com que o estado fundamental de mais baixa energia seja populado e sendo este um estado não interagente com o campo do laser, o número de átomos no estado excitado é então diminuído. Isto ocorre porque este intervalo de desligamento dos MOTs é bem superior aos tempos de vida dos estados excitados $\mathrm{K}\left(4 \mathrm{P}_{3 / 2}\right)(\tau=26,13 \mathrm{~ns})$ e $\mathrm{Rb}\left(5 \mathrm{P}_{3 / 2}\right)(\tau=26,63 \mathrm{~ns})$. Desta maneira, garantimos 
que as moléculas ionizadas são provenientes do estado fundamental e não do estado excitado.

As moléculas heteronucleares, bem como as homonucleares são, portanto, provenientes dos estados fundamentais moleculares tripleto (como observado para as moléculas de Rb por Fioretti[45] e por nós, e por Takekoshi para Cs[39]), ou singleto, pois o delay (em ms) entre o pulso de ionização e o desligamento dos MOTs, é muito maior do que o tempo de vida do primeiro estado molecular excitado populado pelos lasers de aprisionamento.

O experimento que realizamos para certificarmo-nos de que as moléculas heteronucleares são de fato detectadas no estado molecular fundamental consistiu na observação do sinal iônico heteronuclear com a variação da intensidade do laser de ionização, conforme pode ser observado na Fig.4.19.

Este resultado mostra, inequivocamente, que a ionização das moléculas KRb, que a priori supusemos como sendo formadas por fotoassociação pelo laser de aprisionamento do $\mathrm{Rb}$ e subsequente decaimento espontâneo para o estado fundamental, realmente procede através de uma transição de dois fótons de mesmo comprimento .de onda provenientes do laser de corante pulsado à partir do estado molecular fundamental em direção a estados vibracionais do estado eletrônico da molécula $\mathrm{KRb}^{+}$ correlacionado à assíntota $\mathrm{K}(4 \mathrm{~S})+\mathrm{Rb}^{+}+e^{-}$. Isto portanto corrobora o nosso esquema proposto para a formação molecular.

O esquema de formação das moléculas diatômicas heteronucleares frias no estado 


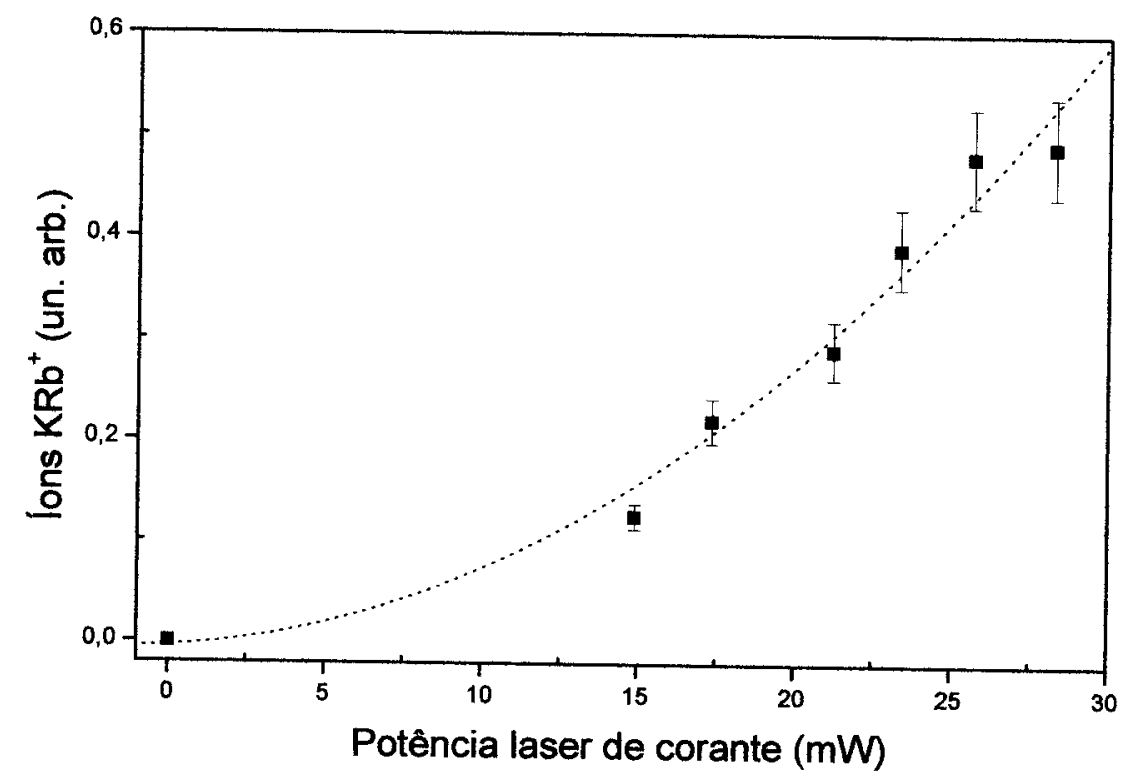

Figura 4.19: Íons moleculares $\mathrm{KRb}^{+}$como função da intensidade do laser de corante pulsado (laser de detecção). Podemos observar a dependência quadrática, a qual indica a ionização como sendo um processo de dois fótons a partir do estado fundamental ${ }^{1,3} \Sigma^{+}$. Acima da potência média de $25 \mathrm{~mW} / \mathrm{cm}^{2}$ podemos notar que ocorre saturação. 
fundamental, que propomos mediante esses resultados, pode ser então representado da seguinte maneira:

$$
\begin{gathered}
K\left(4^{2} S_{1 / 2}\right)+R b\left(5^{2} S_{1 / 2}\right)+\hbar \omega_{R b} \Longrightarrow K\left(4^{2} S_{1 / 2}\right)+R b\left(5^{2} P_{3 / 2}\right) \Longrightarrow K R b^{*}\left(\Omega^{+/-}\right) \\
K R b^{*}\left({ }^{1,3} \Lambda\right)+\hbar \omega_{\text {spont }} \Longrightarrow K R b\left({ }^{1,3} \Sigma\right)(K(4 S)+R b(5 S)) \\
K R b\left({ }^{1,3} \Sigma\right)+2 \hbar \omega_{p} \Longrightarrow K\left(4^{2} S_{1 / 2}\right)+R b^{+}+e^{-}
\end{gathered}
$$

De acordo com as equações acima, a absorção de um fóton $\omega_{R b}$ de um par KRb colidindo nos estados $\mathrm{K}\left(4 \mathrm{~S}_{1 / 2}\right)$ e $\mathrm{Rb}\left(5 \mathrm{~S}_{1 / 2}\right)$ fotossoacia o par em um estado rovibracional do estado molecular eletrônico excitado na região de longo alcance. A emissão de um fóton $\omega_{\text {spont }}$ na região de curto alcance popula estados ligados dos potenciais do estado molecular fundamental. A eq. $K R b\left({ }^{1,3} \Sigma\right)+2 \hbar \omega_{p} \Longrightarrow K\left(4^{2} S_{1 / 2}\right)+$ $R b^{+}+e^{-}$representa a transição de ionização do estado fundamental via uma transição de dois fótons $\hbar \omega_{p}$ realizada pelo laser pulsado, resultando em um átomo de K no estado fundamental, um átomo de $\mathrm{Rb}$ ionizado e um elétron livre.

O esquema de potenciais moleculares e transições envolvidas no processo de formação e detecção que descrevemos acima para os dímeros heteronucleares encontra.se esquematizado na Fig.4.20. As energias de ionização dos átomos de rubídio e do potássio são $33691,02 \mathrm{~cm}^{-1}$ e $34991,2 \mathrm{~cm}^{-1}$, respectivamente.

Simultaneamente à observação de formação de dímeros heteronucleares temos os seguintes processos de formação de dímeros homonucleares também no estado fundamental: 


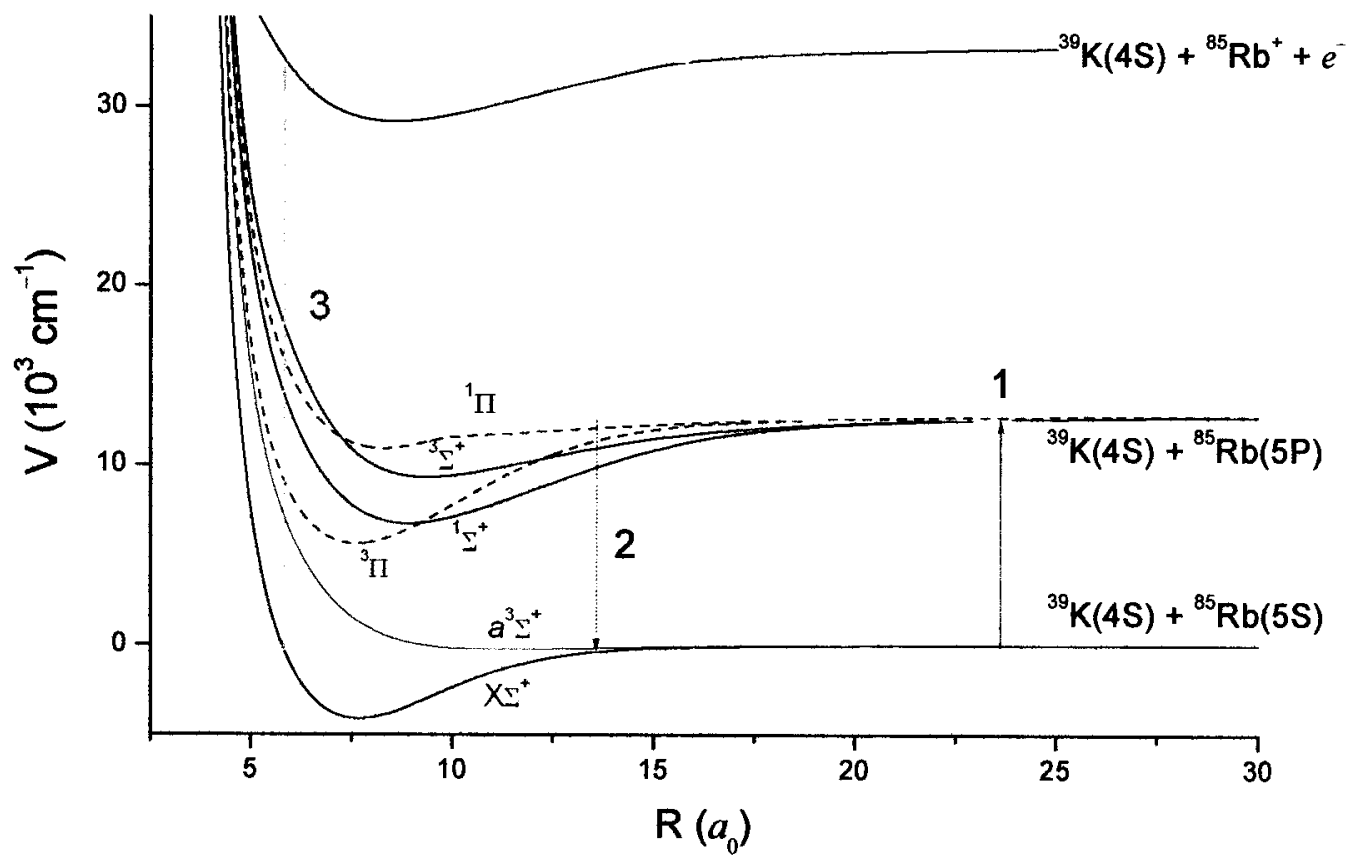

Figura 4.20: Esquema proposto para a formação das moléculas KRb no estado fundamental. No gráfico encontra-se representado apenas o estado singleto, porém o estado tripleto é também populado pelo decaimento espontâneo. A transição de dois fótons de $16.59530 \mathrm{~cm}^{-1}$ popula o estado fundamental da molécula ionizada $\mathrm{KRb}^{+}$. 


$$
\begin{gathered}
K\left(4^{2} S_{1 / 2}\right)+K\left(4^{2} S_{1 / 2}\right)+\hbar \omega_{K} \Longrightarrow K\left(4^{2} S_{1 / 2}\right)+K\left(4^{2} P_{3 / 2}\right) \Longrightarrow K_{2}^{*}\left(\Omega^{+/-}\right) \\
K_{2}^{*}\left({ }^{1,3} \Lambda\right)+\hbar \omega_{\text {spont }} \Longrightarrow K_{2}\left({ }^{1,3} \Sigma\right)(K(4 S)+K(4 S)) \\
K_{2}\left({ }^{1,3} \Sigma\right)+2 \hbar \omega_{p} \Longrightarrow K\left(4^{2} S_{1 / 2}\right)+K^{+}+e^{-}
\end{gathered}
$$

e

$$
\begin{gathered}
R b\left(5^{2} S_{1 / 2}\right)+R b\left(5^{2} S_{1 / 2}\right)+\hbar \omega_{R b} \Longrightarrow R b\left(5^{2} S_{1 / 2}\right)+R b\left(5^{2} P_{3 / 2}\right) \Longrightarrow R b_{2}^{*}\left(\Omega^{+1-}\right) \\
R b_{2}^{*}\left({ }^{1,3} \Lambda\right)+\hbar \omega_{s p o n t} \Longrightarrow R b_{2}\left({ }^{1,3} \Sigma\right)(R b(5 S)+R b(5 S)) \\
R b_{2}\left({ }^{1,3} \Sigma\right)+2 \hbar \omega_{p} \Longrightarrow R b\left(5^{2} S_{1 / 2}\right)+R b^{+}+e^{-}
\end{gathered}
$$

onde $\hbar \omega_{\text {spont }}$ representa a energia do fóton devolvido ao campo de radiação por emissão espontânea. A transiçãode ionização realizada pelo laser de corante produz a ionização das espécies atômicas pelo mesmo processo de dois-fótons uma vez que as mesmas são sintonizadas quase ressonantemente com estados atômicos do $\mathrm{K}$ e do Rb.

Para caracterizarmos a formação de moléculas em nosso MOT misto medimos também a dependência do sinal iônico heteronuclear com a densidade das amostras atômicas. Através da dependência do sinal de íons com a densidade atômica, podemos determinar se as moléculas são originadas através de colisões binárias ou se envolve mais corpos.

Os resultados mostrados no gráfico da Fig.4.21. abaixo foram obtidos fixando-se a densidade da amostra de $\mathrm{Rb}$, e variando a densidade da nuvem de $\mathrm{K}$ através da variação do detuning relacionado ao laser de rebombeio, para duas densidades distintas da amostra de K. A reta de maior coeficiente angular corresponde à densidade 
da amostra de $\mathrm{K}$ igual a $1,7 \times 10^{9} \mathrm{~cm}^{-3}$, e a outra a $1,2 \times 10^{9} \mathrm{~cm}^{-3}$. As potências dos lasers de aprisionamento neste experimento foram $500 \mathrm{~mW}$ para o $\mathrm{Rb}$ e $700 \mathrm{~mW}$ para o K.

Através do procedimento de aumentar ou diminuir a intensidade do sideband gerado pelo modulador eletro-óptico, conseguimos manipular a quantidade de átomos aprisionados e portanto a densidade atômica. Outra opção seria variarmos o campo magnético nas bobinas de aprisionamento, de modo a comprimir ou descomprimir a amostra alterando-se assim o volume da mesma. Ainda, poder-se-ia proceder à variação da densidade atômica através da variação da intensidade do feixe de aprisionamento. Esta última op̧̧ão, contudo, faz com que além da densidade da amostra, a fração de átomos no estado excitado também seja modificada, e portanto não era interessante para nós.

O gráfico da Fig.4.21 abaixo nos fornece a informação que as moléculas KRb são formadas por processos colisionais binários, ou seja, a partir de colisões de dois corpos, pois o comportamento do número de íons é linear com a densidade atômica. Se por acaso as moléculas fossem formadas por recombinação de três corpos, como proposto -por Gabbanini [34] para a formação de $\mathrm{Rb}_{2}$, a curva seria quadrática com a densidade [34].

Outra observação que podemos fazer partindo destes resultados é relativa ao fato da taxa de formação das moléculas KRb depender simultaneamente das densidades de ambas as amostras. Quando variávamos a densidade da amostra de K, a taxa 




Figura 4.21: Íons moleculares $\mathrm{KRb}^{+}$como função da densidade atômica de pico da armadilha de Rb. As linhas sólidas correspondem a ajustes teóricos lineares, mostrando que as moléculas são formadas em processos de dois corpos. O erro na determinação da densidade é aproximadamente $30 \%$.

de formação de KRb também era modificada: diminuindo-se a densidade de $\mathrm{K}$ a quantidade de moléculas hetero também foi diminuída.

\subsection{Taxa de Formação Heteronuclear}

A partir das medidas da variação do sinal de íons com relação à variação da densidade das amostras atômicas podemos obter informações acerca da taxa de formação molecular em nosso MOT. Os resultados anteriores nos mostram que a formação molecular ocorre através de colisões binárias (observe que o gráfico do número de íons com a densidade atômica é linear). 
A variação temporal do sinal de íons heteronucleares deve portanto obedecer à seguinte equação:

$$
\frac{1}{V_{i}} \frac{d I_{K R b}}{d t}=R_{K R b} n_{K} n_{R b},
$$

onde $\mathrm{V}_{i}$ é um volume efetivo, ou de interseç̧ão, que representa o overlap entre as duas amostras, $I_{K R b}$ é o número de íons detectados, $R_{K R b}$ a constante de formação molecular em íons/s, $n_{K}$ e $n_{R b}$ são respectivamente as densidades médias das amostras de potássio e rubídio.

No caso deste experimento especificamente, o volume de intersecção corresponde ao próprio volume da amostra de Rb, uma vez que nesta situação, a mesma encontravase totalmente imersa na núvem de K, conforme pode-se observar na Fig.4.22 que mostra os perfis de intensidades das duas amostras.

Consideremos a largura do pico iônico e o tempo durante o qual moléculas eram detectadas a partir do volume de detecção (compreeendido pelo volume das amostras e pela região adjacente ao trap onde as moléculas caem da amostra pela ação da gravidade.

Considerando-se que a eficiência na deteç̧ão seja da ordem de 50\% (composta "pela combinação entre a eficência de ionização e pela resposta do detector de íons), pois nem todas as moléculas são ionizadas devido a apenas uma fração da amostra ser acessado pelo laser de ionização, determinamos as taxas de formação molecular heteronuclear e homonucleares em nosso MOT misto.

Considerando para o caso do $\mathrm{KRb}$, a largura (a meia altura) do pico, aproximada- 




Figura 4.22: Distribuições espaciais gaussianas representando o perfil de densidade das amostras de Rb e K para um corte transversal em uma das direçóes das armadilhas. Pode-se observar que a amostra de $\mathrm{Rb}$ esteve durante todo o experimento compreendida pelo MOT de $\mathrm{K}$, menos denso (maior volume). Neste gráfico, $n_{K}=1,2 \times 10^{9} \mathrm{~cm}^{-3}$. 
mente $1 \mu \mathrm{s}$, e que o tempo de resposta do detector é $\sim 0,15 \mu \mathrm{s}$, determinamos que são produzidas aproximadamente 7 moléculas/pulso, onde consideramos um tempo de interação (tempo de permanência da moléculas na região do trap) de 1,2 ms (entre as moléculas heteronucleares produzidas e o laser pulsado).

Podemos então determinar a taxa de produção molecular heteronuclear:

$$
\dot{K R b}^{+} \approx \frac{7}{2 \times 1,2 \times 10^{-3}} \simeq 1,16 \times 10^{4} \mathrm{~s}^{-1}
$$

Utilizando a equação de taxa acima, onde o volume efetivo de interseção é $V_{e f f}=$ $V_{R b} \simeq 0,8 \times 10^{-4} \mathrm{~cm}^{3}$, obtemos o seguinte valor para a constante de taxa de formação de moléculas heteronucleares $K_{K R b}$, considerando-se as densidades atômicas $n_{R b}=$ $3,9 \times 10^{10} \mathrm{~cm}^{-3}$ e $n_{K}=1,7 \times 10^{9} \mathrm{~cm}^{-3}:$

$$
R_{K R b} \simeq 2 \times 10^{-12} \mathrm{~cm}^{3} / \mathrm{s}
$$

O valor para a taxa de formação de KRb por nós medida $\left(10^{4} \mathrm{~s}^{-1}\right)$ está completamente de acordo com a taxa teórica calculada por O. Dulieu em resultados ainda não publicados [79]. 


\section{Capítulo 5}

\section{Espectroscopia Fotoassociativa de}

\section{Moléculas Heteronucleares}

Conforme já mencionado, uma das aplicações das moléculas $\mathrm{KRb}$ frias deverá consistir no seu estudo por espectrsocopia fotoassociativa. Por esta técnica, à medida que a frequência de um laser adicional, comumente denominado laser de fotoassociação ou de prova, for varrida para o vermelho da transição de aprisionamento do $\mathrm{K}$ e do $\mathrm{Rb}$ (inicialmente desejamos estudar os estados assintóticos variando a frequência a .partir da ressonância da linha D2 ou D1 do rubídio), ressonâncias no sinal iônico molecular deverá nos indicar as posições dos estados ligados (estados rovibracionais) do estado eletrônico excitado da molécula. Em princípio, pretendemos estudar e mapear a região de longo alcance, cobrindo em seguida todo o espectro em direção ao fundo do poço de potencial. 
Para que possamos realizar espectroscopia das moléculas heteronucleares que hoje produzimos a uma taxa satisfatória para permitir a realização de tais experimentos, passamos também por uma aprendizagem crucial realizando espectroscopia apenas na amostra fria de rubídio. Para tanto, isso envolveu além da produção das moléculas frias $\mathrm{Rb}_{2}$, o desenvolvimento do software que será utilizado para espectroscopia fotoassociativa de KRb ou outras moléculas heteronucleares que venhamos a produzir e detectar.

Este software produzido por nós em Labview, sincroniza a varredura do laser de fotoassociação (ou laser de prova), com a aquisição dos sinais de fluorescência de íns. Isto é feito através da utilização de um clock interno (gerado a partir de um sinal TTL) composto de uma parte do programa destinada a contar eventos. Uma vez que o trigger gerado pelo contador fornece o comando (através de um sinal digital) para o laser dar um passo na frequência, outra parte independente (mas também sincronizada pelo contador) do programa encarrega-se de adquirir os pontos correspondentes aos sinais captados pela fotomultiplicadora proveniente da fluorescência emitida pelo MOT, pelo fotodetector responsável pelo sinal da célula de referência, e - pelo detector de íons, através da utilização de vários (no caso, três) canais analógicos de saída. Uma melhoria que deverá ser implementada para maximizar o sinal de íons moleculares heteronucleares deverá ser a troca da câmara de aprisionamento, visando obtermos melhores condições de vácuo. Contudo, até o presente momento já contamos com o instrumental e os softwares que deveremos utilizar em tais experimentos. 
Neste capítulo discutiremos também sobre alguns aspectos releventes à espectrosocpia de estados moleculares de longo alcance. São aqui apresentados nossos resultados acerca da estimativa das energias dos estados vibracionais situados próximos ao limite de dissociação para o sistema $\mathrm{K}-\mathrm{Rb}$ *. Estas informações são cruciais para que saibamos as regiões espectrais onde procurar por estados ligados da molécula KRb. A motivação para este capítulo surgiu pela necessidade de obtermos uma estimativa para o número de níveis vibracionais que deverão ser provados quando o laser de prova for inserido à montagem experimental básica de produção de moléculas heteronucleares, varrido a partir do limite de dissociação $\mathrm{K}-\mathrm{Rb}^{*}$ até alguns $\mathrm{cm}^{-1}$ para o vermelho da transição da linha D2 do Rubídio, segundo o procedimento usual adotado nesse tipo de experimento.

Evidentemente, existem teorias mais apropriadas e mais completas para a determinação do espectro de energias vibracionais e rotacionais de moléculas diatômicas, porém o cálculo destas energias utilizando cálculos bastante mais complexos que consumiriam muito do tempo que destinamos ao andamento do laboratório, ficando assim, sob encargo de teóricos da área. 


\subsection{Determinação dos estados ligados de longo al-}

\section{cance}

Para estimarmos as energias dos estados vibracionais dos potenciais da molécula $\mathrm{KRb}$, correlacionados assintoticamente ao estado dos átomos separados $\mathrm{K}(4 \mathrm{~S})+\mathrm{Rb}(5 \mathrm{P})$, procedemos inicilamente a um ajuste das curvas de potencial calculados por Rousseau et al por um potencial do tipo Morse, que pode ser facilmente encontrado na literaura em livros textos de mecânica quântica molecular $[68,88]$ e para o qual temos uma solução analítica da equação de Schrödinger para as auto-energias e autofunções do potencial $\mathrm{V}(\mathrm{R})$.

Este ajuste das curvas dos estados eletrônicos do KRb nos forneceu os parâmetros espectroscópicos necessários ao cálculo da energia dos estados da molécula, como descreveremos a seguir. Conforme nossa suposição das moléculas frias em nosso experimento advirem de estados excitados associados à assíntota $\mathrm{K}(4 \mathrm{~S})+\mathrm{Rb}\left(5 \mathrm{P}_{3 / 2}\right)$, inferimos então a localização dos primeiros estados vibracionais relacionados a este limite de dissociação.

- O potencial de Morse é bastante conhecido na literatura e trata-se de uma função potencial empírica, dada pela seguinte expressão:

$$
V(R)=D\left[1-e^{-a\left(R-R_{e}\right)}\right]^{2}
$$

onde a é uma constante para um dado estado eletrônico, sendo basicamente uma medida da curvatura da função potencial, D é a energia de dissociação, que representa 
a profundidade do potencial e $\mathrm{R}_{e}$ é a distância internuclear de equilíbrio.

Outras funções além do potencial de Morse podem ser usadas para representar o potencial de interação entre dois átomos em uma molécula, desde que satisfaçam às seguintes condições:

a) $\mathrm{V}(\mathrm{R})$ deve apresentar um extremo (mínimo) em $\mathrm{R}=\mathrm{R}_{e}$, ou seja:

$$
\left[\frac{d V(R)}{d R}\right]_{R=R_{e}}=0 .
$$

b) Para separações internucleares próximas ao limite de dissociação, o potencial $\mathrm{V}(\mathrm{R})$ deve se aproximar de um valor constante tal que:

$$
V(R=\infty)-V\left(R_{e}\right)=D
$$

Sendo $V(R=\infty)$ tomado arbitrariamente como igual a zero, então $V\left(R_{e}\right)=-D$.

c) Quando $R$ tender a zero, $V(R)$ deve tender a infinito, refletindo a impossibilidade da total superposição dos dois núcleos. Na prática, uma função que assuma um valor muito grande ao invés de infinito é adequada. É facilmente mostrado que o potencial de Morse cumpre todas as exigências acima. Esta forma para representar-se a interação entre dois átomos em uma molécula diatômica, apesar de bastante simples, é bastante interesante. O potencial de Morse é capaz de descrever a anarmonicidade do potencial para distâncias internucleares $R$ situadas a direita da distância de equilíbrio observada nas curvas calculadas por métodos ab-initio, e além disso, a equação radial de Schrödinger apresenta uma solução analítica para os autovalores do poten- 
cial de Morse, dados em termos dos números quânticos vibracional $(v)$ e rotacional (J). Aqui mostramos os termos até segunda ordem da solução para as energias $\mathrm{E}_{v}$, desprezando-se graus de liberdade rotacionais da molécula:

$$
\frac{E v}{\hbar}=\omega_{e}\left(v+\frac{1}{2}\right)-\chi_{e} \omega_{e}\left(v+\frac{1}{2}\right)
$$

onde

$$
\omega_{e}=\frac{a}{2 \pi} \sqrt{\frac{2 D}{\mu}}
$$

e

$$
\chi_{e}=\frac{\hbar \omega_{e}}{4 D}
$$

onde $\chi_{e} \omega_{e}$ é conhecida como constante de anarmonicidade [68].

Podemos observar na Fig.5.1 abaixo, os potenciais calculados por Rousseau ajustados pela seguinte expressão

$$
V(R)=D\left[1-e^{-a\left(R-R_{e}\right)}\right]^{2}+\left(V_{\infty}-D\right),
$$

Aqui, buscamos corrigir a expressão básica do potencial Morse com os valores de . uma escala mais absoluta, isto é com relação à energia de ionização que é o valor de $V_{\infty}$ e $V_{\infty}=V(r \rightarrow \infty)=E_{i o n}$, e parâmetros $D, a$ e $R_{e}$ permanecem inalterados. É importante ressaltarmos que escolhemos a função potencial de Morse devido esta apresentar um número pequeno de parâmetros (somente 3) em relação a outras funções, mas principalmente por esta ser capaz de representar o caráter anarmônico 

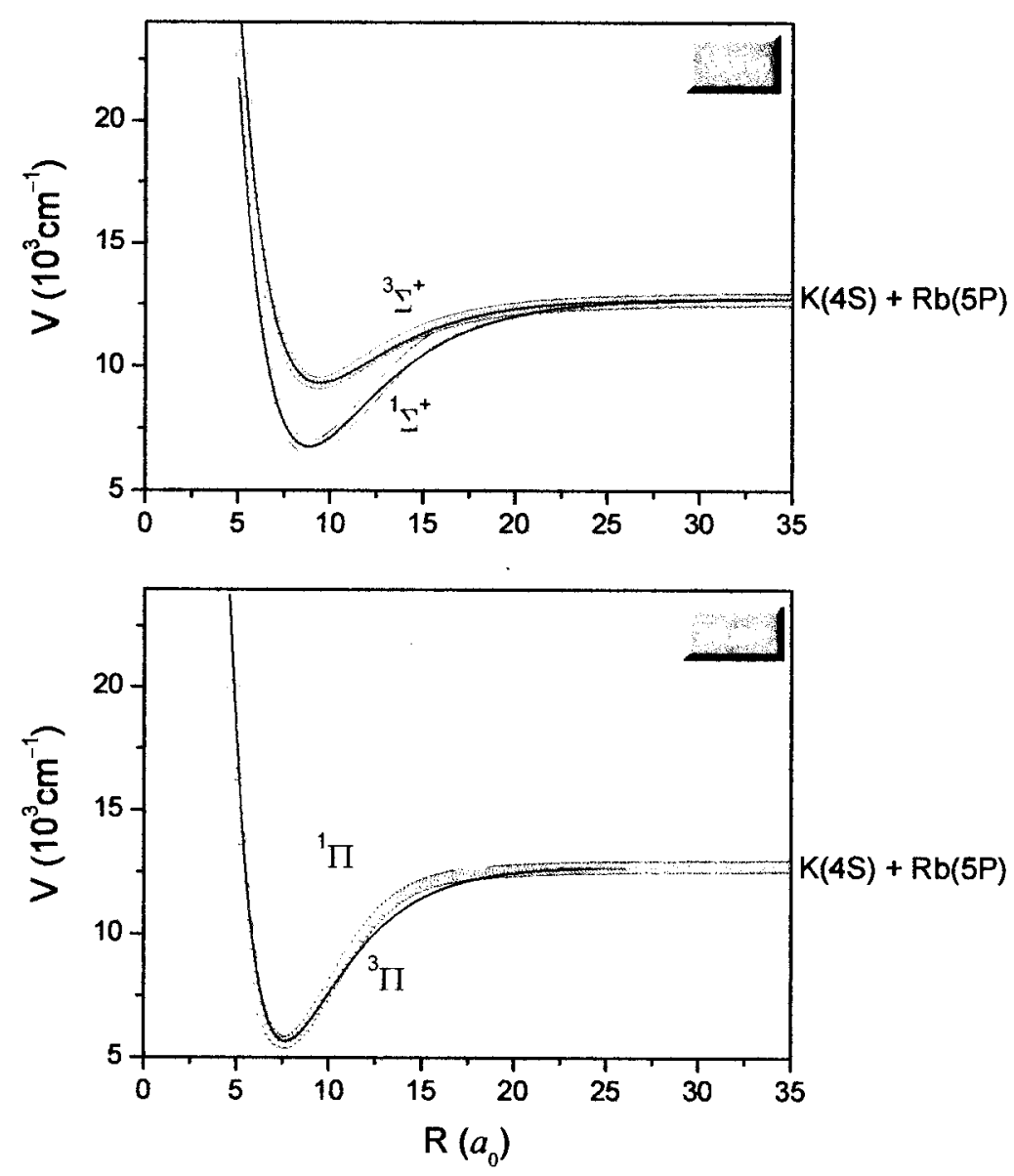

Figura 5.1: Ajuste das curvas de potencial calculadas por Rousseau et al., pela função potencial de Morse para os estados moleculares correlacionados à assíntota $\mathrm{K}\left(4^{2} \mathrm{~S}\right)+\mathrm{Rb}\left(5^{2} \mathrm{P}\right)$.

das vibrações moleculares e ainda fornecer uma solução analítica para o espectro de 'energia como função dos números quânticos rovibracionais.

Outras funções empíricas para o potencial são encontradas na literatura, dentre as quais podemos ressaltar a fórmula de Hulburt-Hirschfelder [89] como uma das melhores funções potencial utilizadas no estudo de moléculas diatômicas, contendo 5 
parâmetros:

$$
V(R)=D\left[\left(1-e^{-x}\right)^{2}+c x^{3}(1+b x)\right]
$$

onde $x=a\left(r-r_{e}\right)$. Nessa função, os parâmetros $a, r_{e}$ e $D$ têm o mesmo significado físico dos parâmetros do potencial de Morse, com $b$ e $c$ sendo duas constantes adicionais usadas para permitir uma maior flexibilidade no ajuste da curvatura para uma faixa maior de separação internuclear.

Na Fig.5.2 mostramos uma comparação entre ajustes realizados com o potencial de Morse e de Hulburt-Hirschfelder para os estados de simetria ${ }^{1,3} \Sigma$. Podemos notar que a segunda expressão se ajusta melhor aos potenciais resultantes de cálculos químicoquânticos.

A partir da realização dos ajustes pelo potencial de Morse, obtemos os valores de $D$, e $a$ que são utilizados para calcular os espectros dos níveis de energia para os potenciais dos estados eletrônicos correlatos à assíntota heteronuclear $K(4 S)+R b(5 P)$ ou $K-R b^{*}$, de acordo com a relação:

$$
\frac{E_{v}}{h}=\nu_{e}\left(v+\frac{1}{2}\right)-\chi_{e} \nu_{e}\left(v+\frac{1}{2}\right)^{2},
$$

onde as frequências:

$$
\begin{aligned}
& \nu_{e}=\frac{a}{2 \pi} \sqrt{\frac{2 D}{\mu}} ; \mathrm{e} \\
& \chi_{e}=\frac{h \nu_{e}}{4 D}
\end{aligned}
$$

são expressas em Hz, e são relacionadas aos parâmetros obtidos dos ajustes teóricos realizados sobre os potenciais e $\mu$ é a massa reduzida da molécula. 


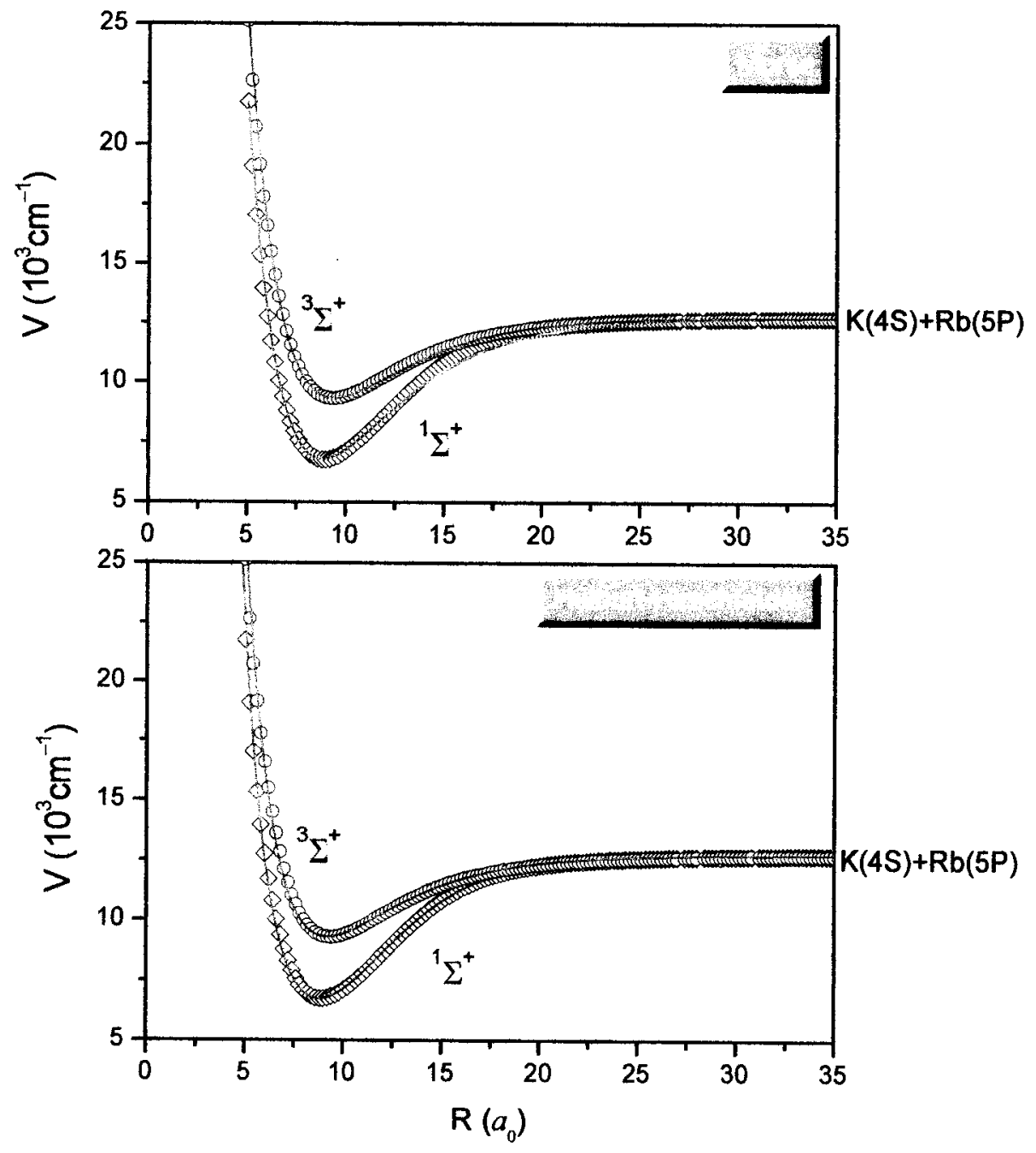

Figura 5.2: Ajuste das curvas de potencial pelas funções potencial de Morse e HulburtHirschfelder. Note que o ajuste teórico utilizando a segunda função é notavelmente melhor, principalmente com relação à curvatura dos potenciais. 
A estimativa do número máximo de níveis vibracionais de um dado potencial é feita de acordo com a relação:

$$
v_{D}=\frac{1}{2}\left(\frac{1}{\chi_{e}}-1\right)
$$

onde $v_{D}$ representa o número vibracional efetivo (semi-inteiro) associado ao limite de dissociação, onde $h v_{D}=D$.

Na Fig.5.3, mostramos a distribuição da energia dos níveis vibracionais relativa ao limite de dissociação como função dos respectivos níveis vibracionais $\nu$ para os potenciais dos estados singleto e tripleto para o sistema $K-R b^{*}$. Na Fig.5.4 são mostrados os níveis de energia próximos ao limite de dissociação do sistema $\mathrm{K}-\mathrm{Rb}^{*}$ para os quatro estados dissociando neste limite.

Podemos observar na Fig.5.4 que há um número menor de níveis, e que são também mais espaçados entre si, nos potenciais de estados singleto ${ }^{1} \Sigma$ e ${ }^{1} \Pi$. Isso é devido ao formato do seus poços, que são mais estreitos, ou de menor alcance. Observandose a Fig.5.4 na qual mostramos os níveis vibracionais localizados nos primeiros 10 $\mathrm{cm}^{-1} \mathrm{a}$ partir do limite de dissociação para os potenciais do primeiro estado excitado do sistema $K(4 S)-R b(5 P)$, podemos verificar esta afirmação.

Na próxima seção, apresentaremos os resultados de um procedimento usado na literatura para a determinação de parâmetros espectroscópicos atômico-moleculares relativos aos potencias de interação de moléculas diatômicas. Alguns exemplos do que pode ser obtido a partir desta abordagem é o coeficiente principal do potencial de longo alcance, a partir do qual outras informações podem ser obtidas, tais como o 


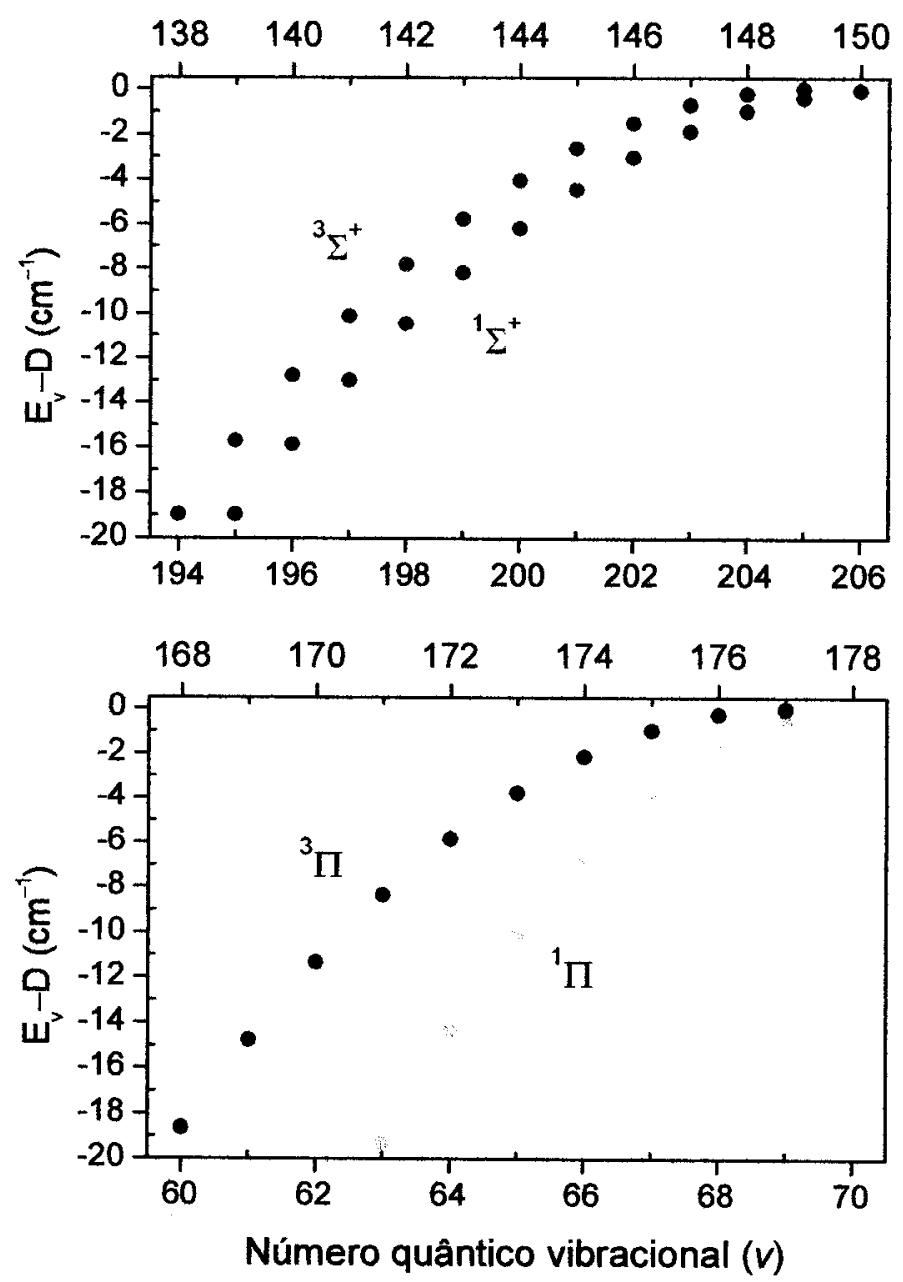

Figura 5.3: Energia dos estados vibracionais como função do número vibracional v. 
tempo de vida do estado e a largura de linha. Esta técnica é independente da técnica espectroscópica utilizada para obter os resultados espectroscópicos, mas é importante notar-se que é especialmente apropriada para espectroscopia de fotoassociação de estados de longo alcance de estados formados durante colisões entre átomos frios colidindo em MOTs, uma vez que a aproximação do potencial pela expansão de potências inversas da separação internuclear $\mathrm{R}$ é válida para o caso das colisões frias, as quais são bastante bem descritas por potenciais de longo alcance que representam a interação de dois átomos frios, que começa a ocorrer a partir de longas separações internucleares. Vale lembrar também que o par atômico que forma a molécula passa a maior parte do tempo próximo aos pontos de retorno clássicos do potencial. Próximo ao ponto de retorno interno os átomos vêem uma barreira infinita, então passam grande parte do tempo próximos ao ponto de retorno externo do potencial, de forma que a aproximação do potencial para a forma de longo alcance, $-C_{n} / R^{n}$, é totalmente justificada para o caso de colisões frias.

\subsection{Procedimento de LeRoy e Bernstein para de- terminação do Coeficiente $C_{6}$}

Aqui descreveremos o procedimento comumente utilizado para obter-se informações moleculares a partir da extração do valor do coeficiente principal do potencial que descreve a interação dos átomos na molécula para a região de longo alcance da 
interação [72]. Uma vez que tenhamos obtido o espectro experimental da molécula $\mathrm{KRb}$ poderemos, a partir da determinação das posições dos estados ligados de longo alcance poderemos determinar o coeficiente $C_{6}$ do potencial de longo alcance.

Partindo da condição semiclássica WKB para os autovalores de um potencial $\mathrm{V}(\mathrm{R})$ :

$$
v+\frac{1}{2}=\frac{(2 \mu)^{1 / 2}}{\pi \hbar} \int_{R_{1}(v)}^{R_{2}(v)}[E(v)-V(R)]^{1 / 2} d R
$$

onde $E(v)$ é a energia do nível $v, R_{1}(v)$ e $R_{2}(v)$ são as distâncias radiais dos pontos de retorno interno e externo, respectivamente, para os quais $E(v)=V\left[R_{1}(v)\right]=$ $V\left[R_{2}(v)\right]$

Lembremo-nos que, próximo ao limite de dissociação, a energia potencial interatômica é descrita pela forma em potências inversas da distância internuclear, e podemos aproximá-la para a forma assintótica:

$$
V(R)=D-C_{n} / R^{n}
$$

$D$ é o limite de dissociação e $C_{n}$ é dado por

$$
E(v)=D-C_{n} /\left[R_{2}(v)\right]^{n}
$$

Se fizermos a seguinte mudança de variáveis $u=R_{2}(v) / R$, obtemos: 


$$
\frac{d v}{d E(v)}=\left(\frac{\mu}{2 \pi \hbar}\right) \frac{C_{n}^{1 / n}}{[D-E(v)]^{1 / 2+1 / n}} \int_{1}^{R 2(v) / R 1(v)} u^{-2}\left(u^{n}-1\right)^{\frac{1}{2}} d u .
$$

Assim, obtém-se uma expressão analítica para os espaçamentos dos níveis vibracionais:

$$
\frac{d E(v)}{d v}=\hbar\left(\frac{2 \pi}{\mu}\right)^{1 / 2} \frac{\Gamma(1+1 / n)}{\Gamma(1 / 2+1 / n)} \frac{n}{C_{n}}[D-E(v)]^{(n+2) / 2 n}
$$

onde $\Gamma(x)$ é a função gama, assim definida:

$$
\int_{0}^{1} t^{x-1}(1-t)^{y-1} d t=\frac{\Gamma(x) \Gamma(y)}{\Gamma(x+y)} ; x, y>0
$$

onde:

$$
\Gamma(x)=\int_{0}^{\infty} t^{x-1} e^{-t} d t, 0<x<\infty .
$$

Embora a variável $v$ seja discreta, é conveniente que a tratemos como sendo contínua (onde $d v=1$ ).

Combinando as constantes, temos:

$$
\frac{d E(v)}{d v}=K_{n}[D-E(v)]^{(n+2) / 2 n} .
$$

Esta é a forma diferencial dada por LeRoy e Bernstein [72]. Em situações práticas "a forma integral é útil:

$$
E(v)=D-\left[\left(v-v_{D}\right) H_{n}\right]^{2 n /(n-2)}
$$

onde a constante $H_{n}$ é dada por:

$$
H_{n}=[(n-2) / 2 n] K_{n},
$$


e a constante de integração $v_{D}$ cujo significado físico é o de índice vibracional (semiinteiro) "efetivo" no limite de dissociação .

Para os estados excitados heteronucleares $\left(n S+n^{\prime} P\right)$, obtemos:

$$
\begin{gathered}
H_{6}=2 \sqrt{\frac{2 \pi}{\mu}} \hbar \frac{\Gamma(7 / 6)}{\Gamma(2 / 3)} \frac{1}{C_{6}^{1 / 6}} . \\
\left(v-v_{D}\right)=\frac{1}{2 \hbar} \sqrt{\frac{\mu}{2 \pi}} \frac{\Gamma(2 / 3)}{\Gamma(7 / 6)} C_{6}^{1 / 6}[D-E(v)]^{1 / 3} .
\end{gathered}
$$

Assim que obtivermos um espectro experimental, do gráfico de $\left(v-v_{D}\right)$ com $[D-$ $E(v)]^{1 / 3}$ obteremos então um valor experimental para a constante $C_{6}$. 


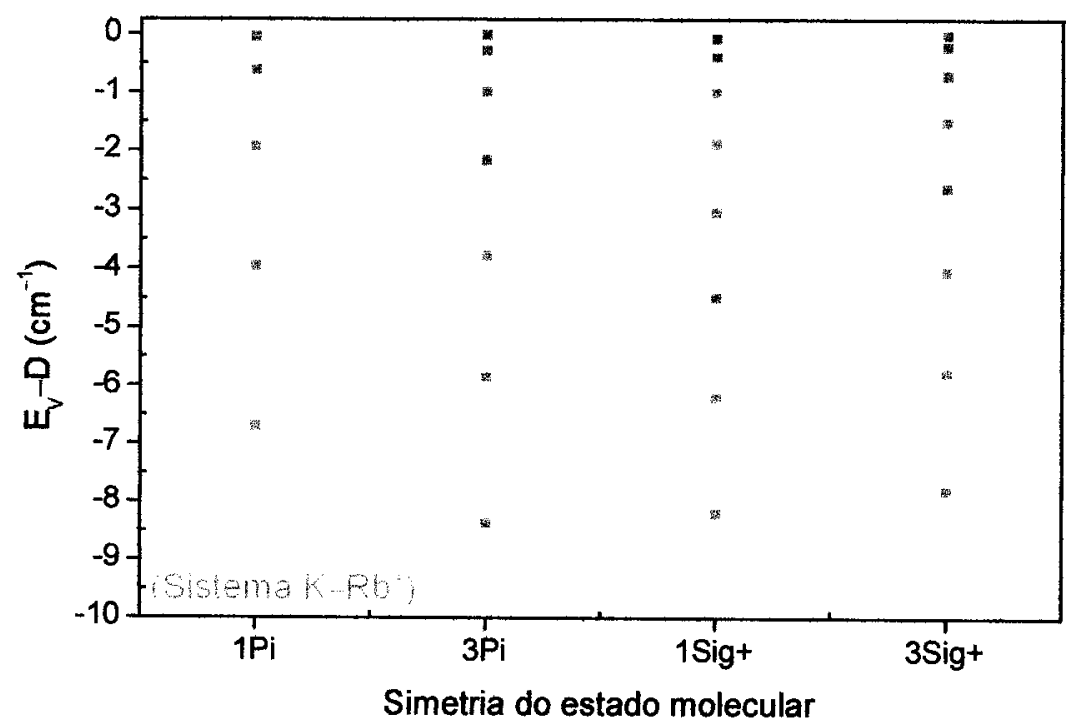

Figura 5.4: Energias dos níveis vibracionais próximos ao limite de dissociação $\mathrm{K}(4 \mathrm{~S})+\mathrm{Rb}(5 \mathrm{P})$ para os estados eletrônicos $\Sigma$ e $\Pi$. 


\section{Capítulo 6}

\section{Conclusões}

Neste trabalho, produzimos moléculas frias heteronucleares e as detectamos no estado fundamental. A produção das mesmas se dá por fotoassociação de dois átomos frios distintos, pótássio e rubídio, colidindo em uma armadilha magneto-óptica mista, seguida por emissão espontânea em direção ao estado fundamental da molécula KRb.

A principal dificuldade de produção de dímeros frios heteronucleares se dá, especialmente, devido à complexidade experimental envolvida na produção e na deteç̧ão das moléculas. Este trabalho, deste modo, representa um esforço bastante grande . em direção à obtenção de dímeros frios no estado fundamental, que envolveu desde a montagem experimental para o aprisionamento simultâneo de potássio e rubídio, até o desenvolvimento das estratégias e técnicas de deteç̧ão, bem como a parte relacionada à aquisição de dados.

As moléculas KRb frias no estado fundamental produzidas em nossa armadilha 
foram detectadas por fotoionização pulsada e observadas por espectrometria de tempo de vôo através da técnica de detecção de íons, que permite a diferenciação entre as diferentes espécies detectadas em nosso esquema. A detecção utilizando um laser pulsado sintonizável nos parece crucial para o sucesso de deteç̧ão dos dímeros frios heteronucleares. Este comprimento de onda favorável situa-se no intervalo de comprimentos de onda correspondentemente às transições para os estados moleculares relacionados à banda difusa do $\mathrm{Rb}_{2}$, que foi estudada em experimentos de absorção e fluorescência $[80,81]$ durante o início da década de 80 , em células contendo altas densidades de vapor de alcalinos, e que atualmente são usadas como estratégia de deteç̧ão de moléculas frias $[34,42]$.

Uma tentativa interessante que deverá ser implementada brevemente em nosso laboratório consiste em utilizar o laser de deteç̧ão na região da banda difusa do $\mathrm{KRb}$, em torno de $586 \mathrm{~nm}$. Nesta região existe a possibilidade de que talvez o sinal iônico heteronuclear seja magnificado, aumentando as chances de sucesso na realização de espectroscopia de fotoassociação [49], até então realizada apenas em sistemas homonucleares.

- As moléculas detectadas primeiramente em nsossa armadilha eram térmicas, formadas a partir dos átomos térmicos presentes no vapor de fundo da câmara de aprisionamento. Sendo quentes, não dependiam dos átomos aprisionados, e assim não nos interessavam. Contudo, foram importantes para nos guiar com relação à região de comprimentos de onda utilizados na detecção. Inicialmente, o sinal por nós obtido foi 
bastante pequeno, mas melhorias no aparato experimental nos propiciou a deteç̧ão destas moléculas a uma taxa da ordem de $10^{4}$ moléculas por segundo. Isto representa uma fonte contínua de moléculas heteronucleares frias que poderão ser usadas em várias aplicações. Além de medirmos a taxa segundo a qual as moléculas são formadas, medimos também sua temperatura translacional e estudamos os mecanismos de formação, a partir de onde propusemos quais seriam os canais (estados moleculares excitados) envolvidos no primeiro passo de formação das moléculas frias.

Simultaneamente à produção das moléculas heteronucleares, $\mathrm{KRb}$, moléculas homonucleares também foram formadas e detectadas em nossa armadilha. As mesmas também foram estudadas com relação à temperatura, taxa de formação. Novamente aqui, também realizamos experimentos para nos certficar de que as mesma eram detectadas no estado fundamental, e não no estado excitado.

Inicialmente em nosso trabalho, nos dedicamos a produção de moléculas frias de césio $\left(\mathrm{Cs}_{2}\right)$. Desde a primeira tentativa de deteção de $\mathrm{KCs}$, passando por NaCs e $\mathrm{NaRb}$, finalmente conseguimos o aprimoramento das técnicas que utilizamos para produzir e detectar as moléculas $\mathrm{KRb}$ frias.

- Outros experimentos futuros que deverão ser realizados em nosso laboratório deverá envolver o aprisionamento das moléculas KRb em uma armadilha óptica de dipolo, para a qual já contamos com um laser de $\mathrm{CO}_{2}$, com uma potência de saída de $100 \mathrm{~W}$ para implementação do aprisionamento dos dímeros frios. Uma vez que a profundidade típica de tal tipo de armadilha é pequena (da ordem de $1 \mathrm{mK}$ ), é estritamente 
necessário que os átomos e moléculas aprisionados já sejam previamente frios. A geometria básica deste tipo de armadilha harmônica envolve o aprisionamento das espécies na região do foco deste laser. Assim, temos uma armadilha com uma direção bastante confinante (coordenada radial), com uma frequência de oscilação mais alta, e uma direção z, colinear ao eixo de propagação do feixe menos confinante (menor frequência de oscilação). Espectroscopia de estados moleculares dos dímeros aprisionados na armadilha de dipolo deverá fornecer espectros de qualidade superior àqueles obtidos em MOTs uma vez que na armadilha óptica, onde a energia térmica dos átomos é muito menor que as separações entre os níveis moleculares ro-vibracionais.

Outra aplicação possível, porém ainda remota, é relativa à obtenção de um condensado molecular. Contudo, para isso será importante o desenvolvimento de produção de moléculas frias no estado vibracional de mais baixa energia $(v=0)$. Isto entretanto não poderá envolver transições para potenciais excitados de Rydberg a partir dos quais tenhamos emissão estimulada vertical para o estado vibracional fundamental do potencial eletrônico fundamental molecular. Evidentemente, além disso, demandará também todas as técnicas envolvidas em produção de condensados bosônicos, " como resfriamento evaporativo, que poderá ser feito, por exemplo, baixando-se a profundidade do potencial harmônico da armadilha de dipolo, técnicas de diagnóstico, etc. 


\section{Referências Bibliográficas}

[1] Metcalf, H. and der Straten, P. V. Laser Cooling and Trapping. Springer-Verlarg, New York, (1999).

[2] S. Chu, T. M. o. N. P. Rev. Mod. Phys. 70, 685-706 (1998).

[3] Tannoudji, C. C. Rev. Mod. Phys. 70, 707-19 (1998).

[4] Phillips, W. Rev. Mod. Phys. , 721-74 (1998).

[5] Cornell, E. and Wieman, C. Rev. Mod. Phys. , 87593 (2002).

[6] Ketterle, W. Rev. Mod. Phys 74, 1131-51 (2002).

[7] Fried, D., Killian, T., Willmann, L., Landhuis, D., Kleppner, S. M. N. D., and Greytak, T. Phys. Rev. Lett 81, 3811-14 (1998).

[8] Bradley, C., Sacket, C., and Hulet, R. Phys. Rev. Lett 78, 985-9 (1997).

[9] Davis, K., Mewes, M.-O., Andrews, M., Druten, N. V., Durfee, D., Kurn, D., and Ketterle, W. Phys. Rev. Lett 75, 3969-73 (1995). 
[10] Anderson, M., Ensher, J., Matthews, M., Wieman, C., and Cornell, E. science 269, 198-201 (1995).

[11] Modugno, G., Modugno, M., Riboli, F., Roati, G., and Inguscio, M. Phys. Rev. Lett 89, $19404(1-4)(2002)$.

[12] Weber, T., Herbig, J., Mark, M., Nägerl, H.-C., and Grimm, R. Science (2002).

[13] Barrett, M., Sauer, J., and Chapman, M. Physical Review Letters 87(1), 010404 (2001).

[14] Hadzibabic, Z., Stan, C., Dieckmann, K., Gupta, S., Zweirlein, M., Görlitz, A., and Ketterle, W. Phys. Rev. Lett 88(16), 160401 (2002).

[15] Schreck, F., Khaykovich, L., Corwin, K., Ferrari, G., Bourdel, T., Cubizolles, J., and Salomon, C. Phys. Rev. Lett. 87, 80403 (1-4) (2001).

[16] Truscott, A., Strecker, K., Alexander, W. M., Partridge, G., and Hulet, R. Science 291, 2570-2 (2002).

[17] Roati, G., Riboli, F., Modugno, G., and Inguscio, M. Phys. Rev. Lett. 89, $150403(1-4)(2002)$

[18] Raab, E., Prentiss, M., Cable, A., Chu, S., and Pritchar, D. Phys. Rev. Lett. , $2631-4(1987)$.

[19] Thorsheim, H., Weiner, J., and Julienne, P. Phys. Rev. Lett. 58, 2420-3 (1987). 
[20] Stwalley, W. C., Uang, Y.-H., and Pichler, G. Phys. Rev. Lett. 41(17), 1164-7 (1978).

[21] Santos, M., Nussenzveig, P., Marcassa, L., Helmerson, K., Flemming, J., Zilio, S., and Bagnato, V. Physical Review A 52(6), R4340-3 (1995).

[22] Telles, G., Marcassa, L., Muniz, S., Miranda, S., Antunes, A., Westbrook, C., and Bagnato, V. Phys. Rev. A 59, R23 (1999).

[23] Marcassa, L., Telles, G., Muniz, S., and Bagnato, V. Phys. Rev. A , 013413 (2000).

[24] Telles, G., Garcia, W., Marcassa, L., and Bagnato, V. Phys. Rev. Lett. , 033406--? (2001).

[25] Schlöder, U., Engler, H., Schünermann, U., Grimm, R., and Weidemüller, M. Euro. Phys. J. D 7, 331 (1999).

- [26] Wippel, V., C.Binder, and Windholz, L. Eur. Phys. J. D , 101-4 (2002).

[27] Shaffer, J., Chalupczak, W., and Bigelow, N. Physical Review Letters 82(6), 1124-7 (1999).

[28] Ferrari, G., Inguscio, M., Jastrzebski, W., Modugno, G., and Roati, G. Phys. Rev. Lett. 89, 053202 (2002).

[29] Marinescu, M. and Sadeghpour, H. Phys. Rev. A 59, 390-404 (1999). 
[30] Wang, H. and Stwalley, W. J. Chem. Phys 108, 5767-71 (1998).

[31] Bahns, J., Gould, P., and Stwalley, W. Adv. At. Mol. Opt. Phys. 42, 171-224 (2000)

[32] Helmerson, K. Nature 402, 587-8 (1999).

[33] Fioretti, A., Comparat, D., Crubellier, A., Dulieu, O., Masnou-Seeuws, F., and Pillet, P. Phys. Rev. Lett 80, 4402-5 (1998).

[34] Gabbanini, C., Fioretti, A., Lucchesini, A., Gozzini, S., and Mazzoni, M. Phys. Rev. Lett. 84(13), 2814-7 (2000).

[35] Nikolov, A., E.E.Eyler, Wang, X., Li, J., Wang, H., Stwalley, W., and Gould, P. Phys. Rev. Lett. 82(4), 703-6 (1999).

[36] Fatemi, F., Jones, K., Lett, P., and Tiesinga, E. Phys. Rev. A 66, 053401 (1-7) $(2002)$.

[37] Vanhaecke, N., Melo, W. S., Tolra, B., Comparat, D., and Pillet, P. Phys. Rev. Lett 89, 063001 (2002).

[38] Takekoshi, T. and Kneize, R. Optics Letters 21, 77-9 (1996).

[39] Takekoshi, T., Patterson, B., and Knize, R. Phys. Rev. Lett. 81, 5105-8 (1998).

[40] Weinstein, J., de Carvalho, R., Guillet, T., Friedrich, B., and Doyle, J. Nature 395, 148 (1998). 
[41] Bethlem, H., Berden, G., Crompvoets, F., Jongma, R., Roij, A. V., and Meijer, G. Nature 406, 491 (2000).

[42] Fioretti, A., Amiot, C., Dion, C., O.Dulieu, Mazzoni, M., Smirne, G., and Gabbanini, C. Eur. Phys. J. D, 189-98 (2001).

[43] Lett, P., Helmerson, K., Phillips, W., Ratliff, L., Rolston, S., and Wagshul, M. Physical Review Letters 71(14), 2200-3 (1993).

[44] Cline, R., Miller, J., and Heinzen, D. Physical Review Letters 73, 632-5 (1994).

[45] Fioretti, A., Comparat, D., Crubellier, A., Dulieu, O., Masnou-Seeuwes, F., and Pillet, P. Physical Review Letters 80, 4402-5 (1998).

[46] Dion, C., Drag, C., Dulieu, O., Tolra, B. L., Masnou-Seeuws, F., and Pillet, P. Phys. Rev. Lett. 86(11), 2253-6 (2001).

[47] Nikolov, A., Ensher, J., Wang, H., Stwalley, W., and Gould, P. Phys. Rev. Lett $84,246-249(2000)$.

[48] Movre, M. and Pichler, G. J. Phys. B: At. Mol. Phys. 10, 2631 8 (1977).

[49] Weiner, J., Bagnato, V., Zilio, S., and Julienne, P. Review of Modern Physics 71(1), 1 (1999).

[50] Joachain, C. Quantum Collisions Theory. Elsevier Publishing Company, New York, (1975). 
[51] Arndt, M., Dahan, M., Odelin, D. G., Reynolds, M., and J.Dalibard. Phys. Rev. Lett. , 625-8 (2001).

[52] Phys. Rev. Lett 85, 2721(1-4) (2000).

[53] Mudrich, M., Kraft, S., Singer, K., Grimm, R., Mosk, A., and Weidemüller, M. Phys. Rev. Lett. 88, 2530001(1-4) (2002).

[54] Marcassa, L., de S. Zanon, R., Dutta, S., Weiner, J., and Bagnato, V. Eur. Phys. J. $D$ (1999).

[55] Mancini, M., de Oliveira, A., Magalhães, K., Bagnato, V., and Marcassa, L. Eur. Phys. J. D 13, 317-22 (2001).

[56] Mancini, M., de Oliveira, A., Magalhães, K., Zanon, R., Dutta, S., Weiner, J., and Marcassa, L. Laser Physics 11, 460 (2001).

[57] Fioretti, A., Müller, J., Verkerk, P., Allegrini, M., Arimondo, E., and Julienne, P. S. Phys. Rev. Lett 55, 3999-4002 (1997).

[58] Wang, H., Gould, P., and Stwalley, W. Phys. Rev. Lett 80, 476-9 (1998).

[59] Gallagher, A. and Pritchard, D. Phys. Rev. Lett. 63(9), 957-61 (1989).

[60] Julienne, P. S. and Vigué, J. Phys. Rev. A 44, 4464 (1991).

[61] Williams, C. J. and Julienne, P. J. Chem. Phys. 101, 2634-7 (1994).

[62] Williams, C., Tiesinga, E., and Julienne, P. S. Phys. Rev. A 53, 1939-42 (1996). 
[63] L.G. Marcassa, . PhD thesis.

[64] Leonhardt, D. and Weiner, W. Phys. Rev. A 52, 44332-5 (1996).

[65] Muniz, S., Marcassa, L., Napolitano, R., Telles, G., Zilio, J. W. S., and Bagnato, V. Physical Review Letters 55(6), 4407-11 (1997).

[66] Marcassa, L., Muniz, S., de Queiroz, E., Zilio, S., Bagnato, V., Weiner, J., Julienne, P., and Souminen, K.-A. Physical Review Letters 73(14), 1911-4 (1994).

[67] Suominen, K.-A. Journal of Physics B: Topical review 29, 5981-6007 (1996).

[68] Herzberg, G. Molecular Spectra and Molecular Structure. Van Nostrand Reinnhold Company, (1950).

[69] Rousseau, S., Allouche, A., and Aubert-Frécon, M. J. Mol. Spect. 203, 235-43 $(2000)$.

[70] Bussery, B., Achkar, Y., and Aubert-Frécon, M. Chem. Phys. 116, 31938 (1987).

[71] Julienne, P., Mies, F., Tiesinga, E., and Williams, C. Physical Review Letters 78(10), 1880-3 (1997).

[72] Leroy, R. and Bernstein, R. B. J. Chem. Phys. 52, 3869-79 (1970).

[73] Julienne, P. J. Res. Natl. Inst. Stand. Tecnol. 101, 487-503 (1996).

[74] Wang, H., Gould, P., and Stwalley, W. Phys. Rev. A 53(3), R1216-9 (1996). 
[75] Band, Y. and Julienne, P. Phys. Rev. A 51, R4317-20 (1995).

[76] Almazor, M.-L., Dulieu, O., Masnou-Seeuws, F., Beuc, R., and Pichler, G. Eur. Phys. J. D 15, 355-63 (2001).

[77] Dulieu, O., Kosloff, R., Masnou-Seeuws, F., and Pichler, G. J. Chem. Phys. 107, $10633-42(1997)$.

[78] Skenderovic, H., Beuc, R., Ban, T., and Pichler, G. Eur. Phys. J. D 19, 49-56 (2002)

[79] O. Dulieu, P. C.

[80] G. Pichler, S. Milosevic, D. V. and Beuc, R. J. Phys. B: At. Mol. Phys. 16, 4619-31 (1983).

[81] Pichler, G., Milosevic, S., Veza, D., , and Vukicevik, D. J. Phys. B: At. Mol. Phys. 16, 4633-42 (1983).

[82] G. Pichler, P. C.

. [83] Beuc, R., Milosevic, S., and Pichler, G. J. Phys. B: At. Mol. Phys. , 739-45 (1984).

[84] Condon, E. Phys. Rev 32, 858-72 (1928).

[85] Swann, C. M. A. W., Robinson, H., and Wieman, C. Phys. Rev. Lett. , 1571-4 (1990). 
[86] Lambrecht, A., Giacobino, E., and S.Reynauld. Quantum semiclass.opt. 8, 457$72(1996)$

[87] Lett, P., Phillips, W., Rolston, S., Tanner, C., Watts, R., and Westbrook, C. Journal of Optical Society of America B 6(11), 2984-3007 (1989).

[88] Weissbluth, M. Atoms and Molecules. Academic Press, (1978).

[89] Hulburt, H. M. and Hirschfelder, J. O. Journ. of Chem. Phys. 9, 611 (1941). 